\title{
Les inscriptions du That Luang de Vientiane : données nouvelles sur l'histoire d'un stūpa lao
}

In: Bulletin de l'Ecole française d'Extrême-Orient. Tome 90-91, 2003. pp. 289-348.

\section{Citer ce document / Cite this document :}

Lorrillard Michel. Les inscriptions du That Luang de Vientiane : données nouvelles sur l'histoire d'un stūpa lao. In: Bulletin de l'Ecole française d'Extrême-Orient. Tome 90-91, 2003. pp. 289-348.

doi : $10.3406 /$ befeo.2003.3616

http://www.persee.fr/web/revues/home/prescript/article/befeo_0336-1519_2003_num_90_1_3616 
Abstract

Michel Lorrillard

The inscriptions of the That Luang of Vientiane

The That Luang in Vientiane, the principal religious building of Laos, has until now only been the subject of a purely descriptive architectural study. But we know, since 1930, that the present stupa covers earlier structures and that it is therefore the result of a relatively slow and complex process of construction. Today, the analysis of a certain number of inscriptional sources, the study of information that is to be found in historical chronicles and the interpretation of archaeological data can together bring us closer to the history of the monument and help to improve considerably our understanding of the context in which it was constructed. The That Luang, earlier known also as the "Phra Mahā That Chao Chiang Mai" and the "Lokaculāmani-thupa", was at first the private family building of the three principal Laotian sovereigns of the sixteenth century: Phothisarāt, Setthāthirāt and Hno Muang. It was certainly the most spectacular product of the cultural and political ties that united the two kingdoms of Lān Nā and Lān Xāng at the time, the first of which was already entering upon its phase of decline, while the second had struck a period of development that was to last a century yet.

\section{Résumé}

Michel Lorrillard

Les inscriptions du That Luang de Vientiane : données nouvelles sur l'histoire d'un stupa lao

Le That Luang de Vientiane, principal édifice religieux lao, n'était connu jusqu'à présent que par une étude architecturale purement descriptive. Nous savons cependant depuis 1930 que le stupa actuel recouvre des structures plus anciennes et qu'il est donc le résultat d'un processus de construction relativement lent et complexe. L'analyse d'un certain nombre de sources épigraphiques, l'étude d'informations issues des chroniques historiques ainsi que l'interprétation des données archéologiques nous permettent aujourd'hui d'approcher au plus près l'histoire du monument - et contribuent à améliorer d'une façon importante notre connaissance du contexte qui entoura sa construction. Le That Luang, autrefois appelé " Phra Mahā That Chao Chiang Mai » et « Lokaculāmani-thupa », fut d'abord l'œuvre personnelle et familiale des trois principaux souverains lao du XVle siècle: Phothisarāt, Setthāthirāt et Hno Muang. Il fut certainement le résultat le plus spectaculaire des liens politiques et culturels qui unissaient à l'époque les deux royaumes du Lan Nā et du Lan Xāng, le premier entrant déjà dans sa phase de déclin, alors que s'amorçait pour le second une période de développement qui devait durer encore un siècle. 


\title{
Les inscriptions du That Luang de Vientiane : données nouvelles sur l'histoire d'un stüpa lao
}

\author{
Michel LORRILLARD *
}

\section{Introduction}

Le stüpa de Vientiane connu sous le nom de "That Luang » est l'édifice religieux le plus important du Laos '. Par la taille d'abord, avec $35 \mathrm{~m}$ de hauteur totale, 3 niveaux de déambulation et sa situation au centre d'une enceinte de près de $8500 \mathrm{~m}^{2}$ de superficie. Sa position en retrait, au sommet d'une butte, accentue d'ailleurs la domination qu'il exerce sur les autres monuments de la capitale, pour la plupart riverains du Mékong. Par son élégance ensuite : généralement décrit comme une œuvre architecturale aux proportions parfaites, il produit toujours la plus vive impression sur les visiteurs : nous verrons que nous en avons déjà un témoignage occidental au XVII ${ }^{\mathrm{e}}$ siècle. Par sa fonction rituelle encore : il est l'objet de la célébration annuelle qui attire le plus grand nombre de religieux et de dévots. Au $14^{\mathrm{e}}$ jour de la lune croissante et à la pleine lune du $12^{\mathrm{e}}$ mois lao, c'est par dizaines de milliers que les fidèles se pressent autour de l'édifice en processions successives. Par sa valeur symbolique enfin, puisqu'il est depuis 1991 l'emblème national de la République Démocratique Populaire Lao.

Pourtant, l'histoire du That Luang est très mal connue. Tout juste sait-on que son édification est liée à la personne du grand roi Setthāthirāt, après son installation à Vientiane dans le troisième quart du $\mathrm{XVI}^{\mathrm{e}}$ siècle. La fonction même du stūpa reste des plus mystérieuses : reconnu comme un reliquaire, plutôt que comme un monument funéraire, la nature de l'objet qu'il recouvre est cependant inconnue. On évoque bien une relique corporelle du Buddha, mais son identité est imprécise et donne lieu à toutes sortes d'hypothèses, y compris les plus fantaisistes. La perception ordinaire du monument est d'ailleurs celle d'une masse compacte et homogène, sur laquelle le temps n'aurait pas

* Maître de conférences à l'École française d'Extrême-Orient.

Je voudrais remercier le Professeur O. von Hinüber et MM. J. C. Eade et J. P. Michels pour leurs remarques judicieuses.

1. Le vocabulaire sanskrit et pâli est translittéré et noté en italiques. Les termes issus des lexiques lao et thai sont transcrits et notés entre guillemets. Afin de faciliter la lecture, les noms propres anciens sont transcrits avec des caractères réguliers, auxquels s'ajoutent quelques signes diacritiques pour la notation des voyelles longues (ex : Lān Nā). Pour la consonne ₹ qui donne lieu à plusieurs transcriptions, nous avons suivi l'usage qui préfère Setthāthirāt à Xetthāthirāt ou à Chetthāthirāt ; Lān Xāng à Lān Sāng ou à Lān Chāng; et Chiang Mai à Sieng Mai ou à Xieng Mai. Les toponymes devenus modernes sont orthographiés suivant la norme actuelle (ex. : Vientiane, That Luang, Luang Prabang). 
joué. La conscience de son évolution est absente - le That Luang serait en quelque sorte hors de l'histoire.

Comment expliquer cette méconnaissance ? On peut arguer du fait que le monument n'a jamais fait l'objet d'un programme de fouilles spécifiques. Entre 1929 et 1935, l'École française d'Extrême-Orient n'avait pour charge que de le restaurer. C'est par hasard que des structures plus anciennes avaient été découvertes, et cette opportunité n'avait pu être exploitée que de façon très partielle et tardive, car la recherche n'était alors pas la priorité de l'administration coloniale qui allouait les budgets. Le rapport extrêmement succinct que L. Fombertaux adressa en 1934 à l'EFEO est révélateur de la brièveté avec laquelle les sondages dans le corps du That Luang furent effectués. Ces notes, qui ouvraient des perspectives intéressantes, ne furent par la suite jamais exploitées. Il faut dire que l'art du Laos, dans son ensemble, a été lui-même notablement négligé par la recherche depuis près d'un siècle ${ }^{2}$. La connaissance de l'architecture lao a ainsi peu évolué depuis le travail essentiellement descriptif que réalisa H. Parmentier en 1911 et 1927. Nous verrons pourtant qu'il est aujourd'hui possible de procéder à des études comparatives qui apportent un certain nombre de résultats.

Jusqu'à présent, le That Luang n'a pas davantage donné lieu à des recherches philologiques. Il est vrai que l'analyse de l'historiographie lao n'en est encore qu'à son commencement, et que le travail de dépouillement des sources - qui comprennent des textes parfois très corrompus - ne révèle pas forcément au premier abord les renseignements que l'on espère. Dans bien des cas, les découvertes résulteront de recoupements avec les données archéologiques ou avec les sources épigraphiques.

Les inscriptions du Laos n'ont suscité elles aussi qu'un nombre très limité de travaux ${ }^{3}$. Les deux stèles inscrites de la porte orientale du That Luang - dont l'importance avait sans doute été pressentie, mais que la difficulté de leur déchiffrement rebutait (la pierre est aujourd'hui très abimée) - étaient restées inédites, hormis quelques passages d'un paragraphe en langue pâli, qui avaient déjà permis de préciser la date de l'inscription (1566), ainsi que les noms de son commanditaire (le roi Setthāthirāt), du stūpa (Lokacūlāmanii) et de la relique contenue dans le monument (Jinaguyhadhātu) ${ }^{4}$. Des estampages probablement réalisés en 1911 ont cependant permis de reprendre le travail de déchiffrement et d'aboutir à une lecture quasiment complète des documents ${ }^{5}$. Celle-ci a révélé le lien qu'une troisième stèle entretenait à son tour avec le That Luang.

2. Il nous faut toutefois citer l'ouvrage d'Henri Marchal, $L$ 'art décoratif au Laos (1964); ainsi que le récent travail de synthèse de M. Giteau, Art et archéologie du Laos (2001), laquelle a également rédigé des études consacrées à la statuaire lao.

3. La Mission Pavie (Études diverses, t. 2, 1898) a édité six inscriptions de Luang Prabang, traduites par le R. P. Schmitt. L. Finot en a transcrit et traduit six autres provenant du Nord-Laos (« Les inscriptions du Musée de Hanö̈ », BEFEO 15/2, p. 27-36), auxquelles il faut ajouter la traduction de petites inscriptions sur feuilles d'or trouvées au That Luang («Ex-voto du That Luong de Vieng-Chan (Laos)», $B E F E O$ 3, p. 660-663). P.-M. Gagneux, enfin, a effectué un travail très important et pratiquement exhaustif sur les inscriptions retrouvées à Vientiane (Contribution à la connaissance de la civilisation laotienne d'après l'épigraphie du Royaume de Vientiane, XVE-XIXe siècles, thèse de $3^{e}$ cycle, EHESS, 1975).

4. En 1917, L. Finot connaissait déjà ces trois noms propres, puisqu'il les cite dans ses « Recherches sur la littérature laotienne » (BEFEO 17/5, p. 70). Il est possible qu'il ait noté une partie du texte de la première stèle lors de son voyage à Vientiane en 1900, à moins qu'il ne se soit basé sur un estampage effectué très tôt (cf. infra). Les onze premières lignes du texte pâli ont été partiellement éditées par le Maha Sila Viravong, ainsi qu'un premier essai de traduction en lao (Pavat Phra Cedi Lokaculāmañ Lü Phra Thāt Luang Vieng Chan, Vientiane, s. d., p. 9-10).

5. Estampages n. 113 et n. 114 (Bibliothèque de l'EFEO, Paris). Ce sont ces estampages qui sont reproduits ici (doc. 6,7 et 16 ). 
L'objet de cet article est donc de contribuer à la connaissance de l'histoire du That Luang, en présentant d'une part un certain nombre d'informations nouvelles issues de sources épigraphiques inédites ou dont la lecture a été révisée, en éclaircissant d'autre part des références littéraires concernant le monument, en établissant enfin le lien entre ces informations et les données de l'archéologie.

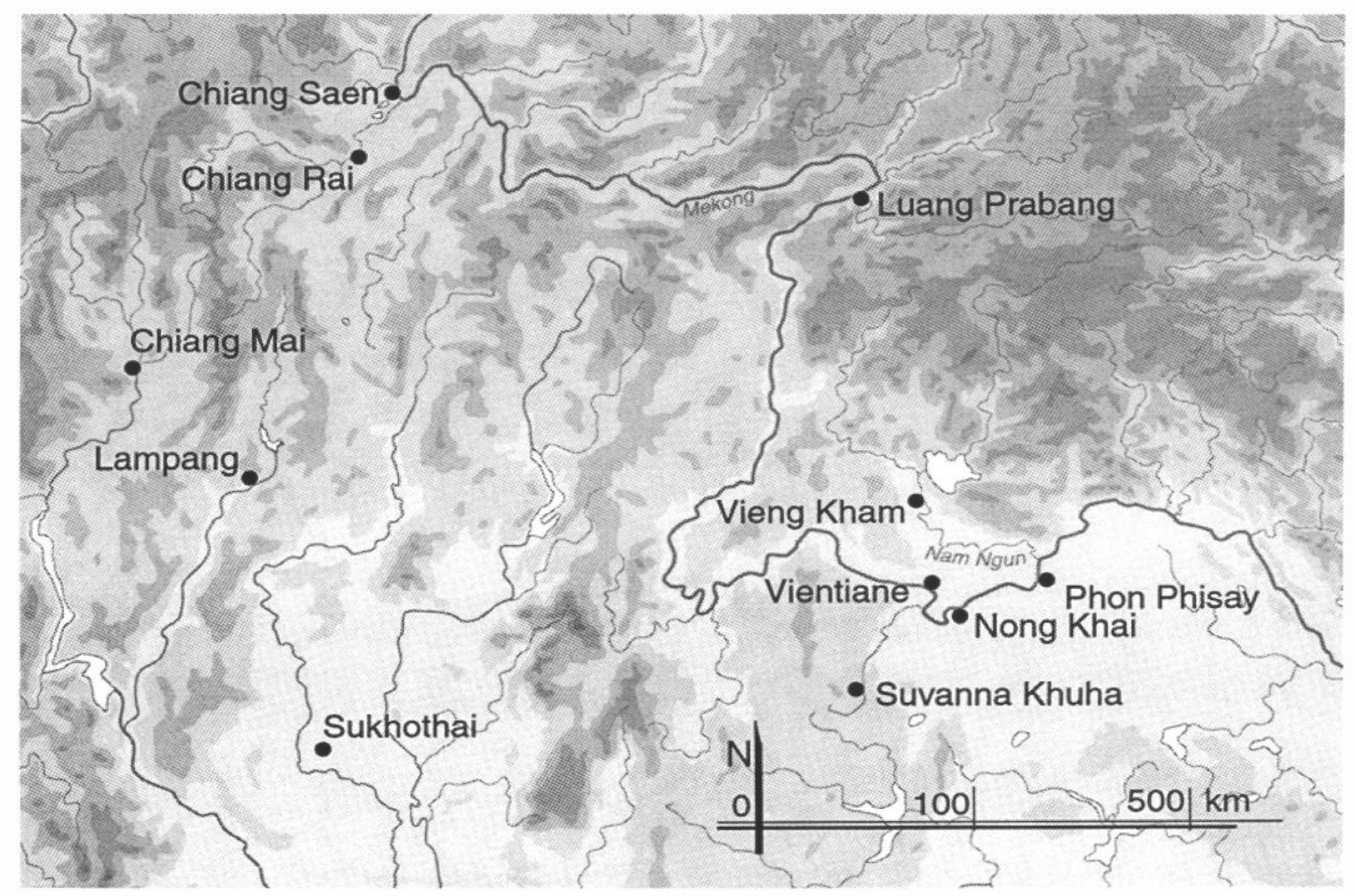

\section{Le monument}

C'est le marchand hollandais Gerrit van Wuysthoff qui nous offre apparemment la première description occidentale du grand stūpa. Dans l'après-midi du 16 novembre 1641 , alors qu'il est conduit avec ses compagnons auprès du souverain du Lān Xāng, il passe «par une grande place carrée entourée d'un mur de pierres percé de meurtrières. Il y a au milieu [de la place] une grande pyramide large et haute, couverte de feuilles d'or dans sa partie supérieure $»^{6}$. Les marchands doivent en faire le tour en portant des cierges avant de pouvoir communiquer avec le roi qui les attend à l'extérieur. Le monument n'est pas nommé - mais Francis Garnier ${ }^{7}$ n'hésite pas à l'identifier au That Luang lorsqu'il parcourt les ruines de Vientiane, le 2 avril 1867. Plusieurs éléments de la description concordent en effet. Le terme "pyramide » ne peut guère désigner qu'un stūpa - et si le That Luang n'est pas le seul monument de ce type à Vientiane, il domine en tout cas très nettement les autres par sa taille et il est le seul qui soit enfermé dans une enceinte. Le texte

6. Le journal de voyage de Gerrit van Wuysthoff et de ses assistants au Laos (1641-1642), 1993, p. 80 .

7. Voyage d'exploration en Indochine, 1885, p. 253-255. 
indique également que le site ne se trouvait pas dans la ville fortifiée, entrevue quelques heures plus tôt, mais à une distance évaluée à un $1 / 4$ de mille, soit un peu plus de $1,5 \mathrm{~km}^{8}$. On conçoit aisément que ce soit ce monument, le plus grand et le plus riche du royaume, que le souverain ait souhaité faire apprécier en priorité à ses importants visiteurs.

Document 1 - Vue du That Luang (angle nord-ouest), (ㅇ Ph. Coste, 2002).

8. Le journal ..., 1993, p. 128. 


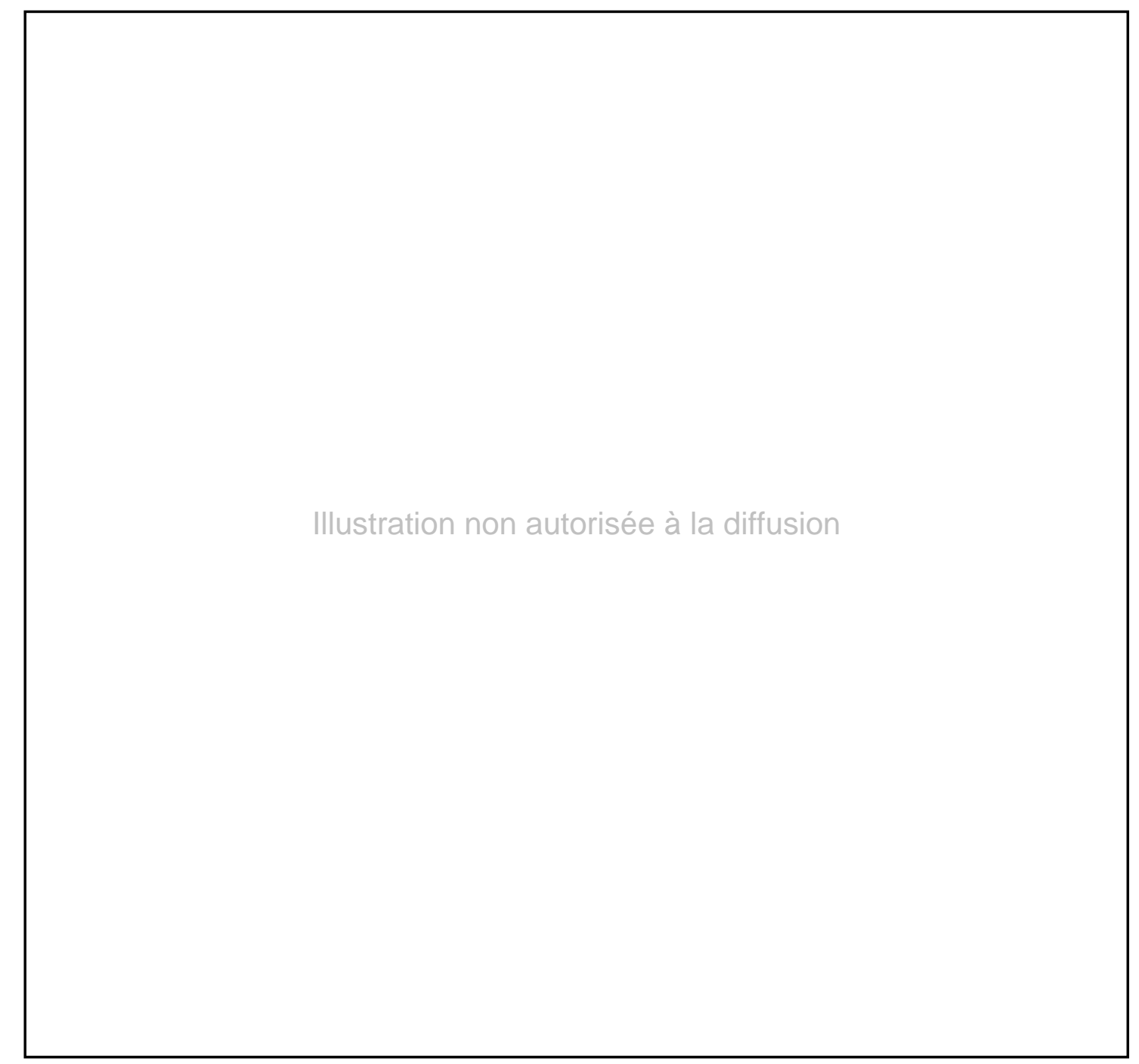

Document 2 - Plan d'ensemble du That Luang (Parmentier, L'art du Laos, 1954 : pl. 38).

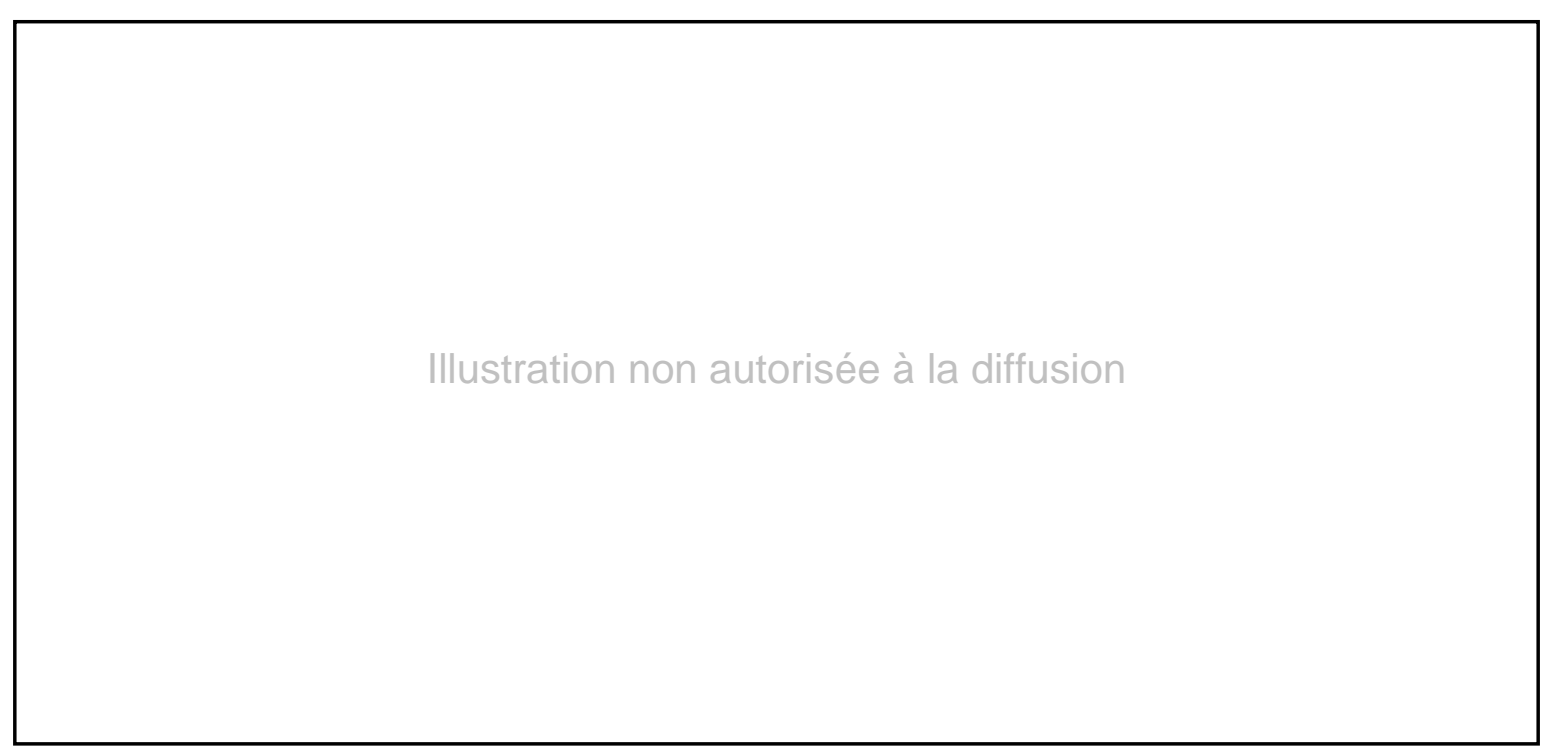

Document 3 - Élévation du That Luang (Parmentier, L'art architectural... 1948 : pl. 30). 
Les premiers relevés du That Luang seront réalisés simultanément par Francis Garnier et Louis Delaporte, en avril 1867. Pendant que le premier dresse le plan du monument, le second en effectue le dessin. C'est ce dernier qui servira de modèle lorsque quelque soixante dix ans plus tard, le $s t \bar{u} p a$, partiellement détruit par les Hos à la fin du XIX ${ }^{\mathrm{e}}$ siècle, sera restauré par l'École française d'Extrême-Orient. Le premier Bulletin de l'institution offre déjà en 1901 une description sommaire de son architecture ${ }^{9}$. Il est également question du monument en 1903, lorsque Louis Finot - qui a dû le visiter trois années plus tôt - fait paraître la traduction de quatre courtes inscriptions pâlies trouvées dans un (ou deux) des petits «thāt» de la galerie-promenoir supérieure en 1896. C'est cependant l'architecte Henri Parmentier, chargé par l'EFEO d'entreprendre « un inventaire complet des principales pagodes du pays, avec des relevés précis de leurs dispositions architecturales, des photographies ou des dessins de leurs motifs décoratifs et de leur mobilier ", qui réalise en 1911 la première véritable étude du That Luang. Enrichie de certains détails, elle ne sera publiée qu'en 1954 dans un ouvrage posthume devenu le livre de référence pour l'architecture religieuse lao: $L$ 'art $d u \operatorname{Laos}^{10}$. Le monument est alors décrit comme se composant, « du centre à la périphérie :

1. - d'une construction bâtarde, restauration de Morin "1, qui a remplacé l'élégant bulbe en carafe représenté par Delaporte (...) ;

2. - du stūpa proprement dit, masse curviligne à quatre arêtes, à courbe basse ;

3. - d'une garniture de thats élevés sur des terrasses considérables à faces courbes ;

4. - d'une première enceinte relevée qui les entoure ;

5. - d'une seconde plus basse, occupée au centre de la face est par un édicule qui abrite une pièce dorée ;

6. - d'un énorme gradin en doucine qui forme base et dont la saillie correspond à quatre édicules relevés ;

7. - d'une large cour dallée de briques entourée ;

8. - d'un cloître, ouvert par quatre pavillons-portes $\gg{ }^{12}$.

Les premières autorités coloniales de Vientiane sont soucieuses de réhabiliter les édifices religieux les plus importants. C'est dans ce contexte favorable qu'Henri Parmentier, qui occupe à l'EFEO le poste de Chef du Service archéologique, adresse le 23 avril 1912 à la direction de l'École un rapport sur les travaux de conservation à exécuter au Laos ${ }^{13}$. Parmi ceux-ci, il fait figurer en bonne place une intervention relative aux pinacles (il s'agit des trente petits « thāt » qui entourent le stūpa proprement dit) du That Luang, " travail peu important [...], qui rendrait à cet intéressant monument son effet réel, perdu aujourd'hui, et qui serait en outre de bonne politique, car ce monument est le plus révéré par les indigènes de toute la région ${ }^{14}$. Les priorités du moment concerneront cependant le Vat Sisaket et c'est ce temple qui sera restauré le premier par deux autres architectes de l'EFEO, d'abord Charles Batteur, entre 1920 et 1923, puis Louis Fombertaux entre 1929 et 1930 . H. Parmentier persiste et évoque une nouvelle fois le That

9. Lunet de Lajonquière, «Vieng-Chan », BEFEO 1/2 (1901), p. 111-112.

10. H. Parmentier, $L$ 'art du Laos, 1954, [rééd. révisée par M. Giteau, 1988]. Un autre ouvrage du même auteur évoque le monument : L'art architectural hindou dans l'Inde et en Extrême-Orient, 1948, p. 171-173.

11. La description d'H. Parmentier date de 1911, elle est antérieure à la restauration de l'EFEO. M. Morin a été le premier administrateur colonial de Vientiane.

12. L'art du Laos, 1954, p. 118-119. Pour le plan et les dimensions du monument, cf. le document 2 qui reproduit la planche 38 de l'ouvrage.

13. $B E F E O 12$, p. 188-197.

14. BEFEO 12, p. 192-193. 
Luang dans un rapport de mission qu'il adresse à l'École le 5 janvier $1928^{15}$. Il y est encore question des pinacles, mais l'architecte insiste cette fois-ci davantage sur la reconstitution des cloîtres. Il évoque également une discussion avec le Résident Supérieur, où il se déclare partisan d'une restauration complète de la flèche centrale du monument (cette « construction bâtarde » mentionnée plus haut), malencontreusement réparée sous la direction du premier administrateur français de Vientiane, et dont la vue choquait tous les visiteurs. Ses recommandations sont acceptées et c'est L. Fombertaux qui, après avoir achevé la restauration du Vat Sisaket, s'attache à la nouvelle entreprise. C'est à cet architecte que l'on doit l'aspect actuel du monument, qui correspond d'une façon assez fidèle à son dernier état de construction.

L'œuvre de restauration du That Luang, qui durera de 1929 à 1936, présentera pour la recherche historique un autre intérêt : celui de révéler des parties plus anciennes du monument, et donc différentes étapes dans sa construction. Les circonstances de la première découverte sont relatées dans une lettre que L. Fombertaux adresse le 13 novembre 1930 à George Cœdès, directeur de l'EFEO ${ }^{16}$. C'est en procédant à la restauration du «pavillon de la prière » $(\mathrm{H}$. Parmentier parle d' "édicule» ou de «chapelle ») de l'Ouest, que l'architecte s'aperçoit de la présence, sous les dernières marches d'accès, d'un escalier plus ancien (cf. doc. 5). Provoquant un éboulis de l'angle nord-ouest du petit bâtiment, il met par ailleurs au jour un nouvel angle appartenant à une terrasse primitive (cf. doc. 4), dont il établit bientôt le plan. Caractérisée par des redans en façade, cette terrasse est établie sur des degrés en latérite et son escalier est flanqué, au moins sur un de ses côtés, d'un socle «sur lequel reposent les deux pieds d'un éléphant dont la moitié du corps saillit du parement... ». Des sondages effectués dans le pavillon de l'Est révèlent également une structure antérieure, mais celle-ci présente quelques différences dans son organisation et semble avoir été recouverte initialement d'une charpente en tuiles reposant sur quatre piliers. L. Fombertaux conclut en écrivant : " J'ai constaté que les pavillons primitifs ont été établis dans l'axe des orientations du That Luong, tandis que les restaurations de basse époque [les pavillons visibles aujourd'hui] ne le sont pas ». H. Parmentier rapporte l'année suivante que "le problème de conservation soulevé par les découvertes si curieuses de L. Fombertaux [...] n'a pu être immédiatement résolu. [...] Il est à présumer d'ailleurs que des fouilles purement archéologiques et réduites au strict indispensable devront être exécutées pour reconnaître au moins en partie les dispositions de l'édifice antérieur que le That Luong actuel a dû englober, suivant les habitudes t'ăi, et que la solution la meilleure sera de remettre ensuite les divers pavillons en état $[\ldots]$; toute autre solution ouvrirait trop de problèmes dont la solution risquerait d'être chanceuse ${ }^{17}$. Ces fouilles archéologiques, menées de pair avec les travaux de restauration, ne sont entreprises qu'à partir du mois de mars 1934. Le 19 avril, L. Fombertaux informe G. Cœedès qu'il a éventré le stūpa sur une longueur de $2 \mathrm{~m}$ et une profondeur de $7,40 \mathrm{~m}$, qu'il progresse vers les niveaux inférieurs, et qu'il considère déjà que cette recherche n'est pas vaine, car il a trouvé sous le monument actuel un stüpa primitif ${ }^{18}$. Celui-ci est décrit plus précisément dans la chronique du Bulletin de 1934 : «il consiste en une construction carrée de $17,88 \mathrm{~m}$ de côté, dont la base prend naissance au niveau du sol du $1^{\text {er }}$ étage. Elle s'élève perpendiculairement sur $5,25 \mathrm{~m}$ pour s'incurver sur $5,35 \mathrm{~m}$ plus haut, suivant un puits de $1,30 \mathrm{~m}$, formant ainsi à $10,60 \mathrm{~m}$ de haut un

15. Archives EFEO, Fonds Parmentier.

16. Archives EFEO, «Monuments historiques, Laos (1899-1954)», carton $n^{\circ} 7$. Cette lettre est reprise presque littéralement dans le $B E F E O 30$, p. 583-585.

17. BEFEO 31, p. 624-625.

18. Archives EFEO, « Monuments historiques, Laos (1899-1954) », carton $n^{\circ} 7$. 
arasement de 15,25 m de côté, que cinq grandes feuilles de lotus couronnent par chaque côté. Celles-ci sont entières et en place sur 1,60 m de haut, mais leur tête a disparu lors de la construction du stūpa actuel. Ce monument est bâti en entier en une maçonnerie de pierres de latérite parfaitement taillées, à joints parfaits et montées par assises régulières sans trace de mortier. [...] Ces vestiges relevés et photographiés, la fouille a été refermée avec les mêmes matériaux ${ }^{19}$.

Le That Luang n'a plus été par la suite l'objet de fouilles archéologiques ou de travaux de restauration. Pierre-Marie Gagneux ${ }^{20}$ rapporte cependant que le 15 octobre 1976 , à l'occasion de l'installation d'un nouveau système de protection contre la foudre qui rendait nécessaire le creusement d'une fosse dans la cour du monument, la Direction des Travaux publics du Laos mit au jour, à 1 mètre en dessous du niveau du sol, de gros blocs de latérite soigneusement taillés et juxtaposés. Il apparaît que ceux-ci se trouvaient dans le prolongement de l'escalier du pavillon de l'Est, ce qui a amené P.-M. Gagneux à conclure à l'existence d'une ancienne chaussée, de direction est-ouest. La fosse fut rebouchée, une fois le dispositif paratonnerre de la prise de terre installé.

Document 4 - Pavillon ouest, angle d'une terrasse primitive (archives EFEO).

19. BEFEO 34, p. 771-772.

20. Notes de mise à jour de L'art du Laos, 1980, manuscrit non publié. Je remercie Manivone Gagneux d'avoir mis à ma disposition ce document. 


\section{Les données manuscrites}

Les chroniques lao apportent très peu d'éléments utiles à la connaissance du passé de Vientiane, surtout en ce qui concerne les temples de la ville. L'historien a pourtant la chance d'y trouver des informations relatives au That Luang ${ }^{21}$. Leur interprétation n'étant pas toujours évidente, en raison des corruptions dont sont affectés la plupart des textes, des recoupements avec les données de l'archéologie et de l'épigraphie s'avèreront souvent très utiles.

L'étude comparative des annales du Nord (Luang Prabang, Xieng Khouang) a montré que celles-ci se regroupaient en deux grandes familles assez distinctes : le Nithān Khun Borom et les Phongsāvadān ${ }^{22}$. La première semble ignorer le That Luang, alors qu'elle fait état de la construction à Vientiane - au milieu du XVI ${ }^{\mathrm{e}}$ siècle - du Vat Phya Vat et du Vat Chan, contemporains de notre monument ${ }^{23}$. La seconde, par contre, évoque sans aucune ambiguïté le stūpa ${ }^{24}$. On y apprend qu'en l'année « kāp cai » 926 de l'ère culla (30 mars 1564 au 29 mars 1565), Setthāthirāt arriva à Vientiane et qu'il y bâtit un grand "chedi » (cetiya) recouvrant et parfaisant le «thāt » autrefois construit par le roi Si Thammasokarāt (Śrī Dharma Aśokarāja). Il édifia également trente " cellules » (représentant ou abritant les) pāramī qui faisaient le tour du grand «thāt». Afin de rendre hommage à la Relique corporelle (sarìradhätu), il fit en outre le don d'une multitude de biens et de joyaux, en nombre tel qu'on ne pouvait véritablement les compter ${ }^{25}$.

Les annales royales de Vientiane sont considérées comme perdues. On admet généralement qu'elles ont été détruites en 1828 par les Siamois, en même temps que la cité dont tous les habitants furent déportés. Un court texte - le Chot Hmāy Het Yo Vieng Chan - a cependant subsisté : il n'est sans doute que le très pauvre reflet de la riche tradition historiographique qui a dû se développer dans le Centre-Laos à partir de la

21. Cette bonne fortune est peut-être due au fait que le That Luang fut (re)construit dans une période de transition (déplacement de la capitale) : son histoire aurait alors été partiellement liée à celle de Luang Prabang. Les temples de cette dernière ville bénéficient en effet d'un traitement particulier dans les chroniques lao. Cf. M. Lorrillard, « The Earliest Lao Buddhist Monasteries According to Philological and Epigraphic Sources », dans The Buddhist Monastery - A Cross-cultural Survey, 2003, p. 187-198.

22. Cf. M. Lorrillard, "Quelques données relatives à l'historiographie lao », BEFEO 86, p. 219-232.

23. Les deux temples sont étroitement associés dans le Nithän Khun Borom (cf. la version traduite dans la Mission Pavie Indochine..., 1898, p. 68), puisqu'ils sont tous les deux fondés par le gouverneur de Vientiane - le Phrayā Chanthaburi - quelques années avant l'arrivée de Setthāthirāt, vers 1560 . Les données de la chronique sont recoupées par celle de l'épigraphie en ce qui concerne le Vat Phya Vat : deux stèles citant son nom et trouvées dans son enceinte (elles sont aujourd'hui conservées au Vat Ho Phra Kèo) commémorent en effet un événement - en principe la fondation - survenu en 1551/52. Quant au Vat Chan, H. Parmentier (L'art du Laos, 1954, p. 90) dit que son «plan est celui du Phya Vat». Un autre indice de son ancienneté semble être le petit stūpa carré à redans qui figure parmi les éléments du complexe.

24. Les erreurs accumulées au cours des copies successives font que le sens original de certaines versions est très incertain. Il en est ainsi des éditions très peu soignées du Phongsāvadān Heng Pathet Läo (IDEO, 1926, p. 26) et du Phongsāvadān Muang Luang Prabāng (Bibliothèque nationale de Vientiane, 1969, p. 22). Une version manuscrite de ce dernier texte, conservée au Palais royal de Luang Prabang, lève tous les doutes.

25. Le texte indépendant du Tamnan Phra Bāng rapporte les mêmes informations. Sa traduction dans la Mission Pavie $(1898$, p. 117) reflète cependant les corruptions du manuscrit, de même que la méconnaissance du contexte historique et religieux par les traducteurs: «Puis il fut résider à Changtaboury Ratsatani (Vieng-Chang), il y éleva un chadey par dessus celui édifié par le Phya Tamasocorath. Il l'entoura d'une maison à trente compartiments pour les prêtres. Il prépara ensuite les offrandes d'usage pour honorer Maha Saricatat : on ne saurait dire quelle quantité il en fit apporter tant il y en eut ». 
seconde moitié du $\mathrm{XVI}^{\mathrm{e}}$ siècle, mais on se doit pourtant de le considérer comme une véritable chronique - $d$ 'autant que sa fonction était justement de maintenir la connaissance d'une chronologie. Peu connu des historiens ${ }^{26}$, d'une lecture par ailleurs assez rebutante en raison de la sécheresse et du caractère souvent énigmatique de son contenu, il n'en est pas moins une source de première importance pour la connaissance de l'histoire du royaume de Vientiane. Les dates qu'il indique paraissent en effet fiables et certaines d'entre elles, très précises, ont pu à la fois fournir les preuves d'une parfaite cohérence sur le plan du calendrier ${ }^{27}$ et être vérifiées par les données de l'épigraphie ${ }^{28}$.

S'il existe différentes recensions du Chot Hmāy Het Yo Vieng Chan, quelques-unes seulement, qui paraissent préserver un état plus complet du texte primitif, font remonter leur chronologie jusqu'au milieu du $\mathrm{XVI}^{\mathrm{e}}$ siècle. C'est le cas d'un manuscrit qui a été collecté par la Mission Pavie autour de $1887^{29}$, dont le texte correspond à celui d'une édition ronéotypée diffusée par le Mahā Champakèomani en 1980. On peut y lire :

« 923 de l'ère [30 mars 1561 au 29 mars 1562], année ruang rao, [il] a construit le Phra Thăt Chiang Mai. »

Le sujet de la phrase est évidemment le roi Setthāthirāt, cité dans les deux phrases qui précèdent, et dont le nom ne fut pas répété ${ }^{30}$. Quant au Phra Thāt Chiang Mai, dont l'identification n'est a priori pas tout à fait évidente, on verra plus loin quel rapport il entretient avec le That Luang.

\section{Les inscriptions}

Les stèles inscrites qui intéressent directement le That Luang sont au nombre de trois. La première et la seconde sont dressées dans la cour même du monument, devant sa porte orientale qu'elles flanquent respectivement sur ses côtés nord et sud. La troisième était située à moins de $300 \mathrm{~m}$ du stūpa, dans l'enceinte du Vat Hnong Bone, mais elle a été rapportée il y a quelques années au musée du Vat Ho Phra Kèo, où elle a rejoint une trentaine d'autres inscriptions. Nous étudierons successivement la stèle nord de la porte orientale du That Luang, la stèle du Vat Hnong Bone, puis la stèle sud de la porte orientale du That Luang.

\section{La stèle nord de la porte orientale du That Luang}

La stèle nord de la porte orientale du That Luang est un gros bloc de grès d'une hauteur de $1,22 \mathrm{~m}$, d'une largeur de $92 \mathrm{~cm}$ et d'une épaisseur de $16 \mathrm{~cm}$. Sa partie supérieure est arrondie, à l'imitation des «bai sema » (bornes des monastères), et indique que la pierre a été soigneusement apprêtée pour l'inscription, comme le sont d'ailleurs la plupart des inscriptions royales. Les deux faces sont inscrites : la première sur 29 lignes, la seconde sur 27 lignes. La largeur du texte de cette dernière est un peu plus importante puisqu'il s'étend sur $78 \mathrm{~cm}$, contre $66 \mathrm{~cm}$ pour l'autre. Par contre, son organisation est

26. La seule référence à ce texte figure dans Akiko Iijima, « Rāy Ngān Beuang Ton Kio Kap 'The short chronicle of Vientiane' ", 2002, p. 208-219.

27. Elles ont passé avec succès les tests d'un logiciel de conversion des différents systèmes calendaires utilisés dans les pays thais. Ce logiciel a été développé par J. C. Eade (cf. The Thai Historical Record - A Computer Analysis, 1996).

28. C'est le cas par exemple pour les dates des travaux effectués au Vat Ho Phra Kèo et au Vat Sisaket au début du XIX ${ }^{\mathrm{e}}$ siècle.

29. Mission Pavie, 1898, p. 96.

30. « 921 de l'ère, année kat met, Phra Say Chao arrive de Chiang Sēn. 922 de l'ère, la sœur de Phra Say, Nāng Khem, décède ». 
plus complexe sur la première face qui est divisée en trois parties bien distinctes. Le sommet de la stèle présente en position centrale un disque horoscopique - le « duang sāta »-qui est ici de forme octogonale et se trouve enfermé dans une sorte de couronne feuillue pointant comme une flamme ${ }^{31}$. Il est flanqué à sa gauche du chiffre de l'ère et à sa droite du chiffre de la mansion lunaire. La seconde partie, qui ne compte que 10 lignes de texte, occupe pratiquement tout le reste de la moitié supérieure de la stèle. La taille des caractères et l'interlignage sont en effet plus importants que dans le reste de l'inscription, et la graphie y est particulièrement soignée. Il s'agit d'un texte en langue pâlie composition originale et dont l'inspiration est proprement royale ${ }^{32}$. Cette partie est sans aucun doute celle qui était perçue comme la plus importante. Le troisième corps de texte remplit toute la moitié inférieure de la première face; il est constitué de 18 lignes pleines en langue lao. Malheureusement, une très grosse cassure, partant de la base de la stèle et remontant jusqu'à la dernière ligne du texte pâli, a fait disparaître plus des $2 / 3$ du texte et empêche toute lecture suivie. La restitution de la partie manquante de la première ligne du texte lao est aisée. Par contre, les énormes lacunes qui figurent dans le reste du texte rendent le sens des quelques mots dont la lecture est possible très incertain. Nous serons réduits ici à des conjectures. La seconde face présente le texte dans son intégralité. Il a cependant souffert de l'usure du temps (ou peut-être fut-il gravé moins profondément) et sa lecture n'est pas toujours aisée. Pratiquement collée au mur de la galerie est, cette seconde face ne peut en outre être déchiffrée in situ que de façon très incommode.

La graphie qui est employée dans l'inscription est l'écriture "tham » (du dhamma). Celle-ci ne présente pas encore les caractéristiques de ce que l'on appellera le « tham lao » - encore usité de nos jours - mais conserve les formes du «tham Lān Nā » ou «tham yuan ${ }^{33}$. En cela, elle ne se distingue aucunement des autres inscriptions lao du début du $\mathrm{XVI}^{\mathrm{e}}$ siècle rédigées dans une graphie autre que l'écriture dite "laïque " ${ }^{34}$. Ces exemples montrent que l'influence du Lān Nā était extrêmement forte durant cette période, à tel point que l'on peut se demander si les graveurs n'étaient pas eux-mêmes des spécialistes venus des territoires du Nord ${ }^{35}$. Il semble que la rédaction des deux faces soit de la même main.

La stèle nord de la porte orientale du That Luang fut pendant plusieurs décennies l'objet d'une datation plutôt approximative. F. Garnier ne se trompe pourtant pas beaucoup lorsqu'il observe en 1867 que «l'inscription [...] remonte à la première moitié du XVI ${ }^{\mathrm{e}}$ siècle $»$. Sachant qu'aucune étude épigraphique n'avait encore été réalisée dans la région à cette époque, son appréciation apparaît des plus honorables. En 1901, l'article du Capitaine Lunet de Lajonquière indique qu' « une stèle commémorative de l'érection du

31. Ce motif n'a pas été retrouvé dans les inscriptions du Laos ou de la Thaïlande de la même époque. Il semble cependant avoir inspiré le graveur de la stèle sud.

32. Les compositions en pâli sont extrêmement rares dans l'épigraphie lao. Celle-ci est la plus longue.

33. Ce fait est mis en évidence par la graphie plus marquée des caractères (translittérés) $\mathrm{k}, \mathrm{j}$, n et $\mathrm{d}$.

34. La stèle nord de la porte orientale du That Luang est dans l'ordre chronologique le $7^{c}$ exemple de stèle inscrite en écriture « tham » retrouvée dans les frontières de l'ancien Lān Xāng (les autres datent de $1527,1555,1559$ et 1563). Il faut mettre à part ici les plus vieilles images inscrites du Buddha trouvées au Laos (fin du XVe-début du XVI ${ }^{\mathrm{e}}$ siècles), toutes rédigées en «tham Lān Nā », car des arguments irrécusables montrent qu'elles proviennent en fait du Nord de la Thaïlande.

35. Cette observation est également valable pour certaines stèles lao du $\mathrm{XVI}^{\mathrm{e}}$ siècle inscrites en écriture laïque qui montrent une graphie identique à l'écriture «fak khām » du Lān Nā. D'autres exemples montrent qu'à cette époque, l'écriture lao s'était déjà en partie détachée de son modèle du Nord. L'écriture s'est probablement diffusée au Lān Xāng à partir de la seconde moitié du XV siècle, alors qu'elle est déjà attestée un siècle plus tôt au Lān Nā. 
monument porte la date de Sakrach $948=1586$ A. D. ${ }^{36}$. Cette lecture incorrecte est reprise en 1903 par L. Finot, ce qui le conduit à effectuer un anachronisme et à conclure son article sur les ex-voto du That Luang ${ }^{37}$ d'une façon erronée. H. Parmentier se trompe à son tour et l'erreur perdure dans ses écrits jusqu'à l'édition posthume de L'art du Laos en $1954^{38}$. Pourtant, elle avait déjà été rectifiée en 1917 par L. Finot lui-même dans ses "Recherches sur la littérature laotienne ${ }^{39}$. Le chiffre qui suit la mention de l'ère, gravé sur la première ligne de la stèle, est en effet 928 - c'est-à-dire 1566-1567 A. D.

La reconnaissance des autres données calendaires - contenues tant dans le texte pâli que dans le disque horoscopique - permet aujourd'hui de dater l'inscription d'une façon plus précise. Pour ce qui est du disque horoscopique, la cohérence pratiquement parfaite entre la position des planètes, le chiffre de la mansion lunaire et le chiffre de l'année conduit à dire sans risque d'erreur que c'est la date du vendredi 3 mai 1566 (calendrier julien) que l'astrologue a voulu fixer ${ }^{40}$. La position légèrement avancée de Vénus importe peu : les erreurs sont fréquentes en ce qui la concerne et cela ne nuit pas au résultat d'ensemble qui dénote une parfaite assimilation de la méthode de calcul ${ }^{41}$. Le problème vient plutôt de la date telle qu'elle est exprimée dans le texte pâli. Le millésime de l'année et le fait qu'il s'agit d'une pleine lune pourraient faire penser que cette date est la même que celle du disque, mais le mois et le jour de la semaine contrarient cette conclusion. Il est certain que nous avons pour le dernier un dimanche. Quant au mois - qui se révèle être Vesākha /Vaiśäkha (6 $6^{\mathrm{e}}$ mois lao) pour le disque -, il est appelé de façon erronée «migga », ce qui laisse à penser qu'il pourrait s'agir de MāgasiralMārgaśĭrșa (1 ${ }^{\mathrm{er}}$ mois lao) ou de Mägha $\left(3^{\mathrm{c}}\right.$ mois lao ${ }^{42}$. Nous aurions plutôt tendance à écarter le premier, car l'omission du suffixe -sira ne s'explique guère. De plus, la pleine lune de ce mois se produisit un mercredi, alors que celle de Măgha eut lieu un samedi, veille du dimanche. La date du texte pâli pourrait donc être le 25 janvier 1567 , le chiffre de la mansion lunaire étant $10^{43}$.

Le fait que l'horoscope et le texte pâli aient pu être gravés à deux moments différents n'est pas en soi quelque chose d'étonnant. Comme on le verra plus bas, l'épigraphie lao du début du XVI ${ }^{\mathrm{c}}$ siècle nous offre d'autres exemples de décalage, en particulier dans les inscriptions royales.

Les deux dates apparemment dictinctes que portent le disque et le texte pâli, de même que la césure qui semble s'opérer entre le texte pâli et le texte lao, nous amènent à nous

36. «Vieng-Chan », 1901, p. 111 . Il semble que le Capitaine de Lajonquière se soit fié à la lecture des aides cambodgiens qu'Étienne Aymonier avait envoyés prospecter autour de Vientiane.

37. Finot, 1903, p. 663. La conclusion est formulée dans ces termes : « À cette époque en effet le Laos était dans une étroite dépendance de la Birmanie, et cette situation s'accorde assez bien avec le style purement birman du stūpa et avec le caractère que présente l'écriture des ex-voto ».

38. Parmentier, 1954, p. 121. L'erreur apparaît également dans L'art architectural hindou, 1948, p. 173. L'architecte ne reprend cependant pas les appréciations de L. Finot sur le style birman de l'édifice.

39. $B E F E O 17 / 5$, p. 70 .

40. L'identification de la date a été rendue possible grâce à l'utilisation du logiciel de conversion mis au point par J. C. Eade.

41. On notera tout de même que l'astrologue s'est dispensé de noter le «horakhun » (skt. ahargana) et le «māsaken » (skt. māsakenda ?) qui indiquent respectivement les nombres de jour et de mois écoulés depuis le début de l'ère. Ceux-ci figurent pourtant dans les stèles royales du Vat Saiya Settha (Nong Khay, 1554), du Vat Tham Suvanna Khuha (province d'Udon Thani, 1563) et de Dan Say (province de Lœi, 1563).

42. La Jinakālamālī, texte pâli rédigé à Chiang Mai au début du XVI ${ }^{\mathrm{e}}$ siècle, montre que l'orthographe des mois donnait lieu parfois à quelques libertés. Ainsi le terme Migasira pour Māgasira.

43. La pleine lune de Māgasira 928 correspond au mercredi 27 novembre 1566 . Le chiffre de la mansion lunaire est 6. 
demander si ce dernier ne fut pas lui-même rédigé à un autre moment. Nous ne le pensons cependant pas, car la surface de la pierre fut sans doute choisie en fonction de la longueur totale du texte qu'elle allait recevoir. Si cette remarque est valable pour la première face, elle l'est cependant moins pour la seconde. Se pourrait-il que cette dernière ait été rédigée plus tard ? Etant donnée la cassure de la pierre, il est difficile de dire si la fin du texte de la première face fut ponctuée par une formule de conclusion. Il est en tout cas certain que ce texte ne se prolongeait pas sur la seconde face, puisque celle-ci débute par une nouvelle phrase. Le sujet de cette dernière se démarque d'ailleurs nettement de ce qui précède et il est clair qu'un nouveau chapitre de l'ordonnance commence. Une autre ambiguïté se produit à la fin de la ligne 17 avec la conclusion de l'ordonnance royale, qui est d'ailleurs marquée graphiquement par un signe de ponctuation finale. À la ligne 18 , commence en effet un nouveau texte qui semble être l'œuvre des grands dignitaires. On peut donc également s'interroger sur la date de ce texte. La différence très nette entre les trois parties du texte lao nous incite plutôt à pencher pour une rédaction en trois phases. Nous ne pensons cependant pas qu'elles aient été très éloignées sur le plan chronologique, car le scribe n'aurait pas omis de le préciser. De plus, les deux dernières parties ne peuvent être postérieures à la disparition de Setthāthirāt, qui survint cinq ans à peine après le commencement de l'inscription.

Avant d'aborder l'étude de texte proprement dite, il sera utile de présenter d'une façon succincte le contexte historique qui entoura la gravure de la stèle. Son commanditaire est cité nommément à trois reprises dans le corps de l'inscription : il s'agit du roi Setthāthirāt (p. Jețthādhirāja), fils ainé du roi Phothisarāt (p. Bodhisārarāja; 1520- 1548) et d'une princesse du Lān $\mathrm{Na}^{44}$. Durant la première moitié du XVI ${ }^{\mathrm{e}}$ siècle, les relations entre les deux grands royaumes t'ai septentrionaux sont pacifiques - et le bouddhisme florissant de la Thaïlande du Nord se diffuse progressivement en pays lao ${ }^{45}$, en même temps que les textes (et donc les écritures) qui le véhiculent. La Jinakālamālī, chronique religieuse pâlie dont la rédaction a été achevée à Chiang Mai en 1527, rapporte qu'en 1523 le souverain du Lān Nā adressa à celui du Lān Xāng un Tipitaka en 60 volumes avec une suite de religieux ${ }^{46}$. Le 12 avril 1527, Phothisarāt fait rédiger à Luang Prabang la stèle du Vat Savanthevalok (skt. Svargadevaloka), qui est la plus ancienne stèle en écriture "tham » que nous ayions retrouvée dans les frontières de l'ancien Lān Xāng ${ }^{47}$. Elle est également

44. On sait peu de choses sur cette princesse, car les principales sources lao, ainsi que la Chronique de Chiang Mai, restent muettes sur l'ascendance maternelle de Setthāthirāt. Certaines versions marginales des chroniques lao rapportent cependant qu'elle s'appelait Nāng Yot Kèo et qu'elle était la fille du roi de Chiang Mai. La compilation siamoise Phongsāvadār Hneua identifie ce dernier à Phra Muang Ket Klao (dates de règne : 1526-1538, 1543-1545).

45. Il s'agit du bouddhisme réformé d'inspiration cinghalaise, qui avait d'abord gagné la Birmanie et les royaumes t'ai du Sud, comme Sukhothai. Une forme de bouddhisme fut pratiquée par les Mons dans la région de Vientiane au cours du premier millénaire et disparut ensuite complètement. Le royaume du Lān Xāng fut créé au milieu du XIV $V^{\mathfrak{e}}$ siècle et les croyances de ses premiers souverains restèrent très certainement profondément animistes. Ce n'est qu'à partir de la seconde moitié du $X^{e}$ siècle que l'idéologie royale lao révèle véritablement la marque du bouddhisme theravâda. Cf. M. Lorrillard, « The Earliest Lao Buddhist Monasteries...», 2003; et "D'Angkor au Lān Xāng: une révision des jugements », 2001, p. 19-34.

46. G. Cœdès, « Documents sur l'histoire politique et religieuse du Laos occidental », BEFEO 25/1, p. 72 et 139 ; Jinakālamālì, A. P. Buddhadatta éd., 1962, p. 127 ; N. A. Jayawickrama (trad.), The Sheaf of Garlands of the Epochs of the Conqueror, 1978, p. 183.

47. On a longtemps considéré que la stèle du Vat Savanthevalok - encore inédite - était également la plus ancienne stèle relevant du Lān Xāng, toutes écritures confondues (trois autres stèles plus anciennes ont été retrouvées dans les frontières du Laos actuel, mais elles se rattachent à l'aire politique 
importante pour son contenu, puisqu'il s'agit d'une ordonnance par laquelle Phothisarāt charge son mahà sangharāja, chef du clergé, de restaurer la religion - et de la purifier en particulier des croyances animistes. Le souci de réforme du roi paraît avoir été particulièrement fort, puisqu'il est exprimé une nouvelle fois en 1535 dans une stèle retrouvée à une soixantaine de $\mathrm{km}$ en aval de Vientiane ${ }^{48}$. Ce sont d'ailleurs les temples de cette ville, qualifiée de « royale » (p. rājadhān̄i), que vise en priorité Phothisarāt. On imagine que la rédaction de l'ordonnance ne se limita pas à un seul exemplaire et que le même texte fut gravé à Vientiane, que ce soit sur de la pierre ou sur des feuilles de latanier ou de métal. Si peu de documents de l'époque de Phothisarāt ont été retrouvés, il est en tout cas sûr que l'œuvre religieuse du roi fut importante, en particulier en ce qui concerne les fondations de temples. Plusieurs d'entre eux continueront par la suite à bénéficier des faveurs royales et l'origine de leurs premiers biens sera alors souvent rappelée ${ }^{49}$. En 1545 , une grave crise de succession secoue le Lān Nā. Une faction importante des dignitaires de ce royaume obtient de Phothisarât l'envoi de son fils aîné pour occuper le trône de Chiang Mai. Le jeune prince arrive dans la ville en juin 1546 et se fait bientôt couronner ${ }^{50}$. Les chroniques t'ai du Nord lui conservent cependant le nom d'Uppayovarāt (p. upa-yuvarāja), comme pour rappeler son statut d'héritier du trône du Lān Xāng ${ }^{51}$. Ce dernier lui est en effet offert après le décès de Phothisarāt, en 1547-1548, et le jeune souverain, qui prend alors le nom de règne de Setthāthirāt, quitte Chiang Mai. En 1551, il fait un bref passage dans la capitale du Lān Nā pour signifier officiellement son abdication ${ }^{52}$. Il revient cependant partiellement sur sa décision en s'emparant de la place forte de Chiang Saen, riveraine du Mékong, où il paraît installé jusqu'en 1559. Les données philologiques, qui nous offrent déjà une chronologie fiable puisque les annales du Lān Nā et du Lan Xāng se recoupent, sont vérifiées pour cette période par les données épigraphiques. Le 4 janvier 1554, la stèle de Chiang Sa, retrouvée un peu en aval de Chiang Saen, mentionne "Sa Majesté... qui règne sur les deux territoires, Lān Xāng et Lān Nā » ${ }^{53}$. Une autre stèle, conservée à Luang Prabang et datée du 20 octobre 1555, évoque quant à elle «Sa Majesté Sai Setthāthirāt (de) Chiang Sēn ${ }^{54}$. Le fait que le roi soit resté longtemps absent du Lān Xāng semble par ailleurs mis en évidence par les textes de cinq stèles lao ayant pour sujet des fondations royales intervenues entre 1549 et 1555 . Aucune d'entre elles ne notifie en effet une présence effective de Setthāthirāt. Les trois premières ${ }^{55}$, dont les rédactions finales respectives datent de 1561-1562, 1564 et 1590, ne mentionnent de façon rétrospective les années 1549,1551 et 1552 que pour marquer le laps de temps qui s'écoula

et culturelle du Lān $N a \bar{a}$. Le déchiffrement récent d'une stèle en écriture lao de la région de Thakhek (Centre-Laos) a cependant révélé que celle-ci pouvait être datée d'une façon certaine du 17 avril 1494.

48. Stèle $\mathrm{n}^{\circ} 2 \mathrm{du}$ Vat Daen Muang, Phon Phisay. Cf. Th. Punnothok, Sìlā Careuk İsān Samay Thai

Lāo, p. 236-240; Cāreuk Nai Prathet Thai, 1986, p. 327-330.

49. Six stèles, datées du milieu du $\mathrm{XVI}^{\mathrm{e}}$ au début du $X V I^{\mathrm{e}}$ siècle, mentionnent rétrospectivement Phothisarāt en tant que fondateur de temple.

50. C. Notton (trad.), Annales du Siam, III volume: Chronique de Xieng Mai, 1932, p. 157-158; D. K. Wyatt \& A. Wichienkeeo (trad.), The Chiang Mai Chronicle, p. 113-114. Les Phongsāvadān lao confirment les données de la Chronique de Chiang Mai.

51. On verra, infra note 97 , qu'une autre explication est possible.

52. C. Notton, 1932, p. 160 ; D. K. Wyatt, 1995, p. 115.

53. Prachum Cāreuk Lān Nā, 2000, p. 227-235.

54. Stèle déposée au Vat Saen, inédite.

55. Il s'agit des stèles des Vat(s) Vieng Kham (Vieng Kham, Gagneux, op. cit, p. 108-114), Phadung Sukh (Phon Phisay, Punnothok, s. d., p. 241-243 ; Cāreuk Nai Prathet Thai, 1986, p. 331-334) et Xieng Maen (Luang Prabang, inédit). 
entre la fondation et sa consécration royale. Dans la quatrième ${ }^{56}$, datée de 1555 , c'est la reine-mère qui consacre les donations. Dans la cinquième ${ }^{57}$, antérieure d'un an, c'est un dignitaire qui remplace le roi. À partir de 1560 - et cela jusqu'en 1567 -, nous notons par contre pour la région de Vientiane la production d'inscriptions royales (huit au total) véritablement commanditées par Setthāthirāt. Poussé par le danger birman, celui-ci a en effet quitté le Lān Nā pour s'installer dans la seconde capitale de son père. À peine arrivé, il a d'ailleurs conclu une alliance avec le souverain d'Ayuthya qui est célébrée à la frontière des deux royaumes, à Dan Sai (actuelle province thaïlandaise de Lœi), le 7 juillet 1560 . Les dignitaires des deux royaumes se retrouvent au même endroit le 6 mai 1563, afin semble-t-il d'inaugurer le monument qui symbolisait cette nouvelle amitié ${ }^{58}$. Des engagements relatifs à l'union des deux familles paraissent avoir été également pris lors de ces deux occasions. En fait, si l'on en croit les annales d'Ayuthya (que recoupent les annales courtes de Vientiane), une première princesse siamoise arriva à Vientiane en 1562-1563, mais elle n'était pas celle que Setthāthirāt attendait et elle fut renvoyée. Sa sœur prit le chemin du Lān Xāng en 15641565. Elle fut cependant interceptée par le «prince félon » de Phitsanulok, ce qui entraîna bientôt le royaume lao dans la guerre, conformément à l'alliance qui avait été conclue avec Ayuthya ${ }^{59}$. Pratiquement au même moment, le Lān Xāng eut à subir une première incursion militaire birmane qui se solda par le rapt d'un certain nombre de membres de la famille royale, dont le Mahā Uparāt (p. mahā upa-rāja) ${ }^{60}$. La campagne contre Phitsanulok, un moment retardée par un changement de règne à Ayuthya, paraît avoir commencé à la fin de l'année 1566 ou au début de l'année 1567. Les troupes lao assiégèrent la ville pendant plusieurs semaines, puis, celle-ci recevant l'aide de forces birmanes, elles furent obligées de se retirer et retournèrent au Lān Xāng ${ }^{61}$. Une nouvelle campagne lao est menée en 15681569 , lorsque la cité d'Ayuthya est assiégée par les Birmans. Les troupes de Setthāthirāt sont cependant défaites avant même d'atteindre la capitale siamoise, et refluent une nouvelle fois vers Vientiane ${ }^{62}$. Il semble qu'elles aient été suivies par les troupes birmanes augmentées de contingents t'ai, puisqu'en 1969, Setthāthirāt est forcé de quitter sa capitale et de se replier vers Vieng Pāk Ngum. Là, il apparaît que les Lao, par leurs harcellements continuels, aient contraint leurs ennemis à battre en retraite ${ }^{63}$. Setthăthirăt disparut d'une façon mystérieuse un peu plus tard, en 1571-1572, peut-être à la suite d'une campagne malheureuse contre les Khmers ${ }^{64}$. À partir de décembre 1572, comme on le verra plus loin, les sources épigraphiques citent déjà son successeur.

56. Stèle du Vat Chommani (Nong Khay, Punnothok, s. d., p. 247-253; Cāreuk Nai Prathet Thai, 1986, p. 336-343).

57. Stèle du Vat Say Settha (Nong Khay, Punnothok, s. d., p. 244-246; Cãreuk Nai Prathet Thai, 1986, p. 382-384).

58. L. Finot, «Les inscriptions du Musée de Hanoï », BEFEO 15/2, p. 28-36; P. N. Nagara, A. B. Griswold, "An Inscription of 1563 A.D. Recording a Treaty Between Laos and Ayodhyā in $1560 », 1992$, p. 788-803. La stèle est aujourd'hui conservée au Musée du Vat Ho Phra Keo.

59. R. D. Cushman, The Royal Chronicles of Ayutthaya, 2000, p. 49-52. Pour cette époque, seule la version Luang Praset (1680) donne une chronologie correcte.

60. Données issues des Phongsāvadān, du Nithān Khun Borom et du Chot Hmāy Het Yo Vieng Chan.

61. R. D Cushman, 2000, p. 52-56.

62. Ibid, p. 69-72.

63. Données issues des Phongsāvadān, du Nithān Khun Borom et du Chot Hmāy Het Yo Vieng Chan. 64. Ibid. 

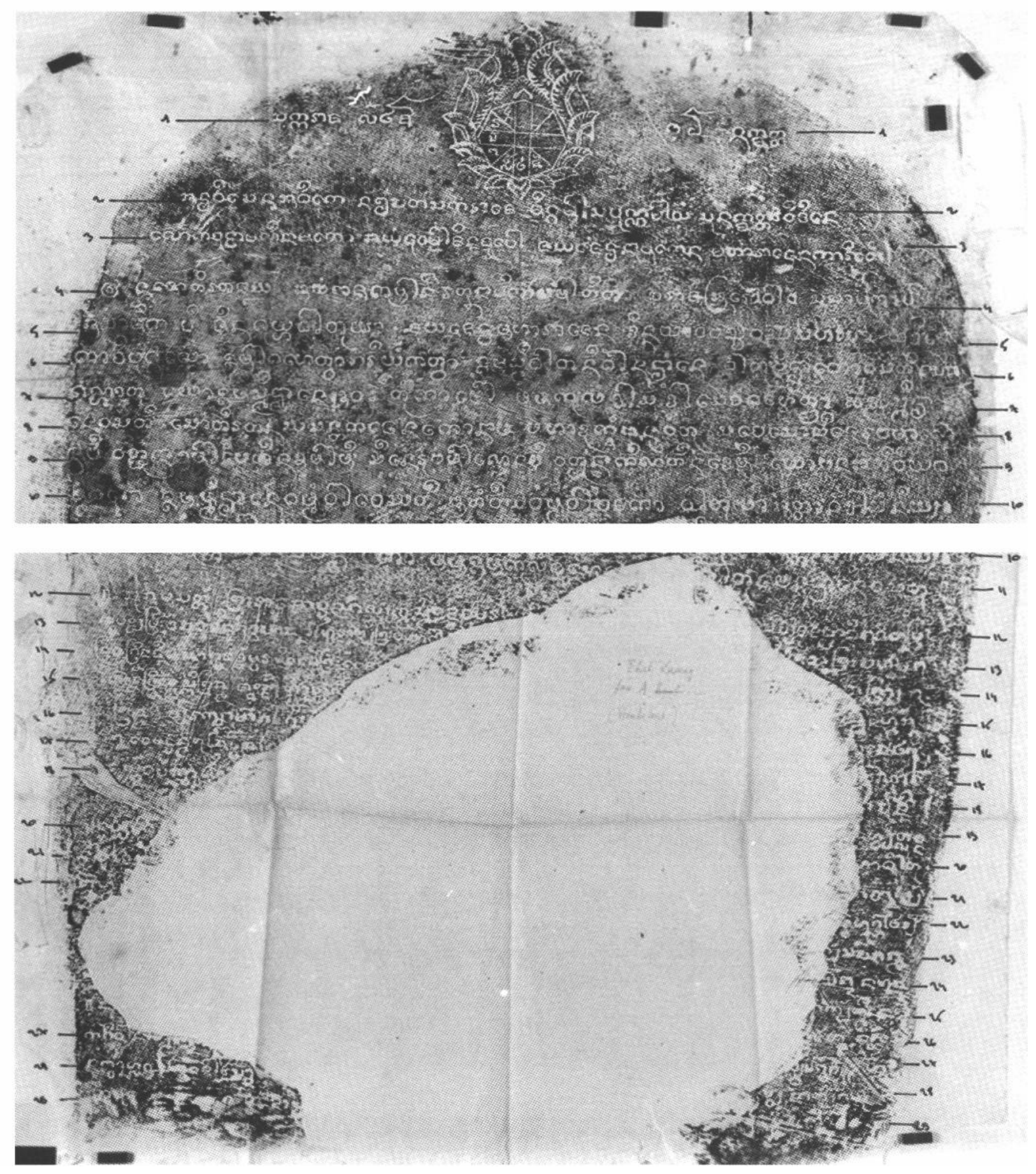

Document 6 - Face 1 de la stèle nord de la porte orientale du That Luang. 

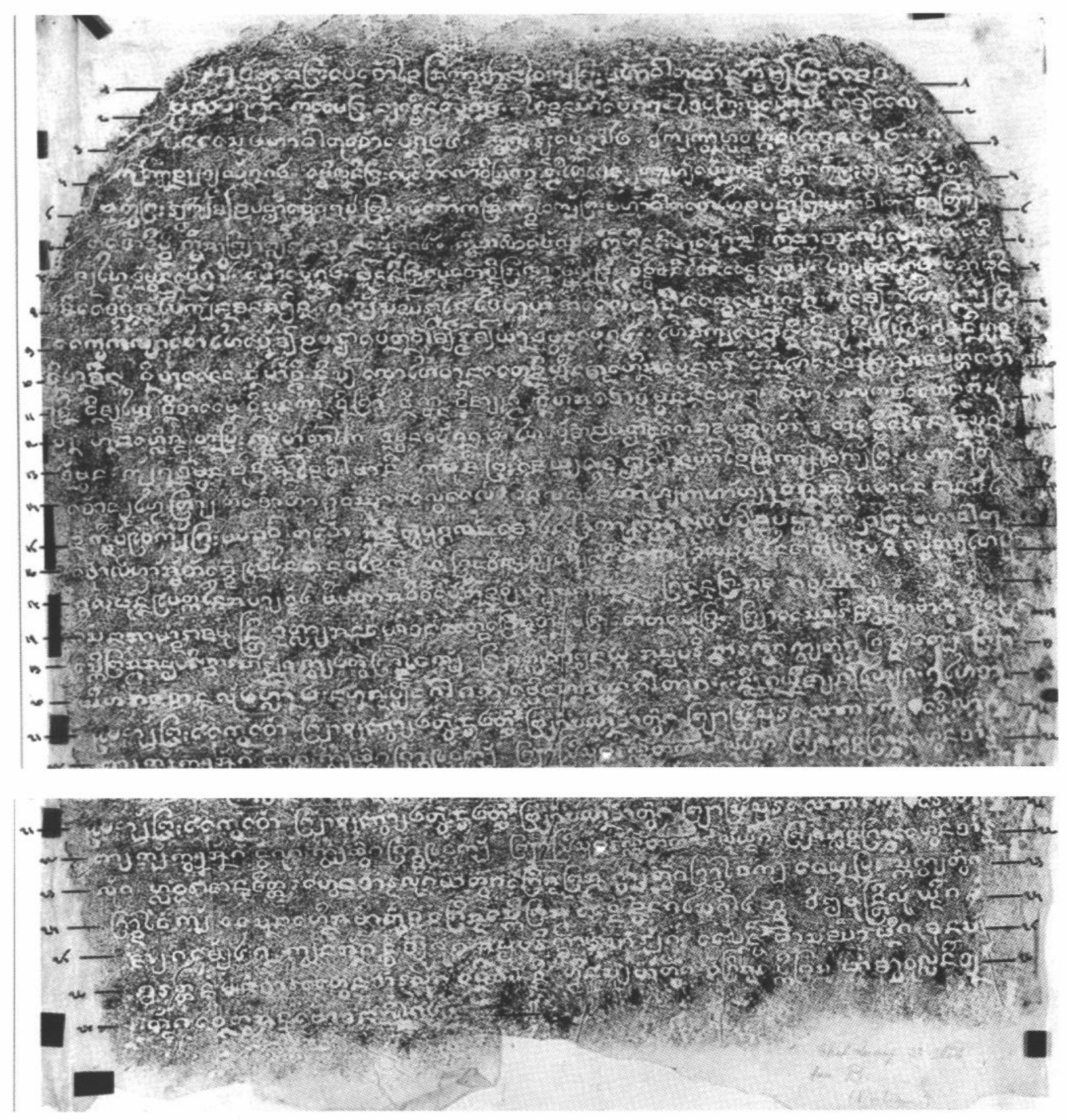

Document 7 - Face 2 de la stèle nord de la porte orientale du That Luang. 
Document 8 - Texte de la stèle nord de la porte orientale du That Luang.

Face 1:

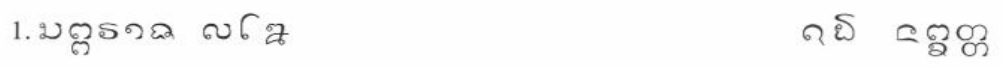

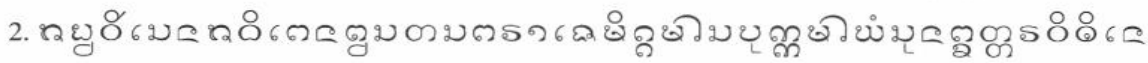

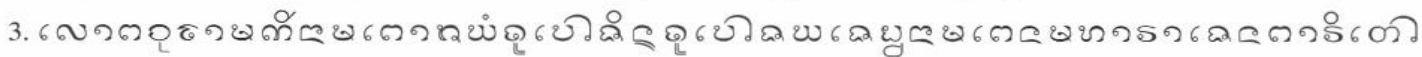

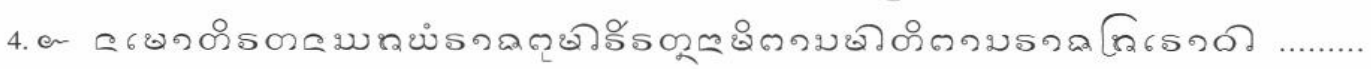

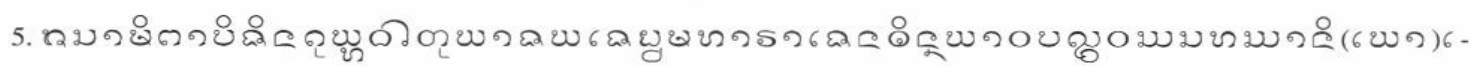

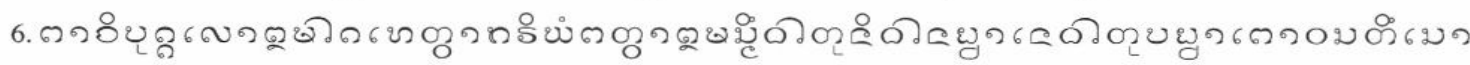

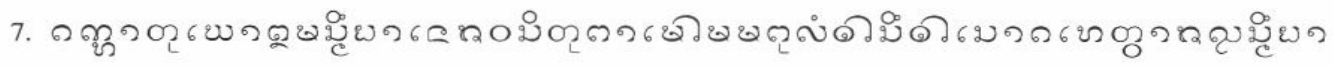

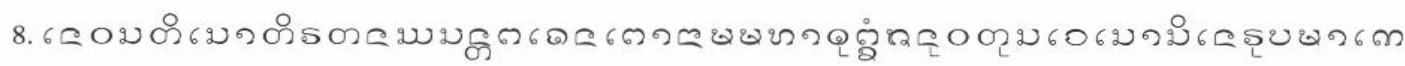

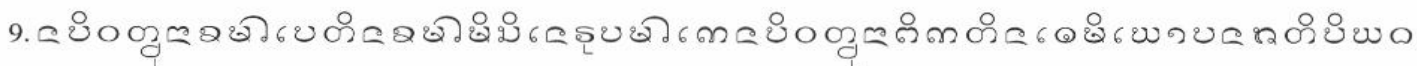

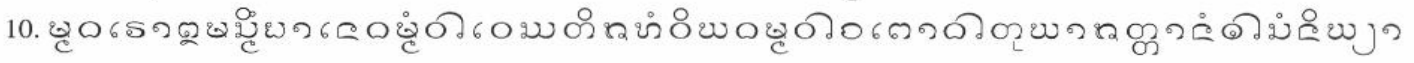

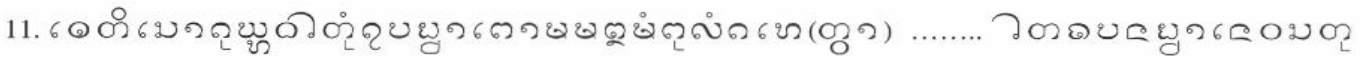

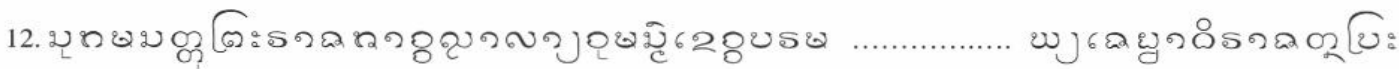

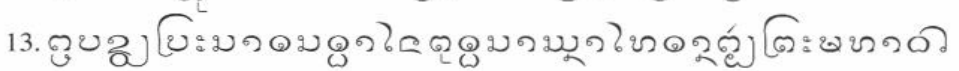

(ฉू)

14. С్రి

[2]2 ... 2

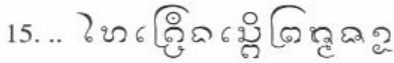

6 นุ้

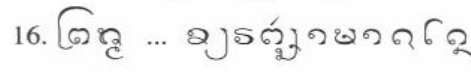

ธ๑ 62

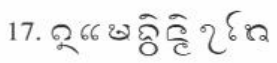

วนวร

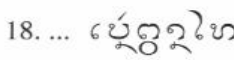

ฮ్ำ

19.

2ูปู

20. \$6ช́

भคคี

21.6022

๑2ळ்

22.

อโร

23.

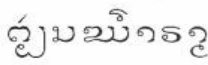

24.

ระุนู

25.

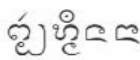

26.

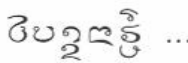

27. ம் ค่อ

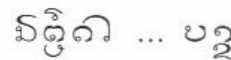

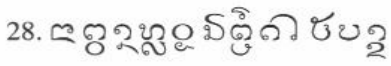

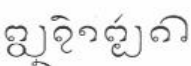

29.... உथ? 
Face 2:

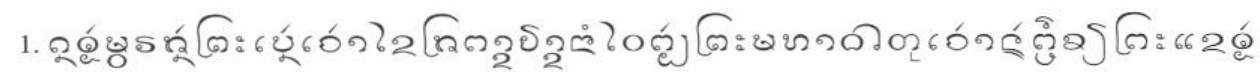

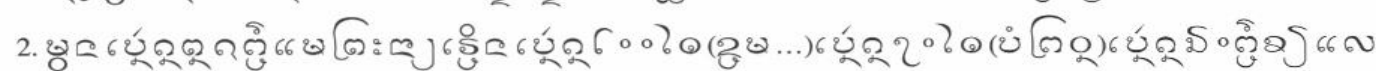

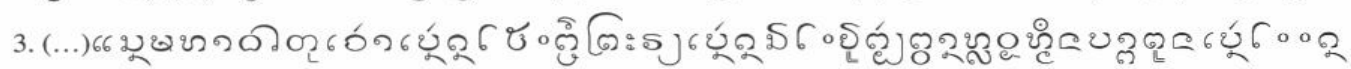

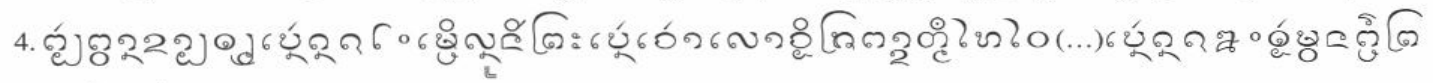

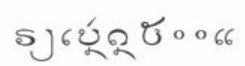

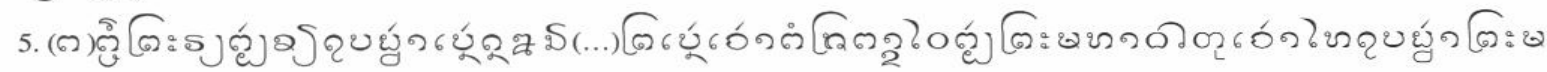

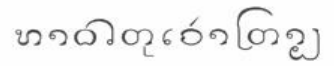

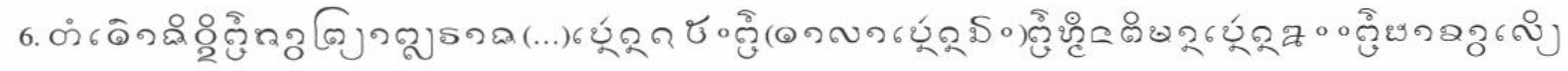

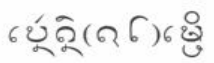

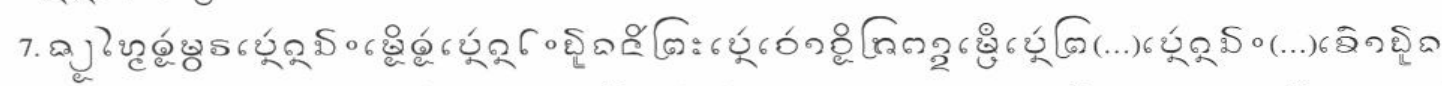

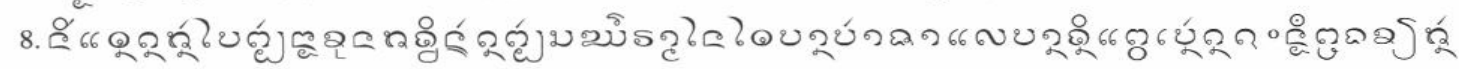
ในจฆ์ตั

9. 6ตูกல ย́n(82)令药

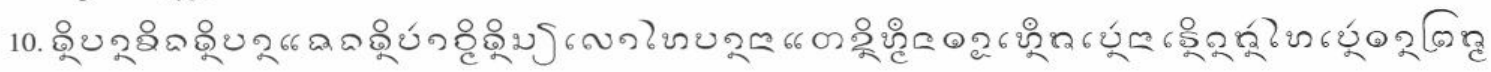
รวavión

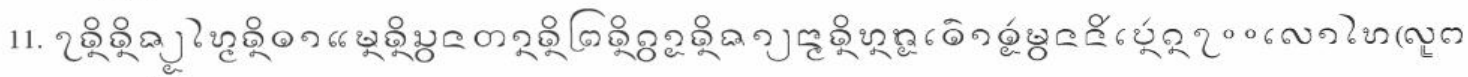

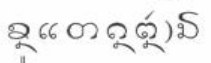

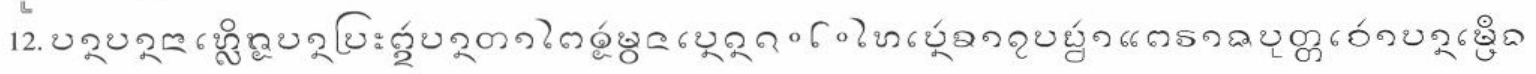
ใรติธิบอ

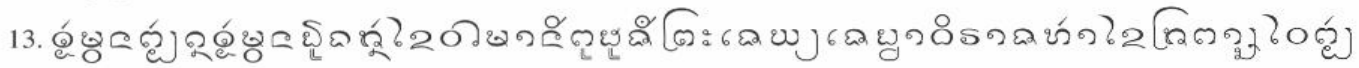

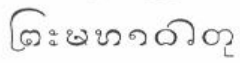

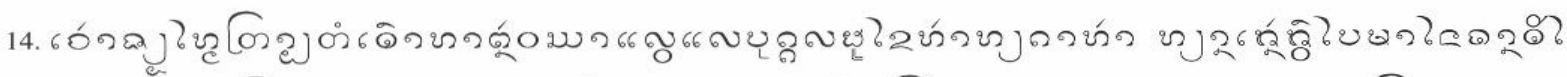

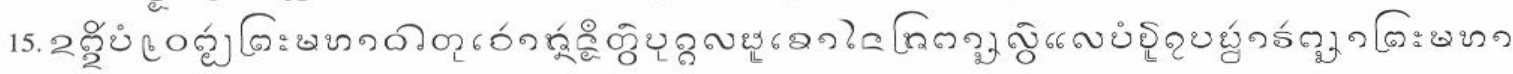
ค००

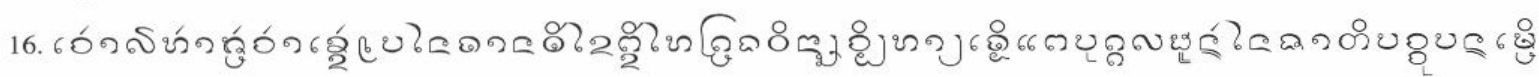
ตขวชขอ

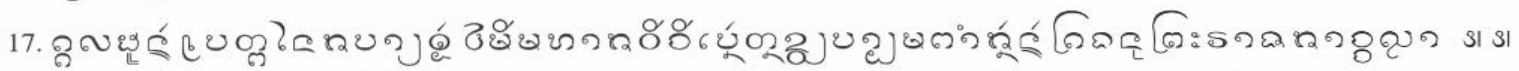

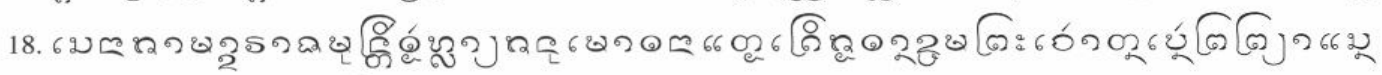

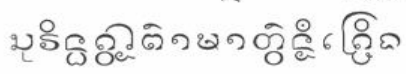




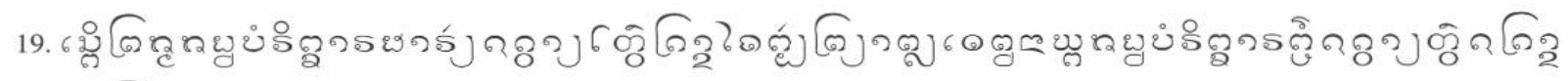

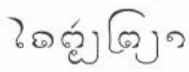

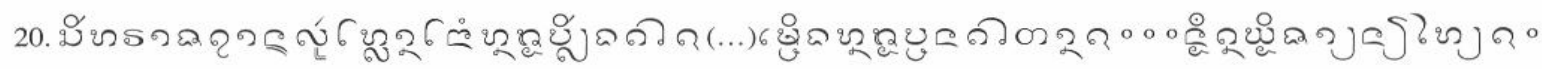
2ชช०2

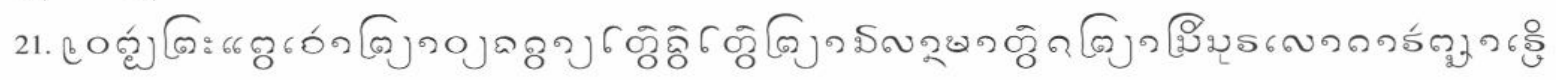
ง่ว?

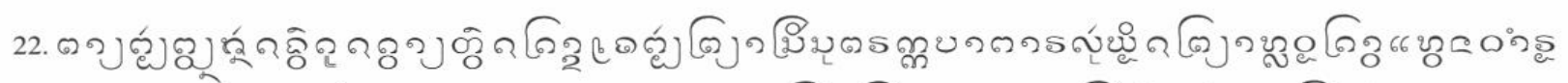

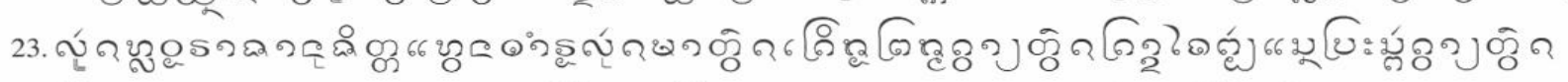

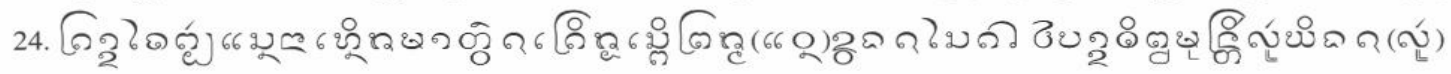

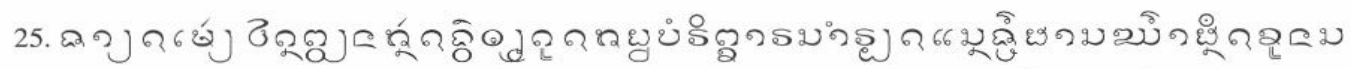

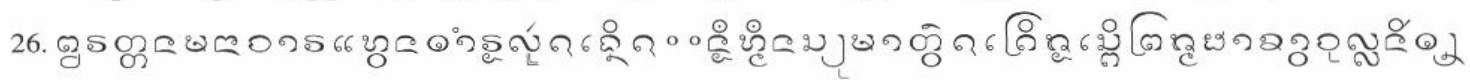

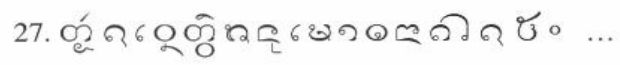


Composition du disque horoscopique

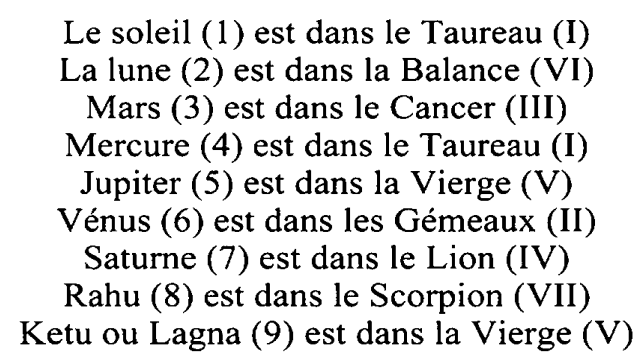

Translittération du texte pâli

1) sakkarāja $928 \quad 16$ nakkhatta

2) atthavisena ${ }^{65}$ adhike navasatasakkarāje ${ }^{66}$ miggamāsapunnamāyam sunakkhattaravidine |

3) lokacūlāmanināmako ${ }^{67}$ ayam thūpo jinathūpo ${ }^{68}$ jayajețthanāmakena mahārājena kārito |

4) namo tiratanassa | ayam rājakumārī ratananāmikā samātikā sarāja-orodhā(...)

5) asāmikāpi jinaguyhadhätuya jayajetthamahārājena dinnā ${ }^{69}$ yāva pañcavassasahassāni $\mid(y o)$

6) koci puggalo imam ${ }^{70}$ gahetvā bhariyam katvā imasmim dhātunidhānaț̣̂āne dhätūpatthāko ${ }^{71}$ vasati(m) so

7) ganhātu | yo imasmim thāne avasitukāmo mama kulam dāsim dāso gahetvā añ̄asmim ${ }^{\text {i2 }}$ thā-

8) -ne vasati so tiratanassa santaka thenako nāma | mahādukkham anubhavatu ${ }^{73} \mid$ sace so sinerupamāne-

9) -nāpi ${ }^{74}$ vatthunā khamāpeti na khamāmi $\mid$ sinerupamānenāpi vatthunā kiñāti ${ }^{75}$ na demi $\mid$ yo pana atipiyadha-

10) -mmadharo imasmim thāne dhammam vā vissasati ${ }^{76} \mid$ aham viya dhammavācako | dhātuy ā attānam dāsam niyy $\bar{a}-$

11) -deti so guyhadhātūpațthāko ${ }^{77}$ mama imam kulam gahe(tvā) ...... $\bar{a}$ tattha ${ }^{78}$ panațthāne vasatu|

65. Le texte donne «athavīsena ", mais dans les premières inscriptions tham du Lān Nā, «tha » et «ttha » se confondent en un même signe graphique. La distinction commence à se produire dans certaines inscriptions à partir du milieu du $\mathrm{XVI}^{\mathrm{e}}$ siècle. D'autres perpétueront encore longtemps la même graphie, qui crée une ambiguîté. La même remarque est valable pour jettha et upatthāko qui paraissent orthographiés « jetha » et "upathāko». Dans le cas où le «th » est une consonne initiale (ex. : thāne), il semble cependant que la boucle inférieure du signe graphique soit plus courte.

66. Le texte donne «nabbasatasakarāje ».

67. Le texte donne « lokaculāmanīnāmako ».

68 . Le texte donne « jinnathūpo ».

69. Le texte donne « dinna ».

70. Le texte donne « imā ».

71. Le texte donne « dhātupațthāko ».

72. Le texte donne « añasmim ».

73. Le texte donne « anuvatu».

74. Le texte donne « sinerupamānenenapi », qui est répété quelques mots plus loin.

75. Le texte donne « kinati ».

76. Le texte donne « vessati », ce qui est manifestement une erreur. Il pourrait également s'agir de la formule dhammam deset $i=$ prêche le Dhamma.

77. Le texte donne « guyham dhātum upatthāko ».

78. Le texte donne « tatha ». 


\section{Traduction}

Face 1

1. 928 de l'ère, mansion lunaire 16 (= visakha)

2. Neuf cent vingt-huit de l'ère, à la pleine lune du mois Migga, un dimanche, sous une mansion lunaire propice.

3. Ce stūpa, le stüpa du Jina, dont le nom est Lokacūlāmani, a été bâti ${ }^{79}$ par le grand roi qui a pour nom Jayajettha.

4. Honneur aux Trois Joyaux. Avec sa mère (et une suivante royale...), cette princesse nommée Ratana,

5. qui est sans époux, a été accordée par le grand roi Jayajettha à la relique secrète du Jina pour 5000 ans.

6. Quiconque la prend (et) en fait (son) épouse, que celui-là prenne résidence en cet endroit abritant la relique, en tant que serviteur de la relique.

7. Celui qui, étant esclave (et) ne désirant pas résider en cet endroit, prend l'esclave (qui est de) ma famille

8. (et) habite un autre endroit, celui-là est en vérité un voleur de la propriété des Trois Joyaux. Qu'il endure une grande souffrance.

9. S'il demande pardon, même avec une somme aussi grande que le Mont Meru, je ne pardonne pas, s'il (l')achète avec une somme aussi grande que le Mont Meru, je ne (la) donne pas. Celui au contraire qui, étant porteur du Dhamma très cher,

10. est en accord avec le Dhamma en cet endroit - je suis comme celui qui dit le Dhamma - se donne lui-même comme esclave à la relique,

11. est le serviteur de la relique secrète, prend celle (qui est de) ma famille (...), qu'il réside là en cet endroit.

12. Que le bonheur soit! Ordonnance royale revêtue du sceau de Sa Majesté Excellente [et Pure. Le Roi qui porte le nom de Phra Se]yya Setthāthirāt \{Jaya Jetthādhirāja $\}$ et

13. agit avec sérénité et foi dans la religion du Buddha a offert au Phra Mahā Thāt \{cassure\}... que le Phra ...

14. revêtu(e) de toutes ses parures, il y avait la mère de Phra Kē[o ?] \{cassure\}... Phrayā ...

15. a donné des armes avec un/des éléphant(s) ... \{cassure $\}$... comme ...

16. avec [...] 12 esclaves gardant les chevaux ... \{cassure $\ldots$ voitures, 27

17. hommes, 7 vaches ... \{cassure $\ldots$

18. ... est chef ... cassure $\}.$. sur la terre

19. ... \{cassure $\}.$. Huay Luang

20. ... 3 bya... \{cassure $\}$ [ma]hā Thāt

21. Chao Sa... \{cassure $\}.$. donné au

22. ... \{cassure $\}$... d'une valeur de 200

23. ... cassure $\}$... au Sangkhārām

24. ... \{cassure $\}$... rāt, des rivières et des étangs

25. ... \{cassure $\}. .$. avec le Hmeun $\mathrm{Na}$

26. ... \{cassure $\}. .44$ bāt Nā Hong ...

27. c'est-à-dire la rizière ... \{cassure\} ...3 parcelles d'une valeur de [ ] bāt

28. rizières du Koān Luang, 3 parcelles d'une valeur de 5 bāt... \{cassure $\ldots$... charrettes avec une valeur

29. ... rizière ... \{cassure $\} \ldots$ maison $\ldots$

79. D'une façon plus littérale : «a été fait bâtir ». 


\section{Face 2}

1. Ensemble des hommes que le Roi a consentis par le serment de l'eau à ce Phra Mahā Thāt Chao : la troupe des esclaves offerts ${ }^{80}$

2. totalise mille individus. La troupe de Mē Phra Nāy Heuan : 200 individus. Les travailleurs de [Dom...] : 70 individus. Les travailleurs de [Bo Kroam] : 30 esclaves, c'est la troupe des esclaves.

3. [...] Sēn Mahā Thāt Chao : 250 individus. Les troupes du Phra Roy totalisent 320 individus : avec le Koān Luang Hmeun Pāk Phūn, 200 individus,

4. avec le Koān Dāp Thiem, 120 individus. Par la suite le Roi a consenti encore pour [...] 180 individus. Au total, la troupe du Phra Roy s'élève à 500 individus.

5. La troupe de Phra Roy et les esclaves totalisent 83 (?) individus. Le roi les accorde au Phra Mahā Thāt Chao pour le service du Phra Mahā Thāt Chao jusqu'à

6. (la fin de) leur vie. La troupe de l'oncle du Phrayā Phala Rāsa [...] : 150 individus. La troupe de [Thā Lā : 30 individus]. La troupe du Hmeun Phimān : 800 individus. La troupe de Phā Khāo Leuy : [12] individus. Sont rentrés à

7. Chiang Mai : 30 individus; (de ?) Muang Thang : 20 individus. Ceux-là, le Roi les a offerts lorsqu'il était Phra [...], au nombre de 30 [...], ceux-ci

8. remplacent les hommes qui sont partis avec Nāng Khun Atthi. Les hommes du Sangkhāram, pris parmi les gens des villages Bān Pāk Sā et Bān Thin Kèo, sont 10 individus. La troupe des esclaves offerts à Phra

9. Kēo Kalyā Chao, qu'elle soit pour (son) service, à commencer par les porteurs de parasol et les porteurs de palanquin, au total 400 personnes. On a donné 8 terroirs: Thin Thām, Thin Pok, Thin Pāk [Khoat], Thin Luang,

10. Thin Bān Khing, Thin Bān Sèng, Thin Pāk Chim, Thin Soy. On a donné des villages et des rizières depuis la terre de Hmeun Thang Hneua. Ces rizières, ces maisons et ces gens ont été offerts à l'intention du Rāsabut Chao (et représentent)

11. sept terroirs : Thin Chiang Mai, Thin Thā Mēn, Thin Soan Tān, Thin Phra, Thin Khoang, Thin Sāy Nām, Thin Hnong Thao, comptant 700 individus. Puis on a donné [...?] trois

12. villages, Bān Nā Leuang, Bān Prakat et Bān Tā Kai. Au total, ils représentent 1020 individus qui sont les esclaves au service du Rāsabut Chao. Ces villages, ces rizières, ces cultures

13. ainsi que tous les gens qui ont été cités ici, Moi, qui porte le nom de Phra Saiya Setthāthirāt Chao, je les ai offerts au Phra Mahā Thāt

14. Chao Chiang Mai pour une durée de 5000 ans. Celui qui d'une part ruse

15. et ne respecte pas le Phra Mahā Thāt Chao, celui qui d'autre part a été affecté et ne demeure pas au service du Phra Mahā Thāt

16. Chao en sortant des limites et en se rendant ailleurs, que celui-là soit perdu pour la vie présente et qu'à sa mort,

17. il tombe dans les quatre enfers, en commençant par le Mahā Avici, en vertu de ces mauvaises actions. Ainsi le veut l'ordonnance royale. || || ||

18. Les seigneurs et les dignitaires royaux, en grand nombre, ont exprimé leur satisfaction au Roi par la présentation d'offrandes. (De la part du) Phrayā Sēn Surintha Khuāng Fā : un cheval, des armes,

19. Ies huit accessoires, un «hoy » de tissus, deux buffles et une charrue. De la part du Phrayā Phala Theppha Nayok: un ensemble des huit accessoires, un buffle et une charrue. De la part du Phrayā

80. C'est le terme d'origine siamoise - «Pradé » ou "phrade » -, peu usité au Laos, qui semble avoir été utilisé. Celui-ci exprime un don total. 
20. Siharāt Ānan : deux enfants et deux petits-enfants, (les terres de) Nam Hnong Ping - valeur [ ] - et de Muang Hnong Bone - valeur en sucre de palme, 1000 - dix hommes et femmes, enfants et adultes, offerts

21. à Phra Kēo. (De la part du) Chao Phrayā Vieng : deux buffles et deux bœufs. (De la part du) Phrayā 3 Lān : un cheval. (De la part du) Phrayā Sisuralokhā Haksā : un bateau,

22. un radeau et une charrette, une paire de bœufs, un buffle et une charrue. (De la part du) Phrayā Sri Suphan Pākān : une fille. (De la part du) Phrayā Luang Khrāo : une bague précieuse.

23. (De la part du) Luang Rāsānusitta ; une bague précieuse, un cheval, des instruments, un buffle et une charrue. De la part du Sēn Prasak : un buffle

24. et une charrue. De la part du Sēn Nā Hneua : un cheval, des armes, une bague précieuse, un collier d'une valeur de quatre bāt. (De la part du) Thipphamontri : une fille,

25. un garçon, quatre épouses, une charrette, une paire de bœufs attelés, un ensemble des huit accessoires pour cent vingt mille (?), un manteau religieux. (De la part de) Khun Sa-

26. ppha Rattana Manāchāra : une bague précieuse, cent d'argent. (De la part du) Hmeun Suy, un cheval, des armes. (De la part de) Phā Khāo Cullani, un cierge.

27. Il s'offre lui-même pour exprimer sa satisfaction, valeur : 150 .

\section{Commentaires}

La stèle nord de la porte orientale du That Luang ne se distingue pas d'une façon fondamentale des autres stèles du Lān Xāng et du Lān Nā. Sa fonction est la même : elle commémore les avantages et les bénéfices que reçoit une fondation religieuse. Un certain nombre de traits originaux lui confèrent cependant une importance toute particulière. Nous essaierons de les mettre en lumière.

\section{Le sujet}

Les stèles du That Luang ont été jusqu'à présent associées à la fondation du monument. Une première lecture de la stèle nord nous force cependant à réviser ce jugement: si le nom du stūpa est bien cité à plusieurs reprises, sa description est cependant absente et il n'est fait aucune mention explicite de travaux architecturaux même si Setthāthirāt est présenté dans le texte pâli comme l'ordonnateur de la construction. L'inscription traite dans son intégralité des offrandes royales qui ont été accordées au monument, ainsi que des dons qui ont été faits par les dignitaires au souverain. On verra pourtant que, dans une certaine mesure, les intuitions des premiers découvreurs de l'inscription avaient quelque fondement.

Il faut attacher une importance particulière à la première partie du document - le texte pâli - qui occupe manifestement une place dominante dans la composition. Il commémore en effet un événement qui dans la conscience collective de l'époque l'emportait probablement sur tous les autres: l'offrande à la relique d'une princesse qui n'est autre que la propre fille du souverain. Il est fort probable que la mention de cette donation exceptionnelle a également figuré dans le texte lao, en tête des offrandes effectuées au stūpa. Si la partie centrale de la ligne 13 a malheureusement disparu, les premiers mots de la ligne 14, faisant allusion à des "parures », semblent bien indiquer qu'une femme était le sujet du passage, d'autant plus qu'il est fait référence ensuite à la mère d'une certaine Phra Kê( ). On pourra sans doute identifier cette dernière à la princesse Ratana du texte pâli, puisque ce nom se traduit en lao par "kēo » (joyau). Sur la face 2, le nom est une nouvelle fois mentionné (ligne 9) - il est suivi du terme d'origine pâlie kalyā(na) qui désigne la beauté - et il s'applique alors à une personne de rang royal (Phra ... Chao) qui 
bénéficie de privilèges tout à fait particuliers, puisqu'elle dispose de quelque 400 serviteurs, parmi lesquels des porteurs de parasol et de palanquin.

Il semble que la mère de la princesse - qui devait être une des épouses de Setthāthirāt - ait été également offerte comme esclave. Il est cependant fait moins de cas de cette dernière, même si elle paraît mentionnée au moins deux fois dans l'inscription.

La suite du texte lao est peut-être moins chargée symboliquement, mais elle n'en est pourtant pas moins importante. Les quinze dernières lignes de la face 1 - malheureusement très abimées et d'une interprétation difficile - semblent traiter de biens et de rizières plutôt que d'esclaves. Le roi n'est d'ailleurs plus le seul donateur, puisqu'un certain nombre de dignitaires paraissent cités : un Phrayā (Sēn Surintha ?) à la ligne 14 ; peut-être le puissant gouverneur du Muang Pāk Huay Luang à la ligne 19; un Hmeun Nā à la ligne 25 ; et un Koān Luang à la ligne 28 - respectant en cela la hiérarchie des fonctions.

Nous avons vu que la rédaction de la face 2 était sans doute quelque peu postérieure à celle de la face 1. Dans les dix-sept premières lignes, en effet, le souverain donne une nouvelle recension des biens qu'il offre au stūpa. Neuf d'entre elles n'énumèrent que des esclaves ; quatre autres mêlent des dons d'esclaves à des offrandes de terres ; quant aux quatre dernières, elles contiennent la formule imprécatoire qui conclut en général ce type d'inscriptions. Les dix dernières lignes de la seconde face présentent quant à elles l'inventaire des dons effectués par les grands dignitaires.

\section{Les dons d'esclaves}

Les offrandes d'esclaves ( «hoy », p. dāsa) sont une chose extrêmement fréquente dans les inscriptions du Lān Nā et du Lān Xāng ${ }^{81}$. Leur nombre est cependant limité - on atteint rarement plus de vingt personnes - et le caractère de notre donation est donc ici tout à fait exceptionnel. Il est d'ailleurs difficile de faire le compte exact de l'ensemble des personnes qui furent offertes. Le chiffre 1000 avancé dans la première ligne de la seconde face n'est pas à prendre dans un sens absolu. Il est estimatif et symbolique, comme les termes « hmeun » (dix mille) et «sēn » (cent mille) qui, appliqués à des fonctions honorifiques, donnaient plus qu'approximativement le nombre de personnes qu'un grand seigneur pouvait commander. En fait, il apparaît même que ce chiffre a été largement sous-estimé, car l'inventaire qui nous est proposé ne totalise pas moins de 3500 personnes. Si toutes sont au bout du compte affectées au stüpa, elles le sont cependant indirectement, puisque divisées en plusieurs groupes - des «troupes », s'il est permis ici d'employer un terme militaire - mis au service de grands personnages qui sont eux-mêmes les serviteurs du monument.

L'identité ou la fonction du premier de ces grands personnages - Mē Phra Nāy Heuan (litt. «la mère du vénérable chef des maisons ») - est difficile à déterminer. Dans un premier temps, on aurait envie de reconnaître la mère de la fameuse princesse, mais le nom se prête extrêmement mal à cette identification. Nous verrons plus tard ce qu'il faut en penser. Deux noms difficilement lisibles apparaissent ensuite, mais il semble qu'il s'agisse plutôt de toponymes - peut-être les villages d'où provenaient les travailleurs œuvrant pour Mē Phra Nāy Heuan ${ }^{82}$. La lecture incertaine du début de la ligne 3 ne

81. Au moins 57 inscriptions du Lān Nā datées de 1458 à 1548 font état de donations d'esclaves (cf. Cāreuk Lān Nā, 1991 ; Prachum Cāreuk Muang Phayao, 1995). C'est plus que pour les donations de terres. Parmi les 17 inscriptions du Lān Xāng antérieures à 1566 qui nous ont été conservées, 8 font référence à des esclaves ou à des serviteurs.

82. Les chiffres 70 et 30 ne donnent pas un total de 200 , qui est le nombre d'individus regroupés par Mē Phra Nāy Heuan. La notation du chiffre 1 à la place de la centaine a peut-être été oubliée. Nous aurions alors 170 et 30 , ou 70 et 130 . 
permet pas de dire si les 250 individus comptabilisés relèvent d'un lieu ou d'un personnage (un Sēn Mahā Thāt Chao ?). Nous rencontrons également un problème avec le Phra Hoy qui est un bénéficiaire important, puisqu'il hérite de 500 serviteurs, peut-être même 583 si l'on considère que le chiffre mentionné à la ligne 5 pourrait être une addition. Le terme " Phra » laisse d'abord à penser qu'il s'agissait d'un religieux. Cette explication est cependant loin de nous satisfaire: les inscriptions et les chroniques du monde t'ai mentionnent des centaines de moines, et le nom jure ici d'une façon évidente avec les habitudes onomastiques. Le personnage était beaucoup plus probablement un officier d'extraction royale («Phra ») qui avait à sa charge une ou quelques centaines (« hoy ») d'hommes. Ces derniers sont d'ailleurs divisés en trois groupes distincts, dont deux au moins étaient contrôlés par des chefs : le Koān Luang Hmeun Pāk Phūn et le Koān Dāp Thiem.

L'identification des bénéficiaires suivants n'est pas davantage aisée. La référence à un oncle paternel ( āo ») d'un certain Phrayā Phala Rāsa (...) est surprenante dans la mesure où le nom du personnage n'est pas cité. On peut donc se demander si ce n'est pas le Phrayā Phala Rāsa (...) lui-même qui était l'oncle : celui-ci pourrait alors être un frère cadet de Phothisarāt. Le Hmeun Phimān est manifestement un chef militaire. Quant à Phā Khāo Leuy, peut-être s'agit-il d'un laïc qui observait la discipline religieuse.

L'inscription évoque ensuite des gens de Chiang Mai offerts lorsque le roi était encore Phra (...) - dont le retour aurait été permis. Cette information est intéressante car elle confirme l'hypothèse de la présence à Vientiane d'un certain nombre d'hommes du Lān $\mathrm{Na}$, que beaucoup d'indices permettent déjà de déceler. La mention à la ligne 11 d'un terroir dit de «Chiang Mai » va également dans ce sens ${ }^{83}$.

Le temple ou la communauté monastique, désigné(e) dans cette inscription par le terme "sangkhārām » (p. sañghārāma), pourrait paraître lésé(e) avec ses dix esclaves mais ce chiffre correspond bien aux effectifs qui sont d'habitude attribués à un sanctuaire. On en conclut pourtant que l'intérêt du That Luang était bien distingué de celui du sangha, ce qui est un fait totalement exceptionnel. Le stūpa, qui est généralement un des éléments du complexe monastique (parfois le premier), est ici complètement indépendant et bénéficie d'un statut très particulier. Il n'est plus seulement un édifice religieux, il est également et surtout un monument royal, et relève en tant que tel de la seule autorité du souverain ${ }^{84}$. Le "sanghārām » était probablement situé à quelque distance, peut-être à l'emplacement de l'actuel Vat Hnong Bone, comme nous le verrons plus loin.

Les deux derniers bénéficiaires se différencient manifestement très nettement des autres, car en plus d'un grand nombre d'esclaves, ils reçoivent une large surface foncière. Il est vrai qu'ils sont tous les deux de rang royal ("Chao »). La princesse Kēo Kalyā est la première. Nous avons vu que c'est à l'évidence le don de sa personne qui constitue le sujet du texte pâli. Étant esclave, elle n'en reste pas moins la fille du souverain - et son nouveau statut ne fait peut-être justement qu'accroître les faveurs qu'on lui accorde. Les huit domaines qu'elle reçoit n'ont pas été identifiés. Il est possible qu'ils aient été éloignés de Vientiane, comme ce sera le cas pour les terres offertes dans la stèle sud. Le Rāsabut (p. rājaputta) est probablement le frère de la précédente : son nom indique en effet qu'il

83. Le bourg thaïlandais qui fait face à Vientiane s'appelle «Sri Chiang Mai ». Nous n'avons cependant retrouvé aucune occurrence ancienne de ce nom (le lieu s'appelait autrefois «Phan Phao ») et nous ne proposons donc pas de l'identifier au terroir («thin ») de Chiang Mai qui est mentionné dans notre texte.

84. On remarquera que contrairement aux autres inscriptions du Lān Xāng qui commémorent des donations, aucun religieux n'est ici pris à témoin. La brisure de la pierre sur la première face n'aurait pu suffire à masquer la référence aux « garants de l'intérieur ». 
est fils du roi ${ }^{85}$. Il doit normalement s'agir de Hno Muang ${ }^{86}$, dont nous verrons que l'attachement pour le That Luang restera grand. Pour autant, sa mention dans le texte lao est ici curieuse, car elle manque dans le texte pâli. Il est d'ailleurs difficile de croire qu'un personnage si important, puisque destiné à prendre la succession de son père, ait été lui aussi «totalement» placé au service du That Luang. On penchera davantage pour une position honorifique, qui justifiera d'ailleurs l'octroi de sept domaines, de trois villages et de plus de mille serviteurs. La situation géographique des terres n'a pas été identifiée.

Le nombre des esclaves mis au service du That Luang étant tout à fait exceptionnel, on peut se demander quelle était la tâche de tous ces gens. Une explication nous est donnée pour certains d'entre eux, ainsi le personnel de la princesse qui devait veiller essentiellement à son bien-être, de même que la main d'œuvre importante qui était chargée de mettre en valeur les dix-huit domaines attribués aux deux princes. Quant au reste des effectifs, nous ne pouvons qu'émettre des hypothèses. Ces gens n'ayant à cultiver aucune terre et n'étant donc chargés de nourrir personne, leurs forces durent être employées à d'autres tâches - et il ne peut guère s'agir ici que de travaux de construction. Dans cette perspective, un certain nombre de termes énigmatiques commencent en effet à trouver une explication. Ainsi le mot «kong» - associé d'une façon curieuse aux esclaves ${ }^{87}$ - qui désigne la troupe, le corps ou un service particulier. On peut conclure qu'il désignait ici les différents groupes d'ouvriers. Le sens du nom «Me Phra Nāy Heuan » devient également plus clair. Le terme "mē », qui désigne habituellement une femme (dans son sens strict «la mère »), prend dans certains cas l'acception de chef et s'applique donc à un homme ${ }^{88}$. Ce sens est ici renforcé par l'emploi du terme synonyme « nāy ». Le terme " phra » exprime une nouvelle fois le lien avec la famille royale. Quant au terme " heuan » (au sens strict, " la maison »), il peut signifier d'une façon générale le bâtiment. Le titre pourrait donc désigner tout simplement un chef de la construction, un architecte ou un entrepreneur.

\section{Le nom du monument}

Il est utile de s'attarder sur un point qui n'a jamais été mis en évidence et qui a pourtant une très grande importance : le nom d'origine du stūpa. L'appellation "That Luang » sous laquelle le monument est connu depuis au moins la fin du XIX ${ }^{\mathrm{e}}$ siècle est en fait une désignation tout à fait banale, puisqu'elle signifie simplement "grand thāt ». Un peu avant 1917 , le déchiffrement par L. Finot ${ }^{89}$ d'une partie du texte pâli avait permis de connaître le véritable nom du monument tel qu'il était cité par Setthāthirāt : "Lokacūlāmaṇi ». Le terme cūlāmaṇi est bien connu dans la littérature bouddhique. Il désigne

85. Il faut comprendre ce terme dans son acception littérale. À partir de la fin du XVIII siècle, au moment où les Siamois contrôleront la succession des plus hautes fonctions au sein des royaumes rivaux de Vientiane, de Luang Prabang et de Champassak, le « rāsabut » deviendra un titre important, qui lui permettra éventuellement de prétendre ensuite aux dignités de « rāsavong », d' « uparāt », et enfin à la souveraineté.

86. Hno Muang, cité sous son nom royal dans la seconde face de la stèle $\mathrm{n}^{\circ} 1$ du Vat Suvanna Khuha (Punnothok, s. d., p. 271 - l'éditeur parle à tort de la stèle n 2 ; Cāreuk Nai Prathet Thai, 1986, p. 306307), est qualifié de « rāsakummān » (p. rājakumāra), c'est-à-dire d'enfant (mâle) royal ou du fils du roi. Les sources ne donnent aucun autre garçon à Setthāthirāt.

87. Dans les autres inscriptions t'ai, les esclaves sont toujours présentés en tant qu'individus ou familles. Il est fréquent que leur nom soit répertorié.

88. Par exemple « mē thap » qui désigne le chef de l'armée, le général.

89. «Recherches sur la littérature laotienne », BEFEO 17/5, p. 70. L. Finot n'a jamais publié de traduction de ce texte, mais il se peut qu'elle ait figuré dans ses notes. Dans son article, il mentionne brièvement les noms de Jaya Jeț̣ha, du Cūlāmaṇi et du Jinaguyhadhātu. 
un joyau inséré dans une crête ${ }^{90}$ ou un diadème, mais également la chevelure du Buddha coupée sur les rives de l'Anomā ${ }^{91}$. Le nom semble avoir été particulièrement répandu à l'époque de Setthāthirāt. Lorsque ses troupes, par exemple, partent à l'attaque de Phitsanulok, elles ont à faire face à une avant-garde ennemie postée à proximité d'un temple appelé $C \bar{u} l a \operatorname{lan}^{2}{ }^{92}$. Il est d'ailleurs intéressant de remarquer que cet événement eut lieu l'année même où fut gravée la stèle (1566-1567), ou en tout cas à une date très proche. Dans une inscription trouvée à Chiang Saen (ville où Setthāthirāt séjourna longtemps) datée de 1488, Cūlāmani est cette fois-ci le nom d'un dignitaire ${ }^{93}$. Il n'est pas douteux qu'une recherche exhaustive permettrait de trouver d'autres occurrences ${ }^{94}$. Il est également possible d'opérer un parallèle entre Lokacūlāmaṇi et Lokamoli, puisque les deux composés sont sémantiquement très proches ${ }^{9 \dot{5}}$. Il est d'ailleurs certain que Setthāthirāt avait rendu hommage à un édifice portant le second nom, puisque les cendres du Phrayā Muang Ket Klao - le souverain de Chiang Mai auquel il succéda en 1546 étaient précisément conservées dans le stūpa du Wat Lokamoli, qui venait juste d'être édifié ${ }^{96}$. Le Phrayā Muang Ket Klao, nous apprennent certaines sources, était le grandpère maternel de Setthāthirāt ${ }^{97}$. Il est important de souligner ici (cela n'ayant jamais été fait jusqu'à présent) que le Phrayā Muang Ket Klao s'appelait également Setthāthirāa ${ }^{98}$ et que c'est probablement pour rappeler et affirmer sa filiation au personnage que le jeune souverain lao, lorsqu'il commença à régner, choisit le même nom. On pourrait alors penser que le nom original du That Luang est tout simplement un hommage que Setthāthirāt aurait rendu à son aïeul. Le texte pâli aurait ainsi un caractère essentiellement familial, puisqu'il est également consacré à la fille du roi - dont le nom rappelle d'ailleurs celui de sa grand-mère (Yot Kēo). On verra bientôt que cette explication du nom Lokacūlāmani peut être soutenue par d'autres arguments, qui relèvent aussi bien de la philologie que de l'archéologie. Jusqu'à présent, ce nom a cependant donné lieu à une interprétation tout autre, qui ne paraît pas moins acceptable. Le fait qu'il ait été accordé à un stūpa a en effet conduit à penser que c'était la référence au Củlämanicetiya ${ }^{99}$ - reliquaire mythique bâti par le roi des dieux dans le Tâvatimsa - qui avait été voulue : le nom Lokacūlāmani participerait ainsi au

90. L. Finot (ibid.) traduit lokacūlāmani par « aigrette du monde ».

91. G. P. Malalasekera, Dictionary of Pāli Proper Names, 1997, p. 909.

92. R. D. Cushman, 2000, p. 53.

93. Inscription du Wat Phan Tong Tem, Prachum Silā Cāreuk Phak thi 4, B.E. 2513, p. 18.

94. Le nom apparaît également dans l'épigraphie de Sukhothai (inscriptions 2 et 15).

95. P. moli/moli : a chignon; crest, turban (T. W. Rhys Davids \& W. Stede, Pali-English Dictionary, 1999 , p. 543). Associés à loka (le monde), moḷi et cūlāmani ont le même sens symbolique, étroitement associé à la cosmologie bouddhique.

96. C. Notton, 1932, p. 151-153 ; D. K. Wyatt, 1995, p. 108-109.

97. Cf. supra note 51. On comprendrait ainsi mieux le nom que la Chronique de Chiang Mai donne au jeune prince arrivé du Lān Xāng: Upa-yuva-rāja. Le fils de Phothisarāt aurait également été l'héritier direct du Phrayā Muang Ket Klao.

98. La Chronique de Chiang Mai donne le nom Settharāt (p. jettha-rāja), mais une inscription (inédite) sur une image de Buddha, datée du 2 décembre 1529, fait référence au Phra Say Setthāthilāsa Chao. La date coïncide avec celles du premier règne de Phrayā Ket, alias Phra Settha (1526-1538). L'image a été retrouvée dans le Vat Xieng Men de Luang Prabang, mais il paraît évident (contenu de l'inscription, utilisation du calendrier de Chiang Mai, données paléographiques, style du Buddha) qu'elle a été rapportée du Lān Nā, comme bien d'autres statues que l'on trouve aujourd'hui au Laos. Le fait qu'elle soit conservée au Vat Xieng Men est des plus intéressants, car on sait que c'est le premier temple que Setthāthirāt fonda à Luang Prabang, en 1551 (stèle du Vat Xieng Men, 1590, inédite), c'est-à-dire au moment où il renonça au trône de Chiang Mai.

99. G. P. Malalasekera, 1997, p. 909. Cf. également M. Giteau, Art et archéologie du Laos, 2001, p. 110, n. 60 . 
symbolisme du monument - qui est déjà marqué par la référence au Mont Meru dans le texte pâli, ainsi que par la présence des trente « pinacles » qui abritent autant de pāramī.

Il semble pourtant que ce nom riche de sens n'ait pas eu la plus grande faveur auprès des masses populaires, car il apparaît uniquement dans le texte pâli, que seul un nombre très restreint de lecteurs pouvait comprendre. Dans le texte lao, le nom est tout autre : il s'agit du «Phra Mahā Thāt (Dhātu ${ }^{100}$ ) Chao Chiang Mai », soit le "grand stūpa du roi (ou du prince) de Chiang Mai ». Le roi auquel il est fait référence paraît être le souverain lao lui-même. L'appellation est alors importante, car elle montre que dans la conscience collective de l'époque, la personne de Setthāthirăt était encore très étroitement liée à son expérience du pouvoir au Lān $N \bar{a}$ - qui avait duré près de douze ans, alors que la moitié de ce temps seulement avait ensuite été passée à Vientiane. Dans la mesure où la référence au "Chao Chiang Mai » remplace le nom pâli Lokacūlämani, rien n'empêche cependant de croire, à la lumière des données qui précèdent, qu'elle ait désigné également l'aïeul de Setthāthirāt, dont le nom n'était pas forcément connu à Vientiane. Dans les deux cas, la référence pourrait être révélatrice d'un sentiment qui était peut-être partagé par la plus grande partie des sujets de Setthāthirāt, à savoir que le monument lui-même avait un caractère étranger - qu'il pouvait être une importation, tout comme les textes, les écritures, les images et les techniques qui se diffusaient alors au Lān Xāng.

L'habileté des architectes du Lān Nā avait déjà été prouvée de multiples façons dans les territoires t'ai du Nord, en particulier dans les cités où Setthāthirāt avait résidé, comme Chiang Mai ou Chiang Saen. Nous savons que, dès son arrivée dans la première, il était allé vénérer le Phra Chedi Luang ${ }^{101}$. Il n'est pas douteux qu'il se rendit également auprès du Mahā Thāt de Haripunjaya/Lamphun, que les souverains du Lān Nā ne cessaient d'embellir ${ }^{102}$. On ne peut croire alors qu'il n'ait cherché à doter sa nouvelle capitale d'édifices semblables. Des modèles architecturaux, ainsi que des artistes capables de les représenter, accompagnèrent sans aucun doute le roi lorsque celui-ci vint s'installer à Vientiane.

\section{Les travaux de construction}

L'hypothèse selon laquelle un nombre important d'esclaves aurait été affecté à des travaux de construction au That Luang est en grande partie vérifiée par les chroniques lao. Nous avons vu en effet que le Chot Hmāy Het Yo Vieng Chan - dont la chronologie s'avère relativement fiable - rapportait la construction par Setthāthirāt, en 1561-1562, d'un Phra Mahā Thāt Chiang Mai. Ce monument, difficilement reconnaissable en l'absence d'autres données, peut maintenant être identifié au That Luang. Le Chot Hmāy Het Yo Vieng Chan est la seule chronique qui ait conservé le véritable nom lao du monument - le point doit être souligné.

Nous avons rapporté plus haut que les Phongsāvadān, textes issus de la tradition historiographique de Luang Prabang, nous apportaient également des informations sur le That Luang. La chronologie y est légèrement différente de celle qui est exposée dans le Chot Hmāy Het Yo Vieng Chan, puisqu'il est question de l'année 1564-1565. La référence au monument se fait cependant plus précise, car l'on apprend qu'il ne s'agit pas d'une

100. Le terme dhātu s'applique, à l'origine, uniquement à la relique. C'est ce sens qui est d'ailleurs employé dans le texte pâli (jinaguyha-dhātu), qui utilise thüpa / nominatif : thūpo (= Skt. stūpa) pour le monument. Par extension, dhātu en viendra cependant vite à désigner le reliquaire lui-même.

101.C. Notton, 1932, p. 158 ; D. K. Wyatt, 1995, p. 113.

102. Cf. Jinakālamātī. La chronique montre que dans la seconde moitié du $\mathrm{XV}^{\mathrm{e}}$ siècle et le premier quart du $\mathrm{XVI}^{\mathrm{e}}$ siècle les souverains du Lān Nā bâtirent et enrichirent un grand nombre de stūpa. Les sources épigraphiques confirment la profusion des fondations pour cette époque. 
fondation, mais bien plutôt d'une restauration, voire même d'une reconstruction. Les textes évoquent en effet l'existence d'un premier stūpa - construit par Asoka - que Setthāthirāt aurait recouvert par un nouveau monument, dont le pourtour aurait été caractérisé par l'alignement de trente structures associées aux pāramī. Ces détails prennent toute leur importance à la lumière des découvertes archéologiques qui ont été faites en 1930. L. Fombertaux montre en effet dans ses notes l'existence d'un stüpa primitif. Pour bien comprendre le plan d'ensemble de ce monument, il faut cependant se référer à un croquis de l'architecte retrouvé récemment dans ses archives (cf. doc. 9 et 10 , page suivante). On constate que la description des textes lao est alors très exacte : le stüpa actuel recouvre bien - au sens strict - un stūpa antérieur ; il est par ailleurs entouré de trente pinacles ou petits « thāt », structures manifestement postérieures au monument primitif.

\section{Les pāramī (perfections)}

Le rapport entre les pinacles et les pāramī est parfaitement vérifié, puisque l'on sait que chacun des premiers portait sur sa face principale une inscription faisant référence à l'une des secondes. Les inscriptions originales ont aujourd'hui toutes disparu, mais quatre d'entre elles - gravées à l'intérieur d'un cartouche rectangulaire - étaient encore visibles il y a une trentaine d'années ${ }^{103}$. Le texte de chacune se limitait à un mot: khanti-pāramī (perfection de patience), khanti-upapāramī (degré inférieur de la perfection de patience), khanti-para[matthapāramī] (degré supérieur de la perfection de patience) et saccaupapāram̄̄ (degré inférieur de la perfection de vérité). En 1976, la Direction des monuments historiques de la RDP Lao a d'ailleurs entrepris de redonner aux trente pinacles un semblant de leur état original en faisant inscrire sur chacun d'eux la mention d'une des perfections ${ }^{104}$. Les identités respectives des trente pinacles n'étaient cependant pas marquées uniquement par ces inscriptions extérieures. On sait que chacune des structures était pourvue d'une niche intérieure qui contenait elle-même des inscriptions mentionnant les pāramī. L. Finot indique en $1903^{105}$ que l'un (ou deux) des petits « thăt ", éventré(s) par la foudre en 1896, a (ont) révélé cinq objets, dont deux petites stèles en or sur lesquelles étaient respectivement gravées les formules adhițthāna-paramatthapāramī (degré supérieur de la perfection de résolution) et mettā-upapāramī (degré inférieur de la perfection de bonté). Deux des autres objets étaient également inscrits : il s'agissait de feuilles d'or portant un texte pâli de 6 lignes, consistant en de cours extraits du Tipitaka ${ }^{106}$. La restitution graphique de l'alphabet employé montre qu'il s'agissait de l'écriture " tham » du Lān Nā, du même type que celle qui fut employée pour les stèles du That Luang. C'est cette écriture également qui fut utilisée pour les inscriptions des pinacles.

103.P.-M. Gagneux, 1975, p. 205-208.

104. P.-M. Gagneux, 1975. La mention des pāramī n'est plus gravée, mais en relief, avec du ciment. Les cartouches ont été refaits en fonction des dimensions anciennes : $25 \mathrm{~cm}$ pour la hauteur, de 40 à 60 $\mathrm{cm}$ pour la longueur.

105. «Ex-voto du That Luong de Vieng-Chan (Laos) », BEFEO 3, p. 660-663.

106. L. Finot classe ces textes dans la catégorie des bhānavāra. Le cinquième objet était une petite gaine en argent, de forme conique. L'ensemble de ce petit trésor paraît avoir disparu assez vite, puisque S. Karpelès le cherche en vain en 1929. Elle signale cependant un autre groupe d'objets qui avaient été également trouvés au That Luang : 2 that en or massif ; 2 feuilles d'or ; 2 boîtes en or, incrustées de pierreries ; 2 fleurs en or ; 1 bague en or ; 2 Buddha en pâte de bois, plaqué d'argent ; 1 that d'argent, 1 boîte en argent (BEFEO 29, p. 521 ). Ces objets semblent avoir également disparu. 


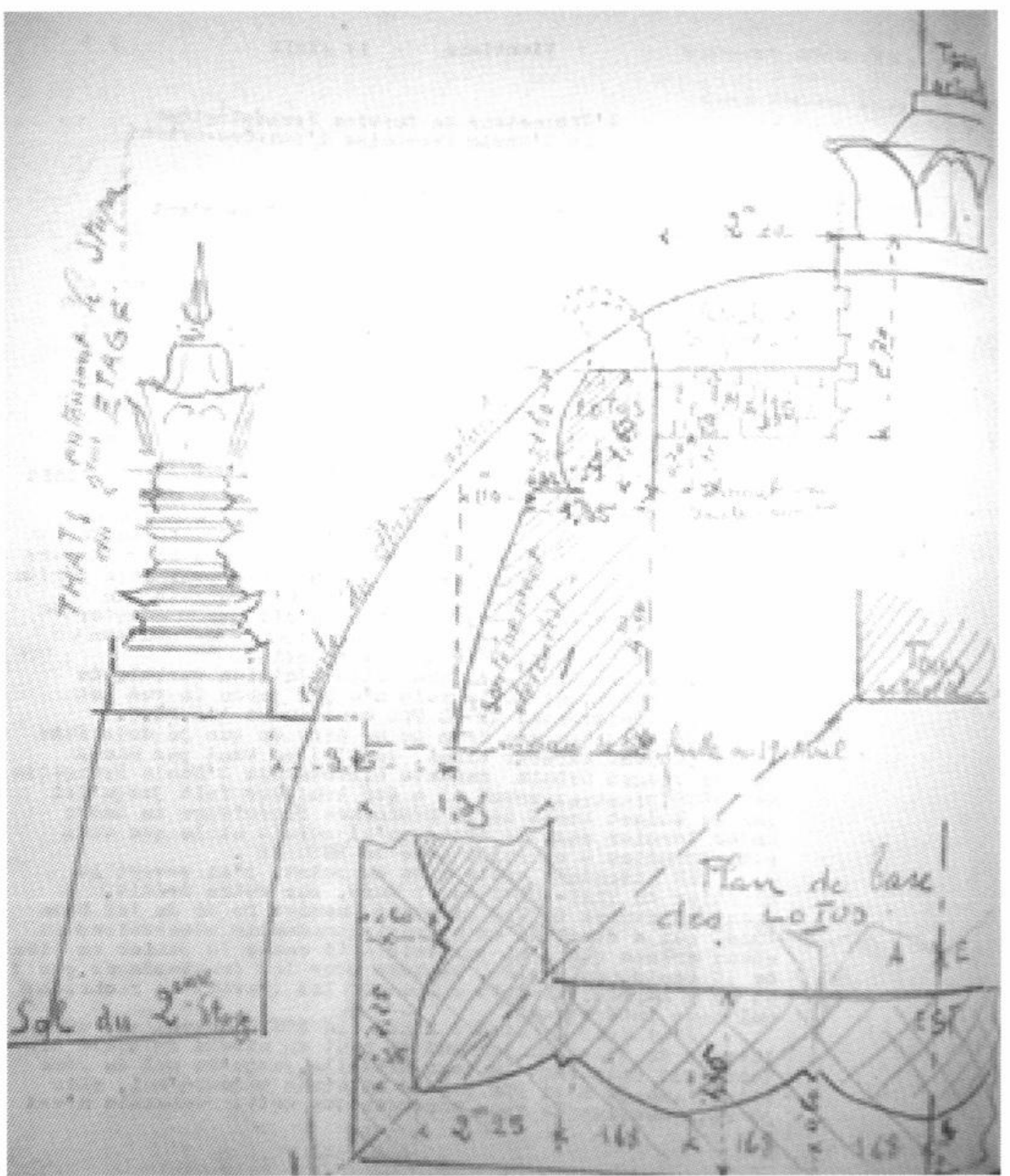

Document 9 - Croquis de Fombertaux.

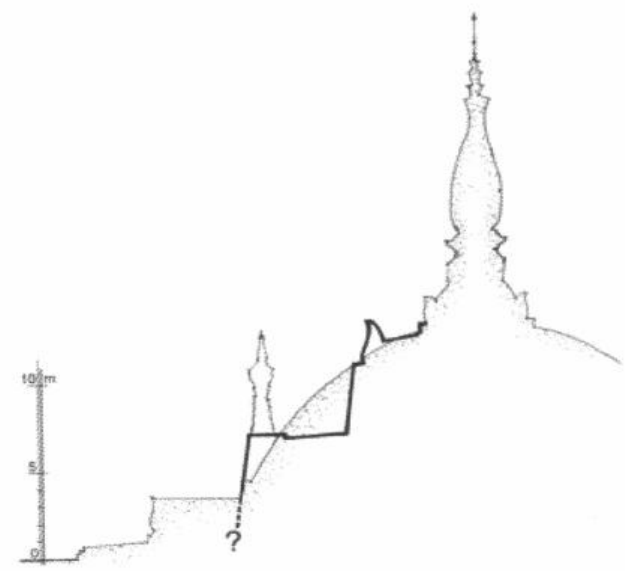

Document 10 - D’après le croquis de Fombertaux (C P. Pichard, 2003). 


\section{La relique}

Les histoires de reliques et de stūpa forment dans la plupart des pays touchés par le bouddhisme theravâda un genre littéraire à part entière, des plus appréciés ${ }^{107}$. Celles-ci ont largement marqué de leur empreinte les chroniques historiques, et il n'est pas rare de voir mentionné dans ces dernières - dès lors qu'il est question d'un important édifice religieux - le nom du plus célèbre des zélateurs du Buddha : Asoka. Afin d'acquérir sa légitimité religieuse, il était obligatoire que le That Luang voie son nom associé à celui du propagateur des 84000 reliques. Les Phongsāvadān lao ne faillirent pas à cette règle : ils respectèrent ce qui n'était somme toute qu'une convention ${ }^{108}$. La référence est pourtant ici intéressante, car elle met en lumière deux points : d'une part l'existence du monument primitif - nous aurons encore l'occasion d'en reparler -, d'autre part la présence dans le stūpa d'une «véritable » relique. Les chroniques emploient à son propos le terme tout à fait générique sarīradhātu. Ce manque de précision est étonnant lorsque l'on sait qu'il existe précisément un lien entre la nature exacte de l'organe hérité du Buddha et le degré de reconnaissance du caractère sacré du monument qui le recouvre. Ainsi, les parties corporelles qui ne se désagrègent pas, tels les cheveux, les dents, les ongles, bénéficientelles d'une faveur toute particulière. Il est probable que cette absence de détails traduit tout simplement l'ignorance des annalistes. En effet, si l'identité de la relique avait été connue, elle ne pouvait pas ne pas être précisée - car c'était alors faire peu de cas de sa valeur. À l'inverse, si le mystère entourait cette identité, il était impossible que les annalistes en inventent une. Il valait donc mieux rester dans le vague.

L'inscription nord de la porte orientale du That Luang devait a priori nous renseigner davantage sur l'identité de cette relique, car elle nous indique son nom. Or, le sens de ce dernier - Jinaguyhadhātu - suscite un certain embarras. Le terme guyha désigne en effet ce qui est caché, ce qui est secret ${ }^{109}$ - et l'on ne peut guère traduire le composé que par "relique secrète (ou mystérieuse) du Buddha " 110 . Cette formule peut être interprétée de deux façons différentes. Nous savons que guyha prend facilement le sens de ce qui est intime, en particulier pour le corps, et nous pourrions donc avoir une référence aux parties sexuelles du Buddha ${ }^{111}$; mais nous pouvons également opter pour une acception littérale du terme, et comprendre que la relique était véritablement cachée, qu'elle n'était plus visible, et donc que son identité était inconnue ou oubliée. C'est cette hypothèse, étayée par la conclusion que nous venons de tirer à propos des Phongsāvadān, qui nous paraît la plus plausible.

107. On peut dire la même chose des histoires légendaires de statues, de saints, d'empreintes du Buddha, etc.

108. Selon la tradition locale, Asoka serait également à l'origine d'un reliquaire enfoui sous le That Luang de Luang Prabang - qui lui-même n'aurait été construit qu'en 1813 sous le règne de Mantha (cf. Ch. Archaimbault, «La fête du T'at à Luong P'răbang », in La fête du T'at, Vientiane, 1973, p. 43, n. 2).

109. T. W. Rhys Davids \& W. Stede, 1999, p. 253.

110.L. Finot, 1917, p. 70.

111. Maha Sila Viravong (s. d., p. 10) a traduit correctement en lao la formule «Jinaguyhadhätu» par «Phra thāt thi lap khong Phra Phuttha Chao " (la relique secrète du Buddha). Dans un article très contestable, le Phagna Bong Souvannavong (1970, p. 7-20) donne à son tour la traduction française " organe secret (organe génital) ». Il reconnaît également un phallus sur une statue de dvārapāla ou de bodhisattva conservée au That Luang - alors qu'il ne s'agit que de la partie supérieure d'une massue ou d'un vajra - et n'hésite pas à écrire que "le That Luang est un monument destiné à symboliser la procréation de l'être humain». Le Dictionnaire laotien-français (M. Reinhorn, 1970, vol. 1, p. 322) définit «khuyha » (guyha) par « la cachette, le secret ; le sexe caché » et «khuyha thāt » (guyhadhātu) par « l'os du pubis [sic] (relique du Buddha)». 


\section{Les offrandes des grands dignitaires}

La quatrième partie de l'inscription - qui commence à la ligne 18 de la face 2 - se distingue d'une façon très nette des précédentes. La césure était déjà annoncée par la fin de la troisième partie, puisque celle-ci s'achève par la formule imprécatoire qui conclut habituellement ce genre d'inscription ${ }^{112}$. Mais elle est surtout mise en évidence par l'objet différent du texte qui commence : il n'est plus question en effet des offrandes que le souverain fait au stūpa, mais des dons que les grands dignitaires font eux-mêmes au roi ${ }^{113}$. L'action de ces dons est exprimée par le terme anumodanā (rendre grâce, exprimer sa satisfaction) qui a plutôt une connotation religieuse - ce qui crée une certaine ambiguïté. On pourrait croire d'abord que les dons s'adressent au bout du compte au monument - ils ne feraient alors que transiter par le souverain -, mais leur nature contrarie en fait cette interprétation. La plupart des biens offerts n'ont en effet guère de rapport avec la religion. Il s'agit d'abord d'armes, de chevaux et de véhicules divers, utilisables aussi bien sur les routes que sur les voies d'eau. Ceux biens rappellent alors le contexte très difficile qui entoura la construction du monument, et l'on peut croire qu'ils rejoignirent l'équipement de guerre qui devait bientôt servir au souverain. Il s'agit également d'animaux de trait et d'instruments agraires - sans aucun doute destinés à la culture des terres offertes par le roi. Le don d'individus, dont plusieurs étaient issus des familles des dignitaires, doit probablement être mis en rapport avec le don de la princesse qui, on le sait, était accompagnée de servantes. Il en est de même pour les bijoux (bagues, collier). La communauté religieuse ne fut toutefois pas oubliée puisqu'elle bénéficie de plusieurs ensembles des huit accessoires fixés par les textes, ainsi que de manteaux. Le Phā Khāo Cullani, dernier donateur de l'inscription, n'était probablement pas un dignitaire ; son nom indique qu'il s'agissait d'un laïc observant la discipline religieuse. Son offrande matérielle se limite à un cierge, mais cette petitesse est compensée par le don de sa propre personne. Le statut manifestement inférieur de cet individu nous fait croire qu'il s'agissait en fait du rédacteur ou du graveur de l'inscription.

La liste des seigneurs et des dignitaires royaux est sans aucun doute établie selon un ordre hiérarchique. Le Phrayā Sēn Surintha Khuāng Fā est le premier de tous. Cela concorde parfaitement avec les données que nous livrent les sources manuscrites et épigraphiques. Successeur de Setthāthirāt sur le trône du Lān Xāng, il est déjà largement mentionné dans les chroniques lao ${ }^{114}$. Les annales d'Ayuthya nous confirment qu'il fut un grand chef militaire ${ }^{115}$. Quant aux inscriptions, elles le citent à plusieurs reprises et cela dès $1535^{116}$. Le Phrayā Siharāt Ānan apparaît également dans tous les types de sources ${ }^{117}$. En 1572, il fut le principal adversaire du Phrayā Surintha et semble avoir été exécuté par ce dernier. Il est cité dans une feuille d'or datée du 13 février 1567 en tant que fondateur d'un cetiya, qui avait peut-être un rapport avec le That Luang ${ }^{118}$. Il se peut que le Phrayā 3

112. La formule imprécatoire vouant à la malédiction ceux qui ne respecteraient pas la volonté royale est un autre héritage de la rhétorique employée au Lān Nā. Dans les inscriptions du Lān Xāng, elle est cependant très vite codifiée et son utilisation est quasi systématique.

113. À l'exception des présents du Phrayā Siharāt Ānan qui sont offerts à la princesse Phra Kēo. Celle-ci bénéficie de terres et d'esclaves.

114. Cf. M. Lorrillard, 1999, p. 45-64.

115. R. D. Cushman, 2000, p. 53 et 55.

116. Stèle $\mathrm{n}^{\circ} 2$ du Vat Daen Muang, Phon Phisay (Punnothok, s. d., p. 237 ; Cāreuk Nai Prathet Thai, 1986, p. 329). Les autres mentions datent de la période où il régna.

117. M. Lorrillard, 1999, p. 48.

118.P.-M. Gagneux, 1975, p. 182-183. Cette feuille a été trouvée à Vat Chom Tay (Vientiane) en 1954. Déposée au Vat Ho Phra Kèo, elle a été volée le 7 janvier 1975. 
(Sām) Lān soit le seigneur lao du même nom mentionné dans la Chronique de Chiang $\mathrm{Mai}^{119}$. Les annales lao nous apprennent par ailleurs que c'est sa fuite vers le Lān Xāng, en 1564-1565, qui fut à l'origine de la première invasion birmane. Celle-ci se solda par la capture du Mahā Uparāt lao qui, fait notable, ne figure pas dans l'inscription du That Luang alors qu'il est cité dans l'inscription de Dan Sai ${ }^{120}$, en 1563. Le Phrayā Sri Suphan Pākān est un autre dignitaire mentionné à plusieurs reprises par les sources épigraphiques ${ }^{121}$. Le Phrayā Thipphamontri apparaît quant à lui aux côtés du Phrayā Sẽn Surintha dans pratiquement toutes les versions des annales d'Ayuthya ${ }^{122}$. Khun Sappha Rattana Manāchāra est peut-être le Chao Lun Sappha de la stèle du Vat Chommani (Nongkhai, 1555) ${ }^{123}$.

\section{La stèle du Vat Hnong Bone}

Le Vat Hnong Bone jouxte directement le That Luang et faisait probablement partie, à l'origine, du même complexe religieux. Deux stèles y ont en fait été retrouvées : l'une fait aujourd'hui partie des collections du Vat Ho Phra Kèo ${ }^{124}$, l'autre est déposée dans le « sim » du Vat Hnong Bone. L'état de conservation de la première permet une restitution quasiment complète de son texte et c'est donc celle-ci qui sera l'objet de notre étude ${ }^{125}$. La seconde est très abimée ${ }^{126}$, mais la lecture assurée d'un certain nombre de fragments de phrases, répartis sur l'ensemble de l'inscription, nous autorise à dire que le texte est identique à celui de la première stèle ${ }^{127}$. L'une des deux inscriptions est donc la copie de l'autre.

La stèle du Vat Hnong Bone qui est aujourd'hui conservée au Vat Ho Phra Kèo (doc. 12 et 13) est un bloc de grès d'une hauteur de $84 \mathrm{~cm}$, d'une largeur de $63 \mathrm{~cm}$ et d'une épaisseur de $10 \mathrm{~cm}$. Le choix de la pierre ne semble pas avoir été dicté par des considérations esthétiques et l'inscription fut gravée sur un matériau pratiquement brut (l'arasement est très grossier), où subsistent de nombreux reliefs. Le scribe en avait pris son parti : il grava aussi bien sur les parties planes que dans les parties « en creux». L'écriture est cependant assez belle et, fait unique dans les inscriptions lao jusqu'ici retrouvées, la seconde face conserve encore le tracé des lignes parallèles horizontales qui servirent de règles pour la dimension des caractères. La stèle possède deux faces inscrites : la première compte 14 lignes qui occupent une hauteur de $30 \mathrm{~cm}$ et une largeur de $50 \mathrm{~cm}-$ la seconde compte 10 lignes qui occupent une hauteur de $36 \mathrm{~cm}$ et une largeur de $40 \mathrm{~cm}$.

La stèle qui demeure au Vat Hnong Bone (doc. 11) a une hauteur de $88 \mathrm{~cm}$, une largeur de $50 \mathrm{~cm}$ et une épaisseur de $15 \mathrm{~cm}$. Le grès qui a été utilisé est le même que celui des stèles du That Luang. La forme de ces dernières a également été reprise et la pierre a

119.C. Notton, 1932, p. 158-159; D. K. Wyatt, 1995, p. 114-115.

120. L. Finot, 1915, p. 34-35 ; P. N. Nagara \& A. B. Griswold, 1992, p. 793-794.

121. Il est cité dans les inscriptions du Vat Phadung Sukh (Phon Phisay, 1552/1564), du Vat Sri Khun Muang (Nong Khay, 1560) et du Vat Hnong Bone (Vientiane, 1567).

122. R. D. Cushman, 2000, p. 50.

123. Punnothok, s. d., p. 249 ; Cāreuk Nai Prathet Thai, 1986, p. 338.

124. Elle a été ramenée dans le temple-musée il y a quelques années et ne porte pas encore de numéro d'inventaire.

125.P.-M. Gagneux (1975, p. 121-126) donne pour cette stèle une description, une transcription en lettres romanes diacritiques, une transcription en écriture lao, ainsi qu'une traduction. Nos lecture et traduction de l'inscription sont sensiblement différentes.

126. Une brève description de la stèle figure dans P.-M. Gagneux (1975, p. 127). L'inscription y est déclarée absolument illisible. Elle n'est pas inventoriée par le Service des musées et de l'archéologie.

127. Le texte de ces fragments de phrases est restitué dans le document 18. 
été parfaitement apprêtée pour recevoir son texte. La stèle ne donne plus à voir aujourd'hui que 15 lignes sur la première face et 9 lignes sur la seconde, toutes incomplètes. Il est cependant sûr qu'elle en comptait davantage - aujourd'hui totalement effacées - sur la partie supérieure de la première face et sur la partie inférieure de la seconde.

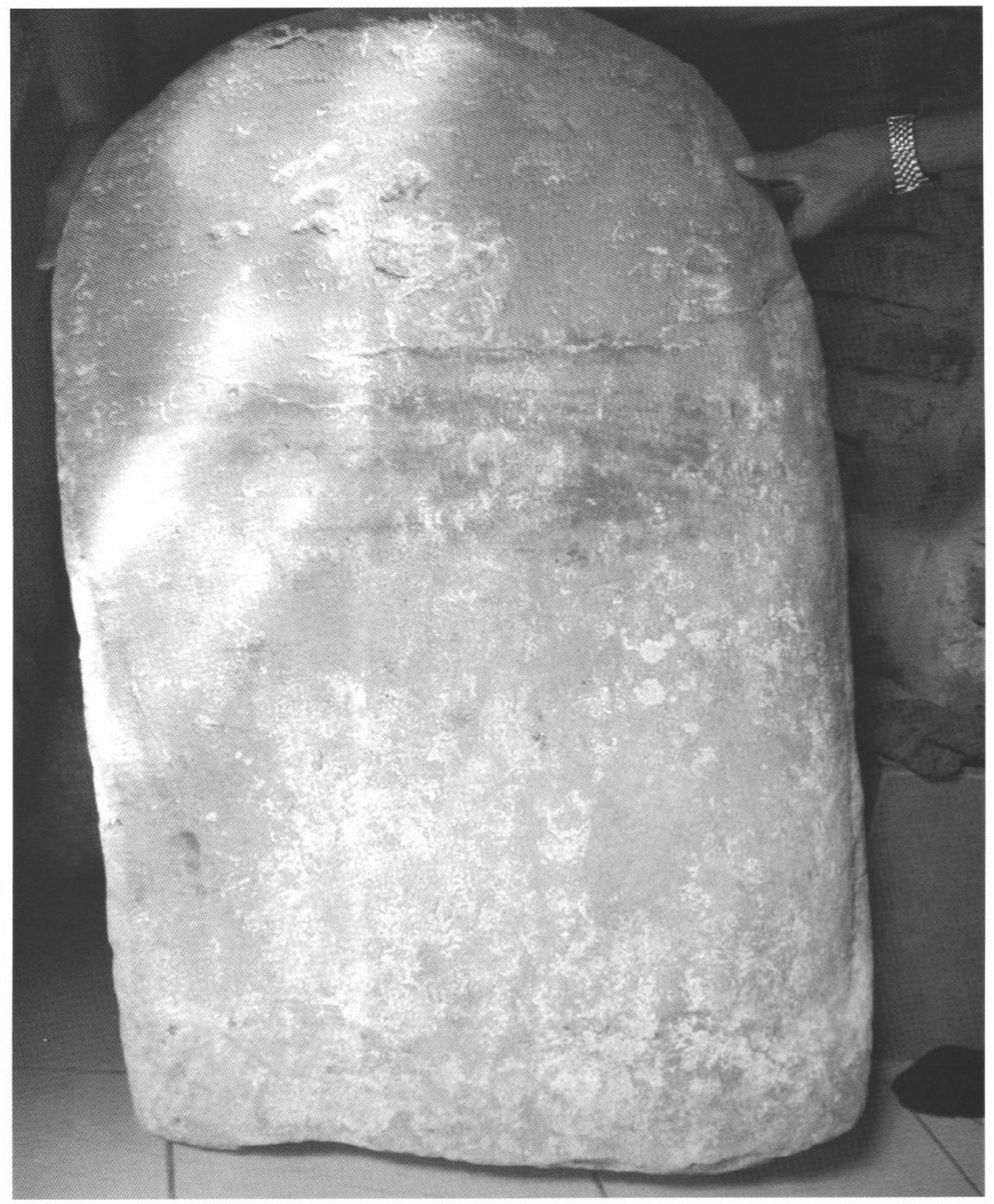

Document 11 - Stèle du Vat Hnong Bone $\mathrm{n}^{\circ} 2$ (in situ). 


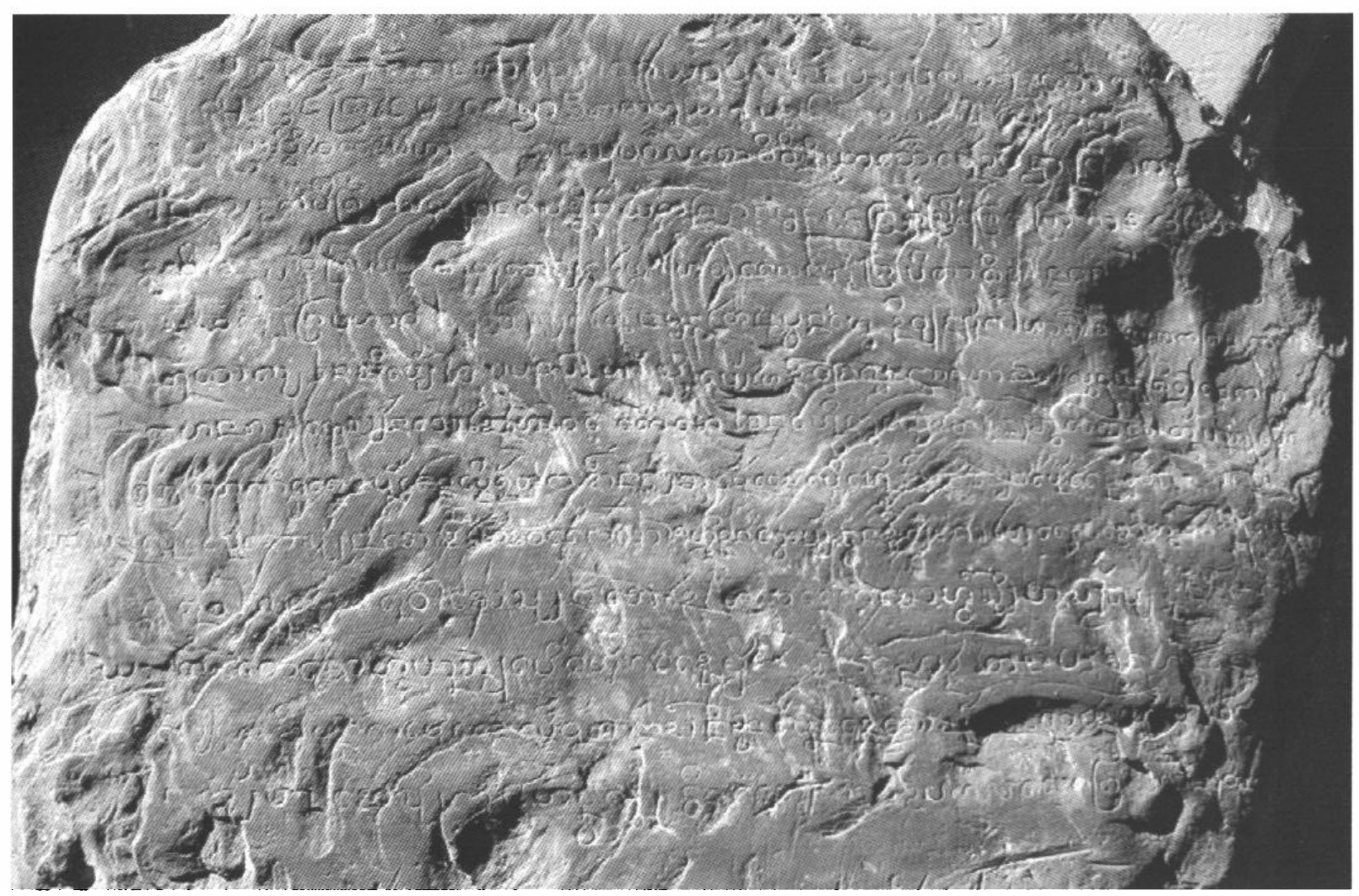

Document 12 - Stèle du Vat Hnong Bone $n^{\circ} 1$, face 1.

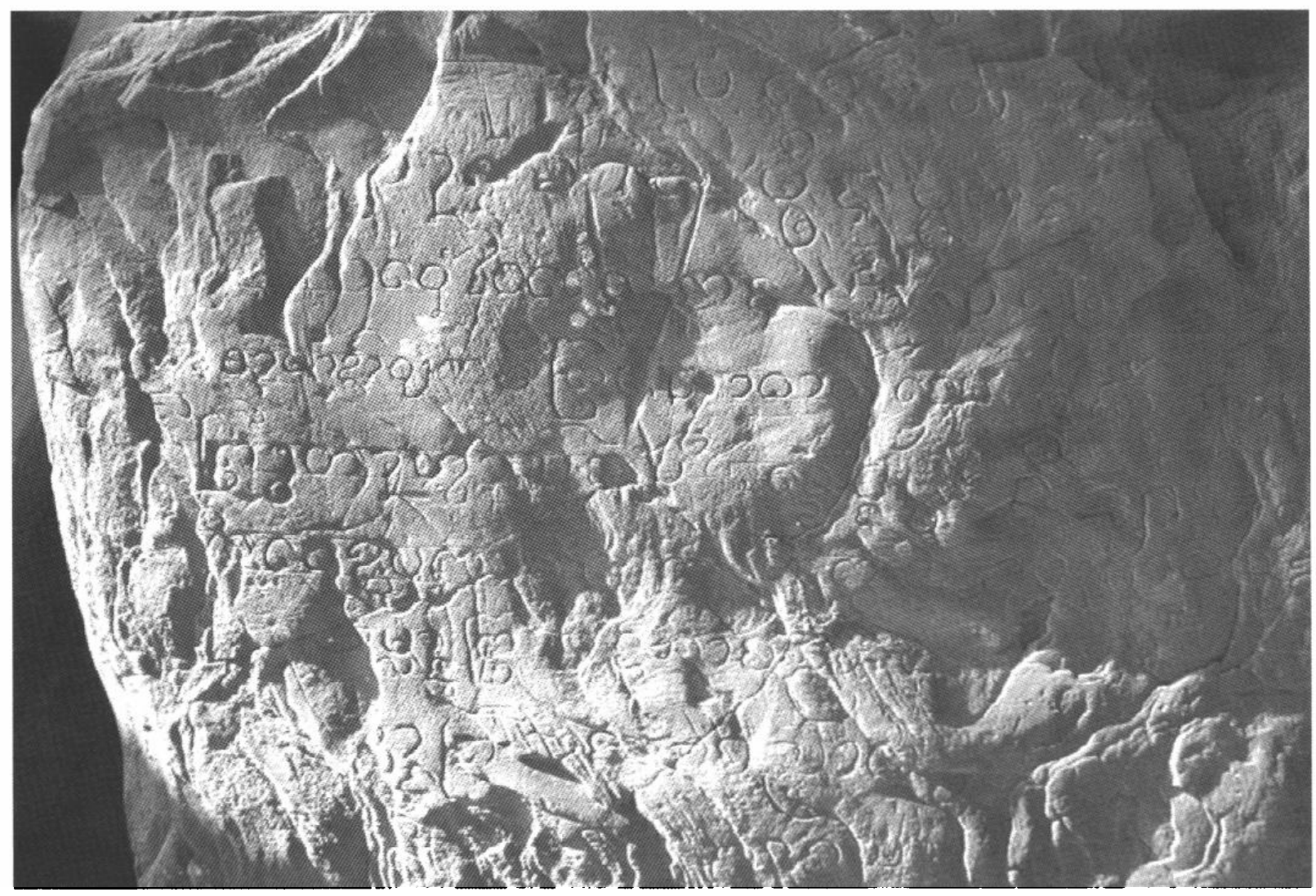

Document 13 - Stèle du Vat Hnong Bone $n^{\circ} 1$, face 2. 
Document 14 - Texte de la stèle du Vat Hnong Bone ${ }^{\circ} 1$

(conservée au Vat Ho Phra Kéo).

Face 1:

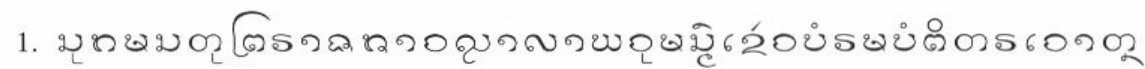

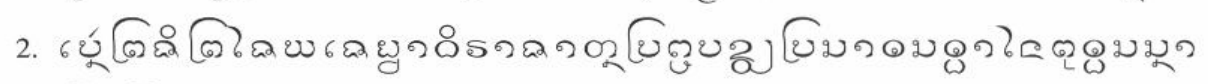

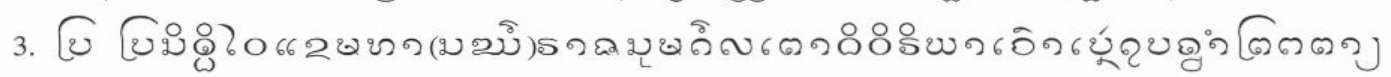

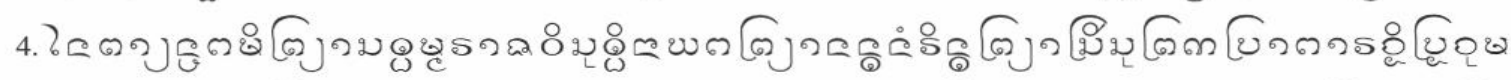

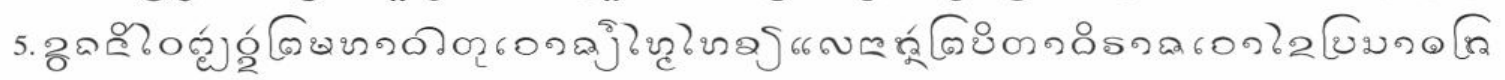

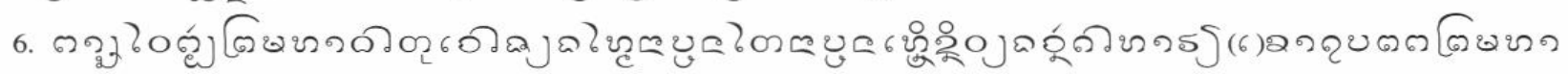

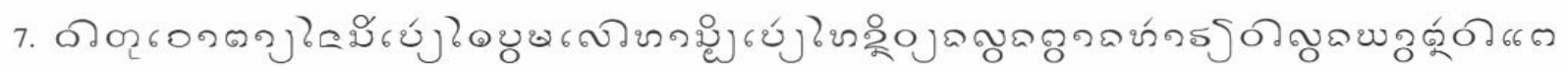
622

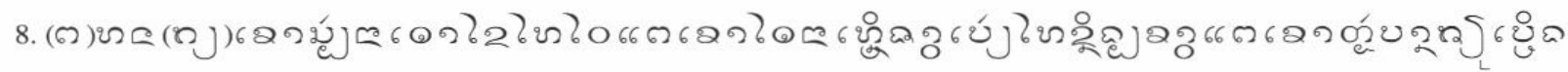

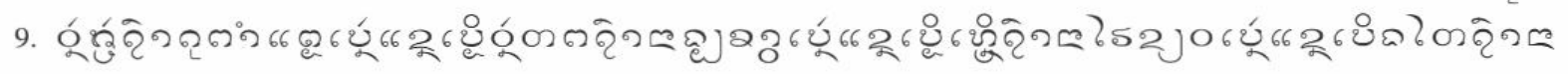
โร2)

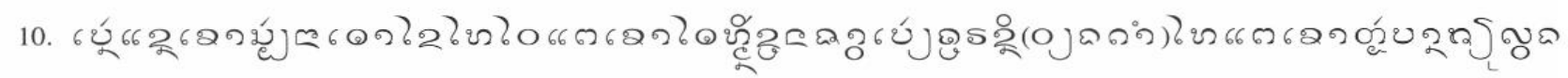

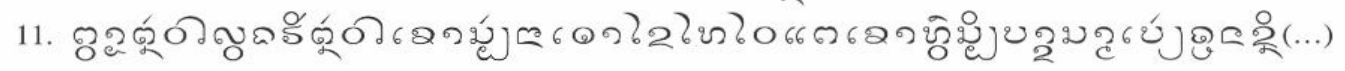

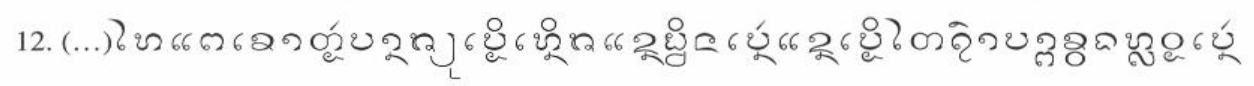

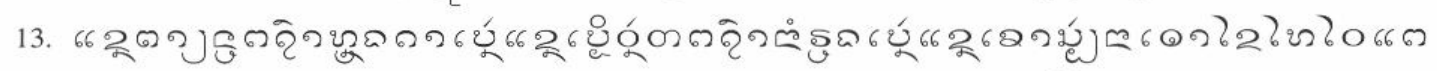

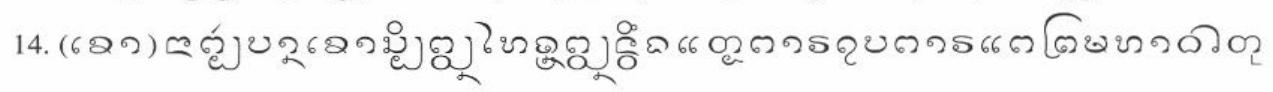

Face 2 :

1............ 6 บ6ขू ……6อ 60

2. ใบ6องข

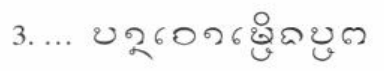

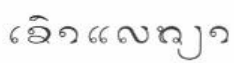

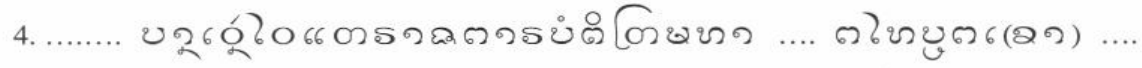

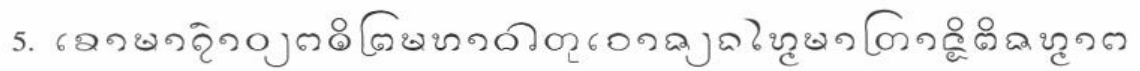

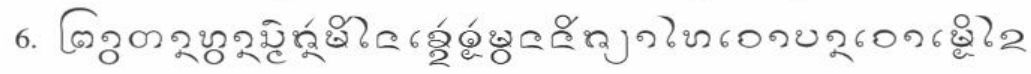

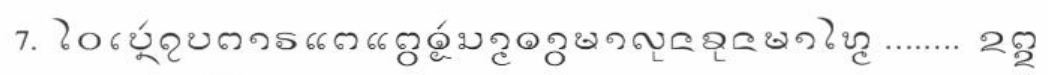

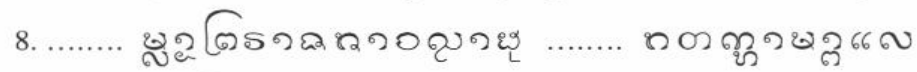

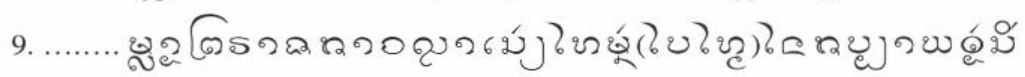

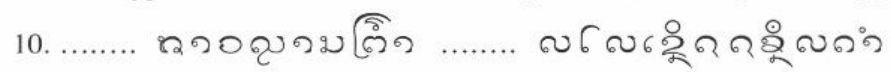


L'étude comparative des deux stèles ne permet pas de reconnaître d'une façon décisive celle qui serait l'original et celle qui serait sa copie. L'écriture " tham » qui a été utilisée pour les deux inscriptions relève du même modèle - le «tham Lān Nā » - et suggère que les deux textes ont été gravés au milieu du $\mathrm{XVI}^{\mathrm{e}}$ siècle. On pourrait penser, étant donné la forme très brute de la stèle du Vat Ho Phra Kèo - que celle-ci a été rédigée dans l'urgence et qu'elle a servi de brouillon. Par la suite, lorsqu'un support plus conforme aux inscriptions royales fut apprêté, on aurait alors procédé à une nouvelle rédaction. À l'inverse, on pourrait croire également que l'inscription conservée au Vat Hnong Bone fut l'original - et que sa copie a été gravée sur un matériau très imparfait, précisément parce qu'il s'agissait d'une copie! A l'appui de cette dernière thèse, on pourrait arguer que les copies, par définition moins anciennes que les originaux, ont plus de chances d'être mieux conservées. Dans le cas qui nous occupe, cet argument doit cependant être repoussé, car l'on sait que la stèle du Vat Hnong Bone servit longtemps à l'affûtage des couteaux - et que son état se dégrada donc beaucoup plus rapidement. Une autre alternative serait de penser que les deux stèles furent rédigées en même temps. Nous n'avons cependant pas d'autres cas semblables pour les inscriptions du Lān Xāng, si ce n'est la seconde face de l'inscription du Vat Daen Muang (Phonphisay, 1530) qui répète pratiquement le texte qui figure sur la première face de la même pierre.

La datation de la stèle du Vat Hnong Bone ne pose pas de problème particulier. La date est indiquée clairement : 929 de l'ère, $9^{\mathrm{e}}$ jour de la lune croissante du $11^{\mathrm{e}}$ mois. Elle correspond au vendredi 12 septembre 1567. Il est cependant dommage qu'un certain nombre de détails textuels aient été omis - tels les deux noms de l'année, ceux du jour ainsi que son chiffre, le « horakhun ", le «māsaken », le chiffre ou le nom de la mansion lunaire, etc. - alors que leur mention est fréquente dans les inscriptions lao du XVI $\mathrm{X}^{\mathrm{e}}$ siècle. En comparant ces données et en vérifiant leur cohérence, nous aurions été certains de la justesse de la date. L'absence de disque horoscopique - autre élément calendaire important de ce genre d'inscription - paraît même quelque peu suspecte.

\section{Traduction}

Face 1 :

1. Que le bonheur soit! Ordonnance royale revêtue du sceau de Sa Majesté Excellente et Pure, le Roi

2. qui porte le nom de Phra Saiya Setthāthirāsā \{Jaya Jeț̣hādhirāja\} et agit avec sérénité et foi dans la religion du Buddha.

3. (Son) accomplissement ${ }^{128}$ (est confié) au Mahā Sangkharāsa Sumangkhala Phothiviriyā Chao, qui en est le garant

4. à l'intérieur. À l'extérieur, le Phrayā Satthammarāsa Visutthinayāka, le Phrayā Nantha Norintha et le Phrayā Sri Suphan Prākān répondent de

5. cet ordre qui est relatif au Vat Phra Mahā Thāt Chao Chiang Mai // Sont reconnus ${ }^{129}$ les esclaves et les rizières que le Phra Pitāthirāsa Chao a offerts

6. cérémonieusement au Phra Mahā Thāt Chao Chiang Mai : les rizières Nā Bone Tai et Nā Bone Hneua sur les terres de Vieng Chan, valeur cinq « hoy »; le riz au profit du Phra Mahā

128. Le rédacteur a omis de répéter ici la référence à l'ordonnance (ājñă), comme c'est le cas dans d'autres inscriptions (exemple : stèle $n^{\circ} 1$ du Vat Phadung Sukh).

129. Dans ce contexte, on donnera au terme «hai» (donner) un sens moins strict que dans les phrases suivantes. 
7. Thāt Chao, à l'intérieur: quatre «bya »; aux travailleurs de Boam Lao ${ }^{130}$ : cinquante « bya »// On donne une terre de la ville qui a pour largeur cinq cent brasses et une longueur de mille brasses.

8. [...] les rizières qui y seront défrichées lui (leur) seront réservées. Les travailleurs des rizières Nā Hneua (fournissent) vingt « bya » // On donne la terre de Ngop Khāo pour qu'elle soit habitée. À

9. l'est, on prend la digue de l'enceinte pour limite; à l'ouest, on prend la rizière Nã Ngop Khāo pour limite ; au nord, on prend la rizière Nā Hai Dieo pour limite ; au sud, on prend la rizière Nā Hai Dieo

10. pour limite. Les rizières qui y seront défrichées lui (leur) seront réservées. Les travailleurs de Hmeun Don (fournissent) vingt «bya »// On réquisitionne la terre de [Vieng Kham] pour qu'elle soit habitée : largeur

11. mille brasses, longueur mille brasses. Les rizières qui y seront défrichées lui (leur) seront réservées. [Les travailleurs de Hoa (?) fournissent] dix «bāt » et trois « bya »// On réquisitionne la terre $[\ldots$

12....] pour qu'elle soit habitée. Au nord, Dèn Thin est la limite ; au sud, on prend la rizière Nā Pak Khoang Luang pour

13. limite; à l'extérieur ${ }^{131}$, on prend l'étang Hnong Khā pour limite ; à l'ouest, on prend la rivière Nam Hong pour limite. Les rizières qui y seront défrichées lui (leur) seront réservées.

14. Des rizières et des villages, pour dix charrettes de riz, que l'on retire une charrette pour le service du Phra Mahā Thāt.

Face 2 :

1. [...] et $[\ldots]$ Chao

2. va jusque [... que les « Chao]

3. Bān » et les « Chao Muang » [ne leur donnent pas de travail, qu'ils ne [...]

4. [...] des villages. Seul l'administration royale de Bophit Mahā [...] pourra leur dire] ${ }^{132}$

5. de venir travailler au Phra Mahā Thāt Chao Chiang Mai. Prescription : tous les produits et les fruits

6. des cocotiers et des palmiers à sucre, sucrés et acides, qui se trouvent dans ce domaine, que les «Chao Bān » et les «Chao Muang » ne s'en emparent pas. Ils

7. sont au service des Trois Joyaux. Que les «Thāo » et les «Khun » qui viendront par la suite observent ce règlement

8. et n'enfreignent pas l'ordonnance royale. Que celui qui agira de façon cupide et

9. viendra contredire l'ordonnance royale aille brûler dans les quatre enfers.

10. Ainsi le veut l'ordonnance royale. 929 de l'ère, $11^{\mathrm{c}}$ mois, $9^{\mathrm{c}}$ jour de la lune croissante.

\section{Commentaires}

Il existe une ressemblance certaine entre l'inscription du Vat Hnong Bone de Vientiane et celle du Vat Phadung Sukh de Phon Phisay, qui lui est antérieure de trois années ${ }^{133}$. Les

130. Le nom de l'endroit indique une zone marécageuse où poussent de hautes graminées.

131. La formule «phāy nook» qui remplace ici «beuang tavan ook » (à l'est) semble indiquer que la limite orientale du terrain dépassait la grande enceinte de Vientiane.

132. Les lignes 1 à 4 comportant un certain nombre de lacunes, la lecture de certains passages a été restituée grâce à des données fournies par des stèles contemporaines, notamment celle du Vat Phadung Sukh.

133. Punnothok, s. d., p. 241-243; Cäreuk Nai Prathet Thai, 1986, p. 331-335. L'édition de Punnothok n'est pas complète, puisque celui-ci ignore les deux dernières lignes de la face 2 , où la 
deux temples sont éloignés d'une soixantaine de $\mathrm{km}$, mais il suffisait de deux journées pour relier par la voie du Mékong les deux muang ${ }^{134}$. On constate d'abord que les témoins de l'" intérieur » (les religieux) et de l'" extérieur » (les laïcs) furent les mêmes, mais il s'agissait alors des plus grands dignitaires du royaume, ce qui montre l'importance des deux inscriptions. La construction, le style et la rhétorique des deux textes sont également très proches, plus qu'avec aucune autre inscription de cette époque. On peut dès lors assurer que le rédacteur de l'ordonnance de 1567 s'inspira très largement de celle de 1564 . Peut-être même, d'ailleurs, avait-il rédigé les deux ${ }^{135}$ ? Les formules d'introduction et de conclusion sont toutefois très proches de celles que l'on trouve déjà dans les premières inscriptions lao, qui elles-mêmes reprennent des modèles issus du Lān Nā. À la différence des inscriptions t'ai du Nord, qui font preuve d'une certaine variété dans la formulation, les inscriptions du Lān Xāng se limiteront dès le début à un certain type de rhétorique, ainsi qu'à des conventions de langage qui se perpétueront très tard ${ }^{136}$. Comme la plupart de ces inscriptions, celle du Vat Hnong Bone a pour sujet les terres qui sont accordées au temple, ainsi que les revenus qui leur sont attachés.

\section{La référence au That Luang}

Jusqu'à présent, le rapport entre l'inscription du Vat Hnong Bone et le That Luang n'avait pas été établi. P.-M. Gagneux avait bien remarqué la mention du «Phra Mahā Thāt Chao Chiang Mai », mais ne connaissant pas les textes des deux stèles du grand monument, il attribuait ce nom au stūpa en ruine qui gît encore dans l'enceinte du Vat Hnong Bone ${ }^{137}$. L'inscription mentionne le nom du grand "thāt», mais elle évoque également le «Vat (du) Phra Mahā Thāt Chao Chiang Mai ». P.-M. Gagneux a donc certainement raison lorsqu'il écrit que ce nom désignait à l'origine le Vat Hnong Bone ${ }^{138}$. Nous pensons que celui-ci pouvait être également le sañghārām mentionné dans la première stèle du That Luang.

\section{Les " garants " de l'ordonnance royale}

Après la formule introductive - qui est pratiquement équivalente à celle de la première stèle du That Luang - le texte enchaîne sur la liste des dignitaires chargés par le roi de garantir l'accomplissement de l'ordonnance. Le premier d'entre eux fait partie de l'« intérieur », c'est-à-dire de la communauté des religieux. Son nom ne nous est pas

seconde date est indiquée. Cette inscription consacre les donations à un temple, dont la fondation remonte sans doute à février 1552 .

134. C'est le temps qu'il faut au marchand hollandais G. van Wuysthoff, lorsqu'il remonte en 1641 le fleuve en direction de la capitale (Le journal ..., op. cit., p. 74). Il est possible qu'une journée ait suffi pour la descente.

135. L'écriture employée pour la rédaction des deux inscriptions est cependant différente : nous avons vu que la stèle du Vat Hnong Bone est rédigée en « tham », celle du Vat Phadung Sukh est rédigée en écriture laïque. La différence d'écriture est généralement révélatrice de l'importance qui était accordée à la fondation ou à la donation. L'écriture tham n'était probablement utilisée que par les grands lettrés. L'emploi plus fréquent de l'écriture laïque dans les inscriptions est certainement significatif d'un niveau de culture moindre.

136. Les inscriptions et les chartes royales $d u X X^{\mathfrak{c}}$ siècle conservent des formules qui étaient déjà employées trois siècles plus tôt.

137. Gagneux, 1980. Les ruines de ce stüpa forment aujourd'hui une butte de 7 à 8 mètres de haut, qui est totalement recouverte par la végétation. La circonférence importante de la base montre que le monument avait dû être de belle taille. Il est très dommage qu'il n'ait jamais donné lieu à des fouilles archéologiques.

138. Une erreur de transcription lui fait cependant croire que ce nom était «Pha Maha That Chao Chiang Mai Na Bone». 
inconnu, puisqu'il apparaît déjà dans la stèle du Vat Phadung Sukh (cf. supra) et sera encore mentionné sur la face 2 de la stèle du Vat Suvanna Khuha, datée du 16 février $1573^{139}$. Le Mahā Sañgharāsā Sumangkhala Phothi Viriyā Chao (mahā-sañgharāja-sumangala-bodhi-viriya) est, comme son titre l'indique, le chef du Sarigha - probablement pour l'ensemble du royaume, car sa responsabilité couvrait également les temples de l'important Muang Pāk Huay Luang (Phon Phisay) ${ }^{140}$. Les trois autres dignitaires sont dits de l'«extérieur», c'est-à-dire qu'ils représentent la communauté des laïcs. Ils sont également tous mentionnés par d'autres inscriptions. Le Phrayā Satthammarāsa Visutthi Nāyaka (saddhammarāja-visuddhi-nāyaka) apparaît dans la stèle du Vat Phadung Sukh, ainsi que dans celle du Vat Sri Muang (Nongkhai), datée du 4 mars $1567^{141}$, c'est-à-dire de quelques mois avant notre inscription. Son titre indique peut-être qu'il était plus spécialement chargé des affaires religieuses. Le Phrayā Nantha Norintha (nanda-narendra) n'est mentionné que dans la stèle du Vat Phadung Sukh. Cette dernière fait également référence au Phrayā Sri Suphan Pākān (śrí-suvarna-prākāra), qui apparaît par ailleurs dans la stèle du Vat Sri Khun Muang (Nongkhai), datée du 6 avril $1560^{142}$, ainsi que dans la première stèle du That Luang (cf. supra).

\section{"Phra Pitāthirāt »}

Une des informations les plus intéressantes de notre stèle réside dans la référence qui est faite à «Phra Pitāthirāt » (pitar-adhi-rāja), désigné comme le premier donateur au Vat Phra Mahā Thāt Chao Chiang Mai. Phra Pitāthirāt est en effet le "royal père " de Setthāthirāt, c'est-à-dire Phothisarāt. La mention rétrospective de ce dernier n'est pas une chose rare dans l'épigraphie lao du XVI et du XVII ${ }^{\mathrm{e}}$ siècle. Mais elle est ici d'une importance particulière, car elle établit un rapport direct entre Phothisarāt et le That Luang - et elle nous ramène une nouvelle fois à la question de la construction du monument.

\section{La construction du stūpa}

Les fondations de temples dans la région de Vientiane ne paraissent attestées qu'à partir de la seconde moitié du XV $\mathrm{XV}^{\mathrm{e}}$ siècle. Elles étaient alors l'œuvre de gouverneurs et de grands dignitaires ${ }^{143}$. La première stèle authentiquement lao - qui date du 17 avril $1494^{144}$ - montre que dans un des grands «muang » du Centre-Laos les sanctuaires pouvaient dès

139. Punnothok, s. d., p. 270-273 ; Cāreuk nai Prathet Thai, 1986, p. 305-307 ; J. C. Eade, 1996, p. 95. La rédaction de cette stèle est très soignée et montre qu'il s'agissait de l'œuvre d'un spécialiste. L'écriture du corps principal de l'inscription est du modèle « fak khām » et se rattache donc au Lān Nā. Celle de la partie supérieure de la stèle, où est inscrite la date, est quant à elle du modèle « tham Lān Nā ". Il est probable que le lapicide était lui-même un homme du Nord.

140. Dans les stèles du Vat Phadung Sukh et du Vat Suvanna Khuha, le titre du personnage est précédé du terme «Somdet » (Sa Majesté), qui désigne le roi ou les dignitaires religieux de très haut rang.

141.Punnothok, s. d., p. 261-264 ; Cāreuk nai Prathet Thai, 1986, p. 344-349 ; J. C. Eade, 1996, p. 93-94. Les deux éditions donnent «Sri Sitthi » (śrī siddhi) à la place de «Visuddhi ». Mais un examen attentif du texte permet de restituer la bonne lecture. Un estampage de cette inscription (référencée «Vat Si Suphan ") est conservé à la bibliothèque de l'EFEO.

142. Punnothok, s. d., p. 254-256 ; J. C. Eade, 1996, p. 88. Un estampage de cette inscription (référencée « Vat Pha Khao ») est conservé à la bibliothèque de l'EFEO.

143. La stèle $n^{\circ} 2$ du Vat Daen Muang (21 ou 23 septembre 1535) - Punnothok, s. d., p. 236-239 évoque de façon rétrospective des donations effectuées par Sāy Muy et le Phrayā Chan (ou son oncle). Ceux-ci sont présentés par les sources manuscrites comme des gouverneurs de Vientiane sous le règne de Saiya Chakkhaphat Phēn Phēo ( $3^{\mathrm{e}}$ quart du XV $\mathrm{X}$ siècle).

144. Cf. supra, note 47 . L'inscription est inédite. 
ces temps anciens bénéficier de riches dotations. Le premier roi du Lān Xāng dont nous savons par l'épigraphie qu'il fut impliqué dans une fondation est Visun, qui régna probablement de 1501 à $1520^{145}$. Mais l'œuvre royale se limitait encore à la région de Luang Prabang. Vientiane ne semble devenir l'objet de toute l'attention des souverains lao qu'à partir de Phothisarāt, qui la transforma en ville royale (rājadhānī) dès avant 1535 . A cette époque, elle possède déjà plusieurs temples où la discipline religieuse est sévèrement contrôlée. Un certain nombre d'entre eux avaient pu être fondés par des dignitaires - ce fut apparemment le cas pour le Phya Vat et le Vat Chan -, mais d'autres étaient de façon certaine des créations du roi. Les sources épigraphiques de la région de Vientiane, hormis notre inscription, impliquent Phothisarāt dans au moins quatre fondations. Son nom est rattaché notamment à l'origine du Thāt Bāng Phoan, un stūpa situé à proximité de Vieng Khuk, dernière étape avant d'arriver à Vientiane par le Sud. Ce stūpa semble avoir eu beaucoup d'importance dès le second quart du $\mathrm{XVI}^{\mathrm{e}}$ siècle. Il est cité dans deux inscriptions qui datent du règne de Setthāthirāt. Il est par ailleurs au centre d'un complexe architectural qui rappelle la disposition du Vat Chet Yot de Chiang Mai ${ }^{146}$.

Les sources manuscrites et épigraphiques montrent que les traditions bouddhiques du Lān Nā exercèrent une influence très forte sur Phothisarāt. Il est certain que la diffusion au Lān Xāng des textes et des images du Nord fut accompagnée par un certain nombre de techniques, parmi lesquelles les modèles architecturaux. L'assertion de l'inscription du Vat Hnong Bone selon laquelle les premières offrandes au That Luang seraient à mettre sur le compte de Phothisarāt nous incite à nous demander si celui-ci ne serait pas à l'origine du premier monument lui-même. La réponse à cette question est difficile : elle ne pourra d'ailleurs être trouvée tant que des sondages n'auront pas été réalisés au cœur même du That Luang. Pourtant, les découvertes effectuées par L. Fombertaux en 1930 nous offrent déjà un éclairage plus net. À l'époque, l'architecte s'était contenté de descriptions - tout comme H. Parmentier -, car l'état des connaissances sur l'architecture des édifices religieux t'ai était encore des plus minces ${ }^{147}$. L'absence de références ou d'éléments

145. Les chroniques font état de fondations de temples à partir de la seconde moitié du XIVe siècle. Mais toute cette première période de l'historiographie lao est entâchée par des contradictions, des anachronismes, ainsi que par des emprunts fréquents à la légende. La plupart des informations ne peuvent être vérifiées.

146. Cf. Sārānukrom Vatthanatham Thai Phāk Issān (Encyclopédie sur la culture thaïe de la région issane), 1999, p. 2247.

147. Le chapitre de L'art du Laos consacré à l'étude du «thāt » (p. 311-319) est symptomatique de cette méconnaissance. H. Parmentier ressent en effet le besoin de faire l'exposé préalable de l'emploi du stūpa et des édifices votifs ou symboliques du bouddhisme, puis de faire le tour des pays qui ont accueilli ce type de monuments. Il évoque alors l'Inde, Java, le Campa, le Cambodge angkorien, la Birmanie, Ceylan, la Chine - et occulte pratiquement le Siam, qu'il ne connaît pas encore. À l'époque où H. Parmentier rédige son texte $(1911,1927$, une courte addition sera faite après 1930 , à la suite des travaux de L. Fombertaux), les études sur les arts des pays t'ai étaient encore très peu développées. Sur le plan de l'architecture, il faut attendre la publication en 1931 de «L'archéologie du Siam » (BEFEO 31, p. 361-448), par J. Y. Claeys, pour avoir de premières informations. Le $3^{\mathrm{c}}$ et dernier chapitre de l'article (p. 420-447) est consacré au Laos occidental, c'est-à-dire au Lān Nā. L'architecte écrit que « les travaux du service archéologique siamois dans cette région, à part un débroussaillement pour le passage des souverains en 1927, se sont bornés à la réfection, au cours de la même année, de la bibliothèque située à l'entrée du Wăt P'ră Sĭng à C'ieng Mẫi » (p. 421). En 1948, avec la publication de L'art architectural hindou dans l'Inde et en Extrême-Orient, H. Parmentier - qui devait décéder l'année suivante - propose deux chapitres consacrés respectivement à l'art laotien et à l'architecture au Siam. Il introduit ainsi le premier : «L'art siamois et l'art laotien pourraient être réunis et étudiés sous un seul nom, l'art thai. Et de fait, au Laos français comme au Siam les édifices de culte encore en service et les images vénérées du Buddha sont de mêmes familles. En outre l'art du Laos et l'art du Siam présentent à côté des arts que nous avons passés en revue des traits communs qui les mettent à part » (p. 150). 
de comparaison ne permettait alors pas de tirer de conclusions sur les influences et les emprunts possibles. Après le travail effectué par H. Parmentier, les temples et les stūpa du Laos n'ont plus donné lieu à des recherches architecturales poussées ${ }^{148}$. Les études concernant l'architecture religieuse thaïlandaise - souvent effectuées à la faveur de travaux de restauration - ont en revanche proliféré, et une documentation importante sur les régions avec lesquelles le Lān Xāng était directement en contact est désormais facilement accessible. Si l'aspect actuel du That Luang ne trouve pas d'équivalent direct dans les monuments de la Thaïlande - sauf dans ceux du Nord-Est qui s'inspirèrent précisément de lui -, il n'en est pas de même pour les structures anciennes découvertes par L. Fombertaux. Deux exemples nous paraissent à cet égard intéressants. Le premier concerne les deux protomes d'éléphant ${ }^{149}$ qui entouraient l'escalier primitif. Ce détail iconographique et son organisation dans le plan étaient bien connus à Chiang Mai : il est représenté d'une façon identique sur le cetiya du Vat Chiang Man, monument rebâti par Tilokarāt en 1478/79, mais dont l'origine daterait du règne de Mangray (fin du XIII siècle), et il est traité d'une façon très semblable sur le cetiya du Vat Hoa Nong de Vieng Kum Kam - à quelques kilomètres de la capitale du Lān Nā -, édifice que l'on date au plus tard du milieu du $X^{\mathfrak{e}}$ siècle. La référence à ces deux sites est également valable pour le second exemple que nous proposons: il s'agit du plan carré à redents, très caractéristique d'ailleurs de l'architecture religieuse ancienne du Lān $N \bar{a}^{150}$. Encore une fois, on constate donc que des modèles issus des territoires t'ai du Nord se sont diffusés au Lān Xäng ${ }^{151}$. Si l'on considère que le That Luang, dans son aspect actuel, remonte au règne de Setthāthirāt, l'édifice antérieur mis au jour par L. Fombertaux ne peut guère, eu égard au contexte historique dont nous venons de tracer les grandes lignes, dater que du règne de Phothisarāt. Ce souverain pourrait donc être le premier fondateur du That Luang ${ }^{152}$. Une autre thèse est toutefois possible : celle consistant à faire remonter à Setthāthirāt l'édifice antérieur lui-même. Il faudrait pour cela admettre que le stūpa de latérite - dont L. Fombertaux nous a laissé le plan général - était déjà associé aux trente pinacles, puisque les Phongsāvadān nous apprennent que leur construction remonte à 1564-1565. Cette théorie paraît au premier abord difficile à défendre, pour des raisons techniques liées à la proportion et à l'esthétique du monument: on a en effet du mal à dissocier les trente

148. M. Giteau (Art et archéologie du Laos, 2001) effectue un admirable travail de synthèse sur toutes les manifestations de l'art lao. Dans son chapitre consacré aux reliquaires, elle rappelle l'embarras que ce sujet avait provoqué chez H. Parmentier. Elle classe elle-même les «thāt » lao en deux catégories, mais ses références sont encore lointaines sur les plans géographique et chronologique : «Un premier type procède, plus ou moins directement, du stūpa singhalais et est constitué essentiellement d'un anda une masse aux lignes arrondies - édifié sur un soubassement élevé. Un second type se présente comme une tour reliquaire dont les lignes évoquent les tours sanctuaires de l'art khmer; mais ici la construction ne comporte généralement pas de chambre intérieure » (p. 103). Pour le cas du stīpa dont l'anda " galbé » est porté par un haut soubassement, elle remarque pourtant que « des édifices de ce type ont été élevés au cours des XVIII ${ }^{\mathrm{e}}$ et XIX ${ }^{\mathrm{e}}$ siècle dans toutes les régions du Laos et au Lān Nā » (p. 105).

149. L. Fombertaux n'en cite qu'un seul, mais nous supposons une symétrie de l'agencement.

150. Le plan carré redenté, qui connaît un certain nombre de variantes, est présent dans pratiquement tous les stüpa de Chiang Mai et de Chiang Saen. Cf. Chirasak Dejvongya, Phra Chedi Muang Chiang Mai, 1998 ; et Phra Chedi Muang Chiang Saen, 1996.

151. L'intégration du motif de l'éléphant dans l'architecture, ainsi que le plan carré redenté, se retrouvent également à Sukhothai (le Wat Maha That et Wat Chang Lom en sont deux exemples), où ils furent en faveur avant même de l'être au Lān Nā. Des modèles semblables peuvent être également trouvés à Ayuthya. Mais nous nous éloignons alors du That Luang, tant sur le plan géographique que chronologique.

152. Cela n'exclut pas la possibilité de l'existence d'un «noyau » encore plus ancien - peut-être môn puisqu'un certain nombre de vestiges de cette culture ont été retrouvés dans la région de Vientiane. 
pinacles du dôme actuel. Pourtant, un monument comme le That Si Phom de Xieng Khuang - stūpa qu'H. Parmentier avait déjà très étroitement mis en parallèle avec le That Luang ${ }^{153}$ - combine d'une façon heureuse la tour-reliquaire imitée des modèles du Lān Nā et une ceinture de trente (ou trente-deux) petits «thāt». Jamais repris ou restauré, ce monument pourrait conserver l'apparence primitive du That Luang. La région de Vientiane montre d'autres exemples de tours-reliquaires à plan carré redenté dont l'origine remonte manifestement au XVI ${ }^{\mathrm{e}}$ siècle ${ }^{154}$. S'il fallait attribuer à Setthāthirāt la construction du monument en latérite découvert par L. Fombertaux ${ }^{155}$, la tâche de l'historien en serait singulièrement compliquée. Il faudrait en effet croire à l'existence d'un monument encore plus ancien (un troisième stüpa?). Il faudrait en outre identifier le souverain qui fut à l'origine de la dernière restauration, c'est-à-dire de la construction du dôme hémisphérique sur plan carré. Nous ne croyons de toute façon pas que le monument ait pu acquérir sa forme définitive en 1566, alors que l'histoire de Vientiane en tant que capitale venait à peine de commencer. Jusqu'à 1828 , année de la destruction de la ville par les troupes siamoises, nombre de souverains importants (Hno Muang, Suriyavongsa, Anu) pouvaient encore parfaire la construction du principal édifice religieux lao, accroissant par là même leur gloire et leurs mérites ${ }^{156}$. Le modèle qui a pu inspirer les architectes de Setthāthirāt resterait alors à identifier. Nous serions tentés de proposer le stūpa du Vat Lokamoli de Chiang Mai, puisque nous avons vu que celui-ci pouvait avoir produit un certain effet sur le souverain lao - et il est en effet possible de reconnaître une certaine affinité entre ce monument et le That Si Phom de Xieng Khuang, qu'H. Parmentier mettait étroitement en relation avec le That Luang ${ }^{157}$. Sur le plan architectural, il est également possible de mettre en relation le stūpa du Vat Lokamoli avec le très important stūpa du Vat That de Luang Prabang ${ }^{158}$. Nous savons d'ailleurs, grâce à une stèle de fondation

153. L'art du Laos, 1954, p. 9, 15, 167 et 223, photo 2 et planche X (notre document 15). H. Parmentier semble croire à la grande ancienneté du stüpa, car il écrit (p. 9) que « quelques-uns [les "thāt" du Nord-Laos], comme le that du Vat Si Phom près de Xieng Khuang, présentent une véritable composition qui les épate sur le sol et fait pressentir le That Luong de Vientiane ».

154. Par exemple le très beau stūpa du Vat Nak de Vientiane, qui se situe d'ailleurs dans un quartier où nombre de vestiges en céramiques, en particulier des pipes, rappellent les productions anciennes du Lān Nā (cf. C. Velder, «La poterie du Wat Si Satthanak, Vientiane (Laos) », 1965, p. 199-201 ; D. Hein, M. Barbetti, T. Sayavongkhamdy, An Excavation at the Sisattanak Kiln Site, Vientiane, Lao P.D.R., 1989). Un ou deux (l'un pouvant être la copie tardive de l'autre) des stüpa du Vat Thep Phon de Muang Khuk peuvent également appartenir à cette période, tout comme les stüpa des Vat(s) Si Muang, Chan et Kang (aujourd'hui détruit) de Vientiane.

155. Les travaux auraient alors pu commencer dès 1561-62, ainsi que l'indique le Chot Hmāy Het Yo Vieng Chan, et s'achever en 1564-65, comme le rapportent les Phonsāvadān.

Une alternative serait de penser que le stūpa de latérite fut construit par Phothisarāt, alors que les pavillons primitifs auraient été l'œuvre de Setthāthirāt.

156. La Jinakālamātī (1962) met bien en évidence le fait que les grands stūpa du Lān Nā sont presque toujours le résultat d'additions successives, qui valent à chaque souverain impliqué un surcroît de légitimité.

157. Pour le plan du stūpa du Vat Lokamoli, cf. Chirasak Dejvongya, Phra Chedi Muang Chiang Mai, 1998 , p. 111 . On remarquera que ce monument est le seul stūpa de Chiang Mai dont le couronnement soit constitué de quatre parties cardinales distinctes, reliées entre elles par quatre angles redentés. Cette disposition pouvait aisément être remplacée par la masse curviligne à quatre arêtes du dôme actuel du That Luang. C'est peut-être là l'explication du couronnement en flèche " galbée » ou " en balustre », dont l'origine a laissé jusque-là perplexes les historiens de l'art (cf. M. Giteau, 2001, p. 104-105).

158. Chirasak Dejvongya, «Kān Seuksā Priep Thiep Cedī Nai Muang Chiang Mai Lae Luang Phra Bāng », 2001, p. 39-40. Les photographies (p. 180 du même ouvrage) des deux monuments montrent très bien leur grande ressemblance. 
datée du 18 mai $1548^{159}$, que le second fut construit vingt années après le premier, mais également et surtout trois années après le dépôt des cendres du Phrayā Muang Ket Klao dans le monument de Chiang Mai.

Document 15 - That Si Phom (H. Parmentier, L 'art du Laos)

À ce niveau de l'analyse, il est intéressant de s'interroger sur la fonction même du stūpa du Vat That de Luang Prabang. Étant donné l'importance du monument, et vu qu'il fut édifié tout juste après le décès de Phothisarāt, on peut très bien imaginer qu'il s'agissait du monument funéraire de ce dernier. Il y aurait ainsi un parallèle parfait entre les deux souverains du Lān Nā et du Lān Xāng, d'autant plus que le commanditaire de la stèle du Vat That (qui se présente également comme le fondateur du stūpa) n'est pas Setthāthirat, qui était encore à Chiang Mai, mais Phra Rāsa Aiyakā Mahā Theva (rāja-ayyakā-mahādeva) Chao - qui devait être la reine-mère, veuve de Phothisarāt, et donc également la fille du Phrayā Muang Ket Klao ${ }^{160}$. Les résultats d'une première étude comparative de différents types de sources permettent ainsi d'établir un lien relativement clair entre le stūpa du Vat Lokamoli de Chiang Mai, celui du Vat That de Luang Prabang et le That Luang de Vientiane. Tant que ce dernier n'aura pas été fouillé en profondeur - dans le cadre d'un projet archéologique que nous appelons de nos vœux - il sera cependant difficile d'aboutir à une conclusion définitive.

159. L. Finot, 1915 p. 27-28. En plus de la date formulée dans le texte, l'inscription porte un disque horoscopique dont la configuration semble indiquer la date du 24 mai 1550. Il s'agit peut-être de la fin des travaux, ou du jour de la rédaction de la stèle.

160. La stèle du Vat That, rédigée en pure écriture «fak khām, » contribue à montrer le lien étroit entre le monument et la culture du Lān Nà. 


\section{Les donations de terres}

Dans son ordonnance de 1566 relative au That Luang, Setthathirāt n'offrait pas de terres destinées à l'entretien du sañgha, à l'exemple de ce que l'on trouve dans la plupart des autres stèles du Lān Xāng et du Lān Nā. Le texte insistait au contraire sur le don d'esclaves, et nous avons vu que ceux-ci devaient être affectés à un labeur fort différent de la culture des rizières et des champs. La stèle du Vat Hnong Bone nous apparaît à cet égard beaucoup plus conventionnelle. Il y est cette fois question de la communauté des religieux - représentée par son dignitaire le plus élevé - et l'inventaire des bénéfices qu'elle reçoit montre qu'elle était de loin la mieux pourvue de tout le royaume. La délimitation des terres est fixée par la mention de différents toponymes qu'il n'est guère facile aujourd'hui d'identifier. Nous apprenons cependant que deux de ces terres avaient respectivement des surfaces de $500 \times 1000$ brasses $(\sim 900 \times 1800 \mathrm{~m})$ et de $1000 \times 1000$ brasses $(\sim 1800 \times 1800 \mathrm{~m})$, ce qui dépasse largement les limites habituellement assignées. Certaines des rizières paraissent avoir été situées à l'intérieur même de l'enceinte de la cité. Il en est ainsi de Nā Bone Tai et de Nā Bone Neua - qui pouvaient être localisées à proximité immédiate du sanctuaire, si l'on admet que Nā Bone est à identifier avec le nom actuel de Hnong Bone ${ }^{161}$. Il s'agissait alors du territoire le plus petit, puisque les religieux ne tiraient que quatre « bya » de la récolte en riz, pendant que les travailleurs en gardaient cinquante ${ }^{162}$. Cette terre semble d'ailleurs avoir un statut bien particulier. C'est celle qui fut donnée par Phra Pitāthirāt (Phothisarāt) et elle reste associée à un certain nombre d'esclaves qui avaient dû être bien recensés. La situation fut probablement différente pour les terres suivantes, puisque l'on apprend qu'elles doivent être défrichées - voire habitées -, et la liberté laissée à leurs travailleurs semble plus importante. On signalera à cet égard l'absence des termes habituels «khā», «khoy », " thāt» (p. dāsa) qui s'appliquent à l'esclave. Ils sont remplacés à partir de la ligne 7 par le terme «thai » qui désigne en principe l'homme libre, même si celui-ci est redevable d'une corvée ou d'un impôt. La seconde terre, qui fait partie également de la ville, ne semble pas être délimitée d'une façon précise, même si sa surface est connue, ainsi que l'identité des gens qui la travaillent. Ils fournissent vingt «bya », donc cinq fois plus que les travailleurs de Nā Bone, mais ils bénéficient du reste des récoltes, puisque leur labeur a été plus dur. La troisième terre doit être définie de façon plus précise, car il s'agit encore d'une zone vierge, dont on envisage le peuplement. Elle jouxte sur son flanc est la digue de l'enceinte, probablement celle qui passait juste derrière le That Luang et dont le tracé est encore reconnaissable aujourd'hui. Cette information est importante, car elle montre qu'au milieu du $\mathrm{XVI}^{\mathrm{e}}$ siècle la ville de Vientiane était déjà pourvue de limites étendues et bien marquées physiquement. Ces dernières devaient avoir été fixées en fonction des particularités de terrain, principalement des rivières et des canaux qui favorisaient les déplacements et l'approvisionnement en eau des rizières : nous aurons l'occasion d'en reparler avec la stèle sud de la porte orientale du That Luang. La troisième terre était limitée en direction de la ville par la rizière Nā Ngop Khāo - et dans les autres directions par Nā Hai Dieo, qui forme toujours un important quartier de Vientiane au nord de l'axe qui mène au That Luang. La double mention de l'endroit est peut-être une erreur du graveur, car si l'on comprend facilement qu'il soit fait référence au Nord, on comprend moins bien, par contre, qu'il puisse être également question du Sud. Les travailleurs de Thin Don qui mettaient en valeur cette terre étaient

161. «Nā »= rizière, « Hnong »= mare.

162. «Bya » désigne le cauris (un petit coquillage), qui était l'unité monétaire la plus basse. Il semble cependant que sa valeur ait été plus importante qu'au Lān Nā. La terre elle-même avait une valeur de 5 «hoy ", qui pouvait correspondre à 50 «bāt» et donc à 400000 «bya » (cf. Khamphi Phra Thammasāt Buran, cité dans M. Reinhorn, Dictionnaire laotien-français, 1970, p. XXXI). 
assujettis aux mêmes conditions que ceux de la seconde terre. La quatrième terre n'est plus située dans le périmètre de la ville. Le nom qui est indiqué - Vieng Kham - a même de quoi surprendre, car si l'endroit est connu des sources anciennes, il n'en est pas moins à une certaine distance de Vientiane : une cinquantaine de $\mathrm{km}$ le sépare en effet de la capitale. Nous verrons cependant avec le texte de la stèle sud de la porte orientale du That Luang que la lecture et l'identification de ce nom peuvent être tenues pour certaines. Les limites du terrain ne sont pas données - les hommes chargés de sa culture pouvaient sans doute les choisir - mais sa surface est déterminée : elle est un peu plus grande que celle de la seconde terre. Il semble que la redevance soit de dix «bāt» et de trois «bya». La cinquième ne porte pas de nom, probablement parce qu'elle n'était pas encore peuplée. Le fait qu'elle soit située hors du périmètre de Vientiane est mis en évidence par la formule "phāy nok" (du côté extérieur) qui remplace ici la référence à l'Est. Il semblerait cependant que sur son côté ouest, c'est-à-dire en direction de la ville, elle ait touchée à l'enceinte, car il est question de la rivière ou du canal Nam Hong qui, jusqu'au début du $\mathrm{XX}^{\mathrm{e}}$ siècle, représentait encore une des limites physiques de Vientiane. L'impôt demandé est ici d'une charrette de riz sur dix obtenues. Cette ponction du dixième de la récolte semble avoir été courante ${ }^{163}$. Pour la première terre de notre inscription, la proportion est assez proche puisqu'elle est de quatre pour cinquante.

\section{La stèle sud de la porte orientale du That Luang}

La stèle sud de la porte orientale du That Luang est un gros bloc de grès d'une hauteur de $1,15 \mathrm{~m}$, d'une largeur de $75 \mathrm{~cm}$ et d'une épaisseur de $12 \mathrm{~cm}$. Elle a très exactement la même forme que la stèle nord, mais elle lui est légèrement inférieure en taille. Seule une face est inscrite - le texte ne remplissant d'ailleurs avec ses 15 lignes que les $2 / 3$ de la surface disponible. La partie supérieure centrale révèle la moitié d'un motif qui, dans sa forme générale, rappelle la couronne de la première stèle. Celui-ci n'habille cependant pas de disque horoscopique : il semble au contraire que le graveur ait voulu représenter une fleur dont le cœur est formé par un bouton. Aucun élément de texte n'entoure le dessin.

L'inscription est aujourd'hui en grande partie effacée, ce qui explique qu'elle n'ait donné lieu à aucune transcription, même de la part des lettrés lao. Le recours à un estampage ancien ${ }^{164}$ permet cependant le déchiffrement de la plus grande partie du texte. L'écriture est la même que celle des stèles précédentes, c'est-à-dire le " tham Lān Nā ». Si l'on était sûr des dates respectives des deux stèles du That Luang, on pourrait même croire que ces deux inscriptions sont de la même main.

En l'absence de toute information sur le texte, on a cru jusqu'à présent que les deux stèles du That Luang étaient parfaitement contemporaines et dataient donc de 1566 . Or, cela apparaît impossible dès lors que l'on reconnaît le nom du roi qui est à l'origine de l'inscription de la stèle sud : il s'agit de Phra Vora Ratana Thamma Pasota Seta Khassa Atsachan Suvanna Samut Khakha Ratana Sāla Rāsa Bophit - mieux connu dans les chroniques sous le nom de Hno Muang -, qui gouverna le Lān Xāng dans la dernière décennie du $\mathrm{XVI}^{\mathrm{e}}$ siècle. Cette identification étant faite, il devient alors très facile de reconnaître dans les deux premières lignes de l'inscription la contrepartie de la stèle nord

163. Cf. par exemple la stèle $\mathrm{n}^{\circ} 2$ du Vat Daen Muang, Phon Phisay (op. cit.).

164. N. 114 (Bibliothèque de l'EFEO, Paris). Cet estampage a probablement été effectué par $\mathrm{H}$. Parmentier, comme celui de la stèle nord. Une photo de la collection personnelle de P.-M. Gagneux nous a également été d'un secours certain. 
du That Luang, c'est-à-dire la mention de la date en pâli ${ }^{165}$. Malheureusement, l'état de la pierre ne livre des données complètes que pour l'année - neuf (cent) cinquante-cinq de l'ère culla (9 avril 1593 au 8 avril 1594) - et nous restons dans l'incertitude quant au mois et au jour. Nous savons juste que ce dernier était un samedi.

La première stèle du That Luang et la stèle du Vat Hnong Bone avaient été rédigées au début d'une période de troubles qui dura en fait jusqu'au second quart du XVII siècle. En 1593-1594, au moment où fut gravée la seconde stèle du That Luang, il semble pourtant que la couronne du Lān Xāng ait retrouvé un certain brillant, et que la continuité avec la période faste qui avait précédé les guerres ait été affirmée. Il sera utile de revenir ici sur les trente années qui suivirent la disparition de Setthāthirāt.

Les annales lao rapportent que la succession de Setthāthirāt donna lieu à une lutte pour le pouvoir entre les deux plus grands dignitaires du royaume. Finalement, c'est le Phrayā Sēn Surintha - dont on a déjà vu qu'il tenait la première place dans l'entourage de Setthāthirāt - qui l'emporta. Beau-père du défunt roi et grand-père du très jeune héritier de la couronne, Hno Muang, il ne se limita pas à la régence, mais se fit aussi proclamer souverain sous le nom de Phra Sumangkhala Phothisat Aiyakarāt ${ }^{166}$. Deux stèles, datées du 11 décembre 1572 et du 16 février $1573^{167}$, le citent avec emphase, ainsi que son petitfils. Le règne ne dura cependant guère, puisqu'entre 1574 et 1576 les Birmans envahirent une nouvelle fois le Lān Xāng, s'emparèrent du roi et du prince, et mirent sur le trône du Lān Xāng l'uparāt (p. uparāja) - peut-être un frère de Setthāthirāt - qu'ils avaient enlevé une dizaine d'années plus tôt. Ce dernier disparut cependant quatre ou cinq années plus tard. Les annales lao rapportent qu'en 1580-1581, les Birmans replacèrent sur le trône le Phrayā Sēn Surintha, qui gouverna jusqu'à sa mort en 1582-1583. Alors que les sources épigraphiques ne fournissent aucune donnée pour les années 1574-1581, une stèle rédigée le 9 août 1582 confirme qu'à cette date, le Phra Sumangkhala Phothisat Aiyaka était encore sur le trône du Lān Xāng. Il semble que son fills ait ensuite régné brièvement, avant d'être déposé par les dignitaires du royaume. Les sources manuscrites, qui s'accordent sur l'identité de son successeur, se contredisent cependant sur la chronologie, puisque les unes font revenir Hno Muang en 1584-1585, alors que les autres ne situent son retour qu'en 1591-1592. Les sources épigraphiques paraissent cependant donner raison aux premières, puisqu'une stèle de Luang Prabang datée du 11 septembre 1590 mentionne le nouveau roi sous son nom de règne: "Phra Vora Ratana Thamma Pasota Seta Khassa Atsachan Suvanna Sammut Khakha Ratana Sāla Rāsa Bophit » ${ }^{168}$. Hno Muang était le fils de Setthāthirāt, le petit-fils du Phrayā Sēn Surintha et le prince héritier que les Birmans avait gardé en captivité pendant plus de dix ans. Dans l'épigraphie lao, hormis la stèle du Vat Suvanna Khuha, il est mentionné dans huit inscriptions, dont six sont datées de 1590 à

165. L'épigraphie lao donne très peu d'exemples de date rédigée en pâli : les deux stèles du That Luang pour le XVI siècle, et cinq inscriptions sur Buddha, gravées entre 1700 et 1714 .

166.P. su-maingala-bodhisatta-ayyaka-rāja. Le terme ayyaka (grand-père) rappelle son lien avec le prince héritier.

167. Face 2 de la stèle $\mathrm{n}^{\circ} 2$ du Vat Phadung Sukh, Phon Phisay (Cāreuk Nai Prathet Thai, 1986, p. 321, J. C. Eade, 1996, p. 95) ; face 2 de la stèle ${ }^{\circ} 1$ du Vat Tham Suvanna Khuha (Punnothok, s. d., p. 270-273 ; Cāreuk Nai Prathet Thai, p. 316-317 ; J. C. Eade, op. cit., p. 95).

168.P./skt. vara; p. ratana; p. dhamma; p. pajjota; p. seta; p./pkt. gaja; skt. aścarya; p. suvanna; p. sammuti; p. khagga; p./skt. sāra; p./skt. rāja; skt. pavitra. Hno Muang est le premier souverain du Lān Xāng à porter un nom de règne aussi pompeux. Il est possible que celui-ci ait été inspiré par le Phrayā Sēn Surintha (dont le nom de règne innovait déjà par sa longueur), car il est porté dès 1573 . On peut y voir une influence d'Ayuthya. 
$1595^{169}$. Il n'y a donc pas contradiction avec les annales qui s'accordent toutes à situer le décès du souverain en $1596-1597^{170}$. Son action politique et militaire est mal connue : on lui prête quelques campagnes militaires afin de réprimer des rébellions de "muang " vassaux, ainsi que la construction de la muraille de Vientiane. Son action religieuse paraît cependant avoir été importante. Il fit un grand nombre de donations, et sa prodigalité touchait en premier les temples que son père et ses deux grand-pères - Phothisarāt et Sēn Surintha - avait déjà pourvus.

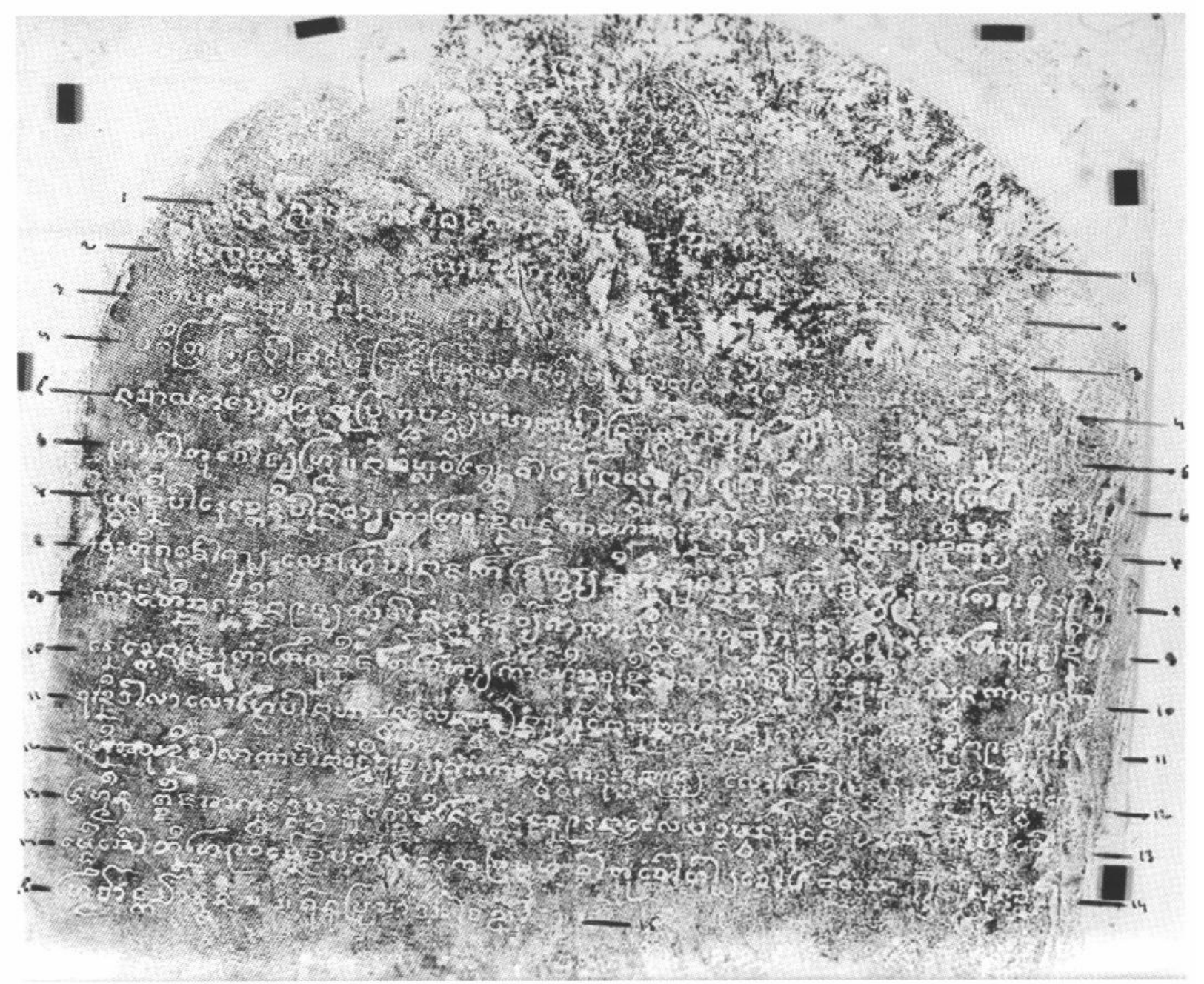

Document 16 - Stèle sud de la porte orientale du That Luang.

169. Vat Xieng Men (1590, Luang Prabang), Vat Sri Bun Heuang (1591, Ban Phoe ?), Vat Si Muang? (1592-93, Vientiane, ne subsiste qu'avec un estampage de l'EFEO), That Luang 2 (1593-94, Vientiane), Vat Muccalintha Aram $n^{\circ} 1$ (1594, Phon Phisay), Vat Phra Ngam Nam Mong $n^{\circ} 2$ (?, Tha Bo), Vat Ho Phra Kèo (1595, Vientiane), Vat Phra Kho (?, Muang Khuk).

170. Deux stèles de Vientiane datées de 1598 mentionnent déjà un nouveau roi. 
Document 17 - Texte de la stèle sud de la porte orientale du That Luang.

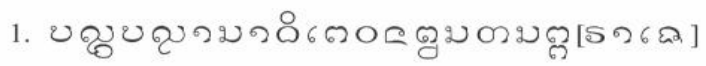
๒วม

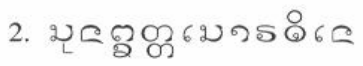

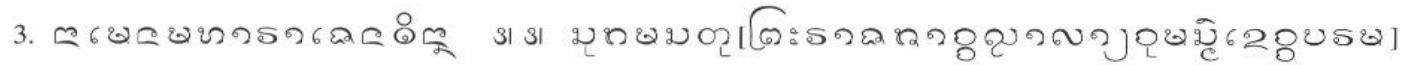

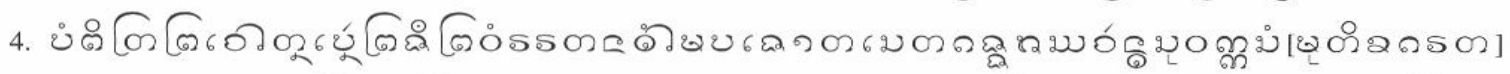

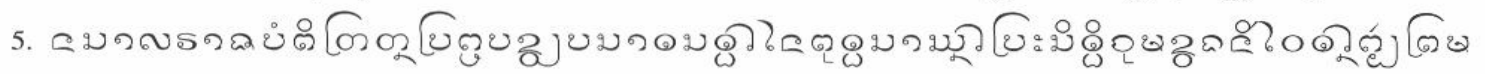

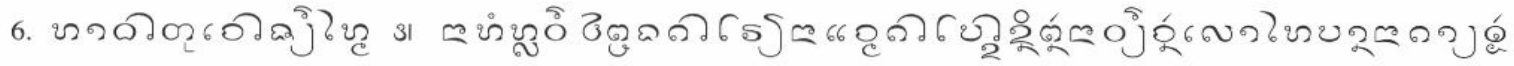

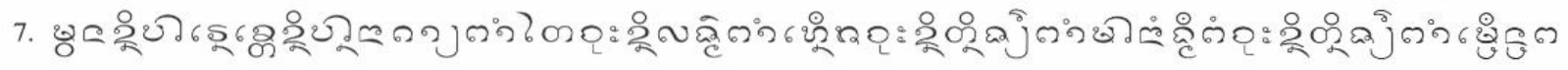

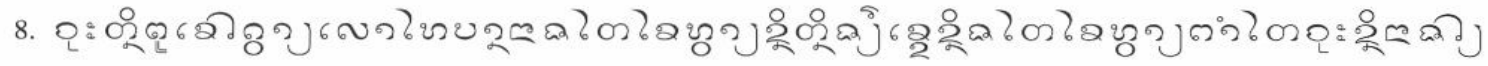

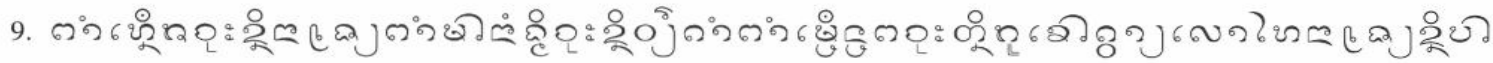

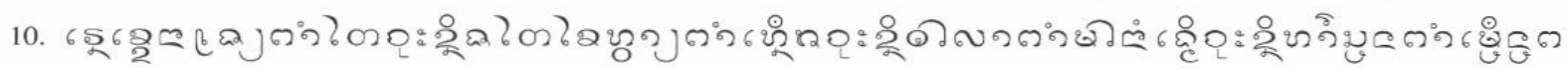

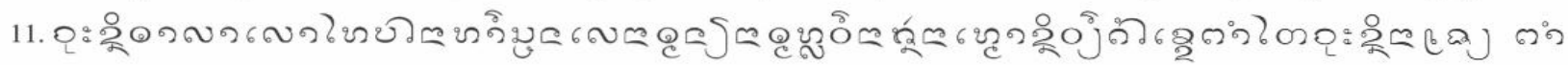

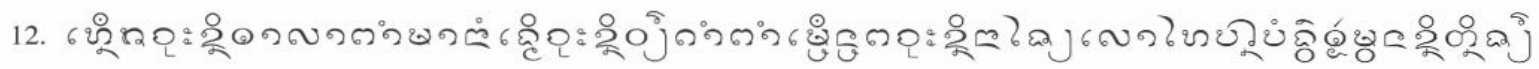 ถุ26ตู

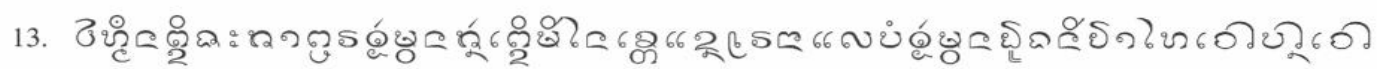

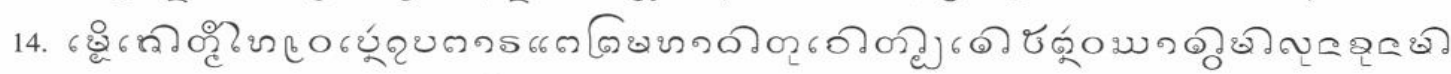

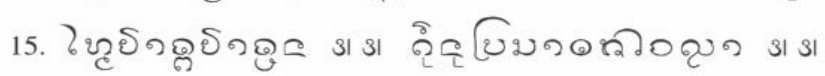


Translittération de l'introduction en pâli

1. Pañcapaññāsādhike ${ }^{171}$ va navasatasaka[rāje] ${ }^{172}$...māsa......

2. sunakkhatta soradine

3. nāmena mahārājena dinnā $\|$ || $\|$

\section{Traduction}

1. Neuf cent cinquante-cinq de l'ère, .... mois ....

2. un samedi, mansion lunaire favorable

3. a été accordé par le grand roi nommé ... \|\|$\|$ Que le bonheur soit! [Ordonnance royale revêtue du sceau de Sa Majesté Excellente et]

4. Pure. Le Roi qui porte le nom de Phra Vora Ratana Thamma Pasota Seta Khassa Atsachan Suvanna Sam[muti Khakha Rata-]

5. na Sāla Rāsa Bophit et règne avec sérénité et foi dans la religion du Buddha a proclamé cette ordonnance à l'intention du Phra Ma-

6. hā Dhātu Chao Chiang Mai || Quatre parcelles ${ }^{173}$ de la rizière Nā Ho Luang, valeur : 2 « hoy »; la rizière Nā Chèm, valeur : 2 « bāt », sur les terres de Phan Nā Vieng Can. // Puis on donne tout Bān Nā Khāy,

7. sur la terre de la forêt Pā Ren. Limites du village Bān Nā Khay : au sud, jusqu'à la terre de Lasom; au nord, jusqu'à la terre de Tin Sieng ; en revenant vers la rivière Nam Ngeum, jusqu'à la terre de Tin Sieng ; vers l'extérieur,

8. jusqu'au pied de la montagne Phu Khao Khuay. // Puis on donne le village Bān Nā Satai Khai Hvāy, sur la terre de Tin Sieng. Limites de Satai Khai Hvāy : au sud, jusqu'à la terre de la rizière Nā Sāy ;

9. au nord, jusqu'à la terre de Nā Saiya ; en revenant vers la rivière Nam Ngeum, jusqu'à la terre de Vieng Kham; vers l'extérieur, jusqu'au pied de la montagne Phu Khao Khuay. // Puis on donne la rizière Nā Saiya, terre de la forêt Pā

10. Ren. Limites de la rizière Nā Saiya : au sud, jusqu'à la terre de Satai Khai Hvāy ; au nord, jusqu'à la terre de Thā Lā ; en revenant vers la rivière Nam Ngeum, jusqu'à la terre de Hāng Son; vers l'extérieur,

11. jusqu'à la terre de Thā Lā. // Puis on donne Pā Nā Hāng Son, la rizière Nā Thom Noy, la rizière $N \bar{a}$ Thom Luang, la rizière $N a \bar{~} A n$, la rizière $N a \bar{a} M a o$, sur la terre de Vieng Kham. Limites : au sud, jusqu'à la terre de Nā Saiya ; au

12. nord, jusqu'à la terre de Thā Lā; en revenant jusqu'à la rivière Nam Ngeum, jusqu'à la terre de Vieng Kham ; vers l'extérieur, jusqu'à la terre de Nā Saiya. // Puis on donne le village de Bān Bo Ngoa complètement, sur la terre de Tin Sieng. La redevance en sel

13. est de quatre «hmeun ». Toutes les semences et contributions diverses qui sont produites dans les limites de ces rizières et de ces mines, que les "Chao Bān " et les "Chao

14. Muang » n'en profitent pas, qu'ils les réservent pour le service du Phra Mahā Thāt Chao pour une durée de 5000 ans. Que les «Thāo » et « Khun » qui viendront

15. par la suite ne les extirpent pas. Ainsi le prescrit l'ordonnance.

171. Le texte donne « Pañcapañāsādhike ».

172. Le texte donne «nabbasakkaräje ».

173. Le terme archaïque «phong » apparaît aussi dans la stèle du Vat Phon Savan (1582). Il semble avoir le même sens que « phan ", qui est le spécificateur de la rizière (d'un tenant). 


\section{Commentaires}

L'inscription sud de la porte orientale du That Luang montre une certaine continuité avec celle du Vat Hnong Bone, davantage d'ailleurs qu'avec celle de la stèle nord. Il est fort peu probable que durant les vingt-sept années qui séparèrent les deux documents, d'autres offrandes d'une certaine ampleur aient été effectuées. Le contexte ne s'y prêtait guère, sauf peut-être durant les toutes premières années qui suivirent la disparition de Setthāthirāt. Notre inscription se caractérise par une structure et une composition très élémentaires : date et nom du souverain donateur, inventaire des dons et brève conclusion. On se concentrera essentiellement sur la seconde partie qui offre des informations nouvelles.

\section{Le don de terres au stūpa}

Si les terres accordées par Setthāthirat au That Luang couvraient déjà une surface importante, celles qui furent offertes par Hno Muang furent encore bien plus vastes et dépassèrent très largement les limites de Vientiane. Il faut peut-être expliquer cette prodigalité par le fait que la personne de Hno Muang était elle-même attachée au stūpa. C'est en effet ce prince qu'il faut sans doute reconnaître dans le Rāsabut Chao de la stèle nord, puisqu'aucun autre enfant mâle de Setthāthirāt n'est connu des sources. Il ne devait être âgé à ce moment que de quelques années, car à la mort de son père, peu de temps après, la régence du Phrayā Sēn Surintha s'avère nécessaire. Contrairement à sa sœur Ratana-Kēo, dont le statut d'esclave (dāsa) du "thāt» est clairement exprimé, Hno Muang ne paraît avoir été investi que de certaines responsabilités, et celles-ci étaient précisément en rapport avec des terres affectées au stūpa.

La stèle sud de la porte orientale du That Luang cite six territoires. Le premier est sans doute le moins important : il est composé de deux rizières qui semblent encore situées dans les environs de Vientiane, et dont les valeurs respectives sont connues : deux " hoy » (vingt «bāt ») et deux «bāt ». La surface des cinq autres, de même que leur valeur et le prix que l'on pouvait espérer tirer de leur mise en culture, ne sont pas indiqués d'une façon précise. Ils sont pourtant situés dans un espace qui paraît déjà organisé, et dont les limites étaient sans doute bien fixées.

Cet espace ne peut être distant de Vientiane de moins d'une trentaine de $\mathrm{km}$. Il est en effet entièrement situé sur la rive gauche de la Nam Ngum ${ }^{174}$ qui constitue la limite occidentale (c'est-à-dire en direction de Vientiane), et s'étend grossièrement vers l'est (vers «l'extérieur») jusqu'au pied de la montagne Phu Khao Khuay. L'étude de la configuration de ces territoires montre qu'ils étaient relativement imbriqués les uns dans les autres. Ils semblent avoir formé un groupe qui suivait un axe SE-NO plus ou moins parallèle au cours de la Nam Ngum - et la limite du plus éloigné d'entre eux, le cinquième, dépassait en amont la ville de Vieng Kham. En fait, d'un point de vue strictement géographique, rien ne s'oppose à ce que la limite à la fois septentrionale et orientale de ce groupe - désignée par le nom de Thā L $\bar{a}$ - soit identifiée à l'actuelle Thā Lăt qui se situe au confluent de la Nam Ngum et de la Nam Lik. Le terme «thā » désigne d'ailleurs une berge, un embarcadère ou un port. Toute cette région, qui constitue également la limite septentrionale de la plaine de Vientiane, a été peuplée depuis fort longtemps. Les témoignages d'une implantation mône y ont été retrouvés en grand nombre et les premières études montrent qu'ils sont à mettre en relation directe avec la civilisation bouddhique qui s'est développée dans le bassin de Korat (Nord-Est de la

174. Nous adopterons la transcription courante « Nam Ngum ». Dans la traduction de l'inscription, nous avons cependant transcrit le nom en fonction de son orthographe et de sa prononciation : « Nam Ngeum ». 
Thaïlande) dans la seconde moitié du premier millénaire ${ }^{175}$. Il semble que Vieng Kham ait été très tôt associé à Vieng Chan (Vientiane), où des vestiges môns ont été également découverts. Les deux villes sont déjà mentionnées ensemble dans la première inscription en écriture t'ai, à la fin du XIII ${ }^{\mathrm{e}}$ siècle ${ }^{176}$. Dans les chroniques lao, leur destin est également soudé dès la période historique la plus ancienne (début du XIV ${ }^{e}$ siècle). Une des premières inscriptions de Setthāthirāt, faisant référence à l'année 1549 (le souverain venait juste d'arriver à Chiang Mai), a par ailleurs été retrouvée à Vieng Kham ${ }^{177}$. Elle mentionne un temple dont le territoire atteint lui aussi les berges de la Nam Ngum. Une autre inscription ${ }^{178}$ retrouvée quelques $\mathrm{km}$ en aval, datée du 12 avril 1623, cite de façon rétrospective Setthāthirāt qui serait le fondateur du Vat Suvanna Chedi Saphang. Le domaine du temple s'arrête encore une fois aux berges de la Nam Ngum. L'occasion est bonne pour rappeler ici l'inscription du Vat Hnong Bone qui évoquait déjà une donation de terres à Vieng Kham.

\section{Le rapport au système de production}

L'octroi de terres aussi éloignées au That Luang peut a priori paraître surprenant. Les données rassemblées nous amènent cependant à réfléchir à une question qui, jusqu'à présent, n'a pas été abordée dans les études historiques sur le Laos : celle des systèmes de production liés à l'organisation du territoire. Pour la seule région de Vientiane, l'étude de l'ensemble des sources épigraphiques - jointe à celle des sources manuscrites et des données archéologiques - montre que le réseau de communication ancien reposait essentiellement sur les voies navigables, et en particulier sur la plus importante d'entre elles, le Mékong. Cela signifie que de très grandes distances pouvaient être parcourues dans le sens du fleuve ${ }^{179}$, alors que l'intérieur des terres, à moins d'être bien irrigué, était peu fréquenté et à peine habité ${ }^{180}$. Vientiane était ainsi relié à un certain nombre de « muang » riverains du Mékong ou d'un de ses affluents - qui constituèrent des étapes régulières aussi bien pour la diffusion des biens que pour celles de la politique royale et de la religion. Le Muang Pak Huay Luang (l'actuel Phon Phisay, province de Nong Khai) fut l'un des éléments les plus importants de ce réseau. Il est intéressant de constater qu'il permettait une ouverture sur les terres de la rive droite, de par sa situation au confluent du Mékong et de la rivière Huay Luang, mais également et surtout vers les terres de la rive gauche, puisque le confluent de la Nam Ngum n'était qu'à quelques kilomètres en aval. Vientiane, Pak Huay Luang et Vieng Kham formaient ainsi les trois sommets d'un «triangle », dont deux des côtés étaient des voies navigables majeures. Or, sur le troisième côté de ce triangle - celui qui joint la capitale aux rives les plus proches de la

175.P. M. Gagneux, 1977.

176. Stèle de Rama Khamheng. Cf. P. N. Nagara \& A. B. Griswold, op. cit., p. 280 ; G. Cœdès, 1924.

177.P.-M. Gagneux, 1975, p. 108-114.

178. P.-M. Gagneux, 1975, p. 174-180.

179. La frontière entre le Lān Xāng et le Lān Nā, telle qu'elle est donnée dans les textes anciens, est marquée uniquement par un lieu riverain du Mékong, en l'occurrence une falaise (Phā Dai). Il en est de même pour la frontière méridionale du royaume, qui est représentée par d'importantes chutes (Li Phi) qui barrent le grand fleuve.

180. Ce constat est le résultat d'enquêtes sur les sources épigraphiques menées récemment dans plusieurs provinces du Laos. Il apparaît clairement que seules les régions en contact direct avec le Mékong ou ses principaux affluents ont connu une bouddhisation ancienne, et même un peuplement dense. Ces observations nous amènent à relativiser l'importance et l'étendue des zones autrefois contrôlées par le Lān Xāng. 
Nam Ngum, un peu en aval de Vieng Kham -, des études géographiques ${ }^{181}$ ont montré qu'il existait anciennement un type d'organisation de l'espace tout à fait particulier. Les systèmes de berge du grand fleuve et de son affluent, qui forment une unité, faisaient en effet partie d'un même aménagement traditionnel que la croissance de Vientiane au $\mathrm{XX}^{\mathfrak{e}}$ siècle aurait détruit. À la saison des pluies, un système d'irrigation et de drainage permettait le stockage des eaux de crue du Mékong, qui étaient ensuite progressivement distribuées dans les rizières pour les besoins du paddy : "ce système était conçu de manière à pallier à la fois une trop faible et une trop forte crue, en jouant sur le rôle complémentaire des crues de la Nam Ngum et du Mékong. Lorsque la crue du Mékong était insuffisante alors que celle de la Nam Ngum était au contraire importante ${ }^{182}$, il était possible de diriger les eaux de la rivière vers la région de Vientiane en utilisant à contre-courant un de ses affluents : la Nam Khem, prolongée par un canal, le Hong Xay Ngom. Un réseau de canaux distribuait ces eaux vers les différentes mares servant de réservoirs. Dans le cas contraire, lorsque la crue du Mékong remontait trop profondément en arrière-berge au risque de détruire le paddy, elle était dirigée vers la Nam Ngum plus basse à ce moment-là par le même moyen, le Hong Xay Ngom et la Nam Khem fonctionnant cette fois dans le sens d'écoulement du ruisseau " ${ }^{183}$. Il est à noter que le site du That Luang avait lui-même un rôle dans ce dispositif, puisque la mare qui le jouxtait permettait à la fois l'évacuation des eaux de crue du Mékong et la retenue des eaux de crue de la Nam Ngum ${ }^{184}$. Les canaux étaient d'ailleurs utilisés pour accéder au monument, celui-ci étant ouvert vers l'est, et non sur la ville (ouest) comme c'est le cas actuellement. À partir de la rive du Mékong, un peu en amont du Vat Chan, il suffisait de remonter le cours de la rivière Pasak - qui formait la limite septentrionale de la ville - puis de suivre le cours du canal Hong Seng qui se confondait bientôt avec la grande enceinte extérieure.

Il n'est cependant pas sûr que le système d'irrigation et de drainage existât déjà au $\mathrm{XVI}^{\mathrm{e}}$ siècle. Le fait que les souverains aient été dans l'obligation de repousser les nouvelles rizières vers la rive orientale de la Nam Ngum montrent que la gestion de l'espace entre Vientiane et la rive occidentale n'avait pas encore été optimisée. Il est cependant tout à fait probable que le réseau des voies d'eau ait été déjà utilisé pour le transport et qu'il ait fortement favorisé le contact entre les berges du Mékong et de la Nam Ngum. C'est cette fréquentation qui devait d'ailleurs sans doute conduire à leur mise en valeur et à une utilisation plus rationnelle des particularités du terrain.

181. Ch. Taillard, «Les berges de la Nam Ngum et du Mekong - Systèmes économiques villageois et organisation de l'espace dans la plaine de Vientiane (Laos) », 1974, p. 119-168.

182. Les crues du Mékong et de la Nam Ngum ne se produisent pas au même moment, en raison de la position très différente des deux sources (l'Himalaya pour le premier, le plateau de Xieng Khuang pour la deuxième).

183. Ch. Taillard, 1974, p. 127.

184. Ch. Taillard, 1974, p. 129. 
Document 18 - Texte de la stèle du Vat Hnong Bone $\mathrm{n}^{\circ} 2$ (in situ).

Face 1:

1.

2. .

3 .<smiles>c1ccc2ccccc2c1</smiles>

4.

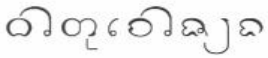

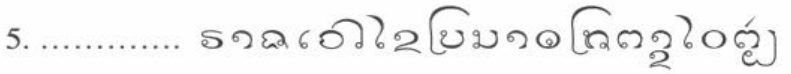

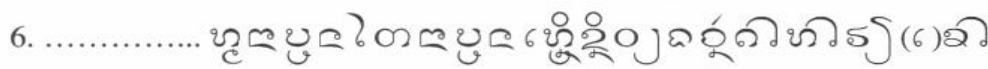

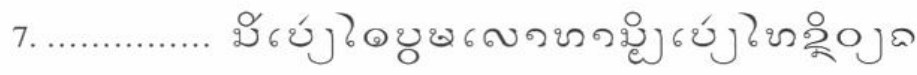

8.

9.

10.

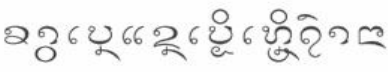

11.

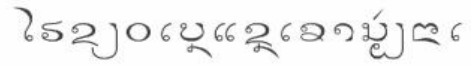

12.

ชேณ ว

13.

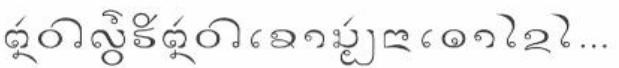

14 ใข 66 ๆ 62 2...

15. 6 ขू....

Face 2 :

1.

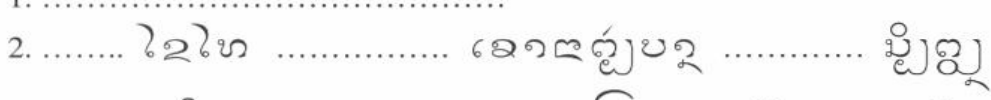

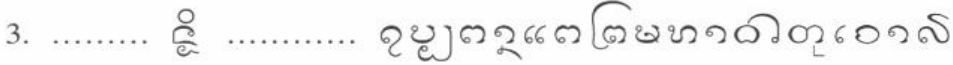

4 .

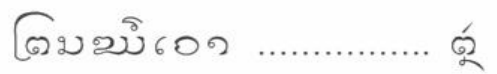

5 .

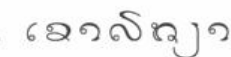
อ

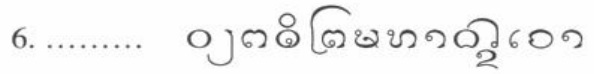

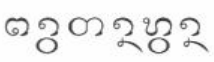

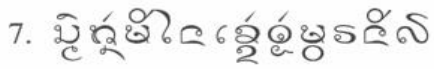
ใชว०เขูฉ

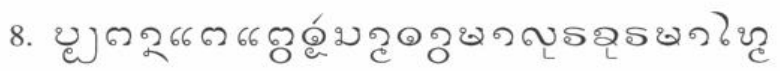

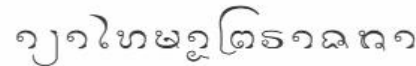

9. ○ ல๐ฆใน คููก กิฉ? 


\section{Conclusion}

Le That Luang, alias «Phra Mahā Thāt Chao Chiang Mai » et "Lokacūlāmanìthüpa », restera sans doute pour longtemps encore auréolé d'un certain mystère. En cela, i] a une affinité profonde avec la relique (dhātu) qu'il recouvre, puisque l'identité de cette dernière reste elle-même secrète (guyha). L'examen des données épigraphiques, manuscrites et archéologiques nous a toutefois montré que le grand édifice a connu au minimum deux états de construction successifs : la (les) structure(s) ancienne(s) découverte(s) par L. Fombertaux, et le stūpa tel qu'il est visible aujourd'hui. Il est certain que l'un au moins de ces états date du XVI ${ }^{\mathfrak{c}}$ siècle. Cela nous est en effet attesté par les trois inscriptions relatives au «thāt», ainsi que par les chroniques de Luang Prabang et de Vientiane. Plusieurs hypothèses touchant à la chronologie du monument apparaissent dès lors possibles.

La première consiste à reconnaître Phothisarāt comme l'initiateur de la construction. La stèle du Vat Hnong Bone présente en effet le souverain comme le premier donateur de terres et d'esclaves au stūpa. D'autres inscriptions témoignent de son zèle à promouvoir la religion, en particulier à Vientiane qui était une ville royale depuis au moins 1535 . Les Phongsāvadān indiquent d'ailleurs que Setthāthirāt ne fit que couvrir et parfaire un cetiya antérieur - et la figure légendaire d'Asoka, référence obligatoire car légitimante, pourrait alors très bien cacher celle du grand réformateur du bouddhisme. Son fils, revenu plus tard régner au Lān Xāng, n'aurait fait que prolonger son œuvre en donnant au stūpa une nouvelle allure, peut-être celle qu'il possède actuellement, plus sûrement un état intermédiaire.

La seconde hypothèse ne dénie pas à Phothisarāt son rôle de fondateur. Elle consiste cependant à considérer Setthāthirāt comme le constructeur de la structure découverte par L. Fombertaux - laquelle en recouvrirait elle-même une autre (jamais mise au jour), celle de son père, sans doute le noyau initial. On a pu constater en effet les affinités de style entre les plus anciens vestiges connus du That Luang et des modèles architecturaux répandus au Lān Nā. Ces derniers - on l'a reconnu pour certain - étaient familiers au jeune souverain lao, ou en tout cas aux artisans qui devaient le suivre dans ses pérégrinations. On ne peut d'ailleurs manquer d'être frappé par le fait que c'est à peine rentré au Lān Xāng, après probablement plus de dix années passées dans le royaume t'ai du Nord, que Setthāthirāt entreprit ses travaux sur le stūpa. Ceux-ci furent de grande ampleur, puisqu'ils durèrent apparemment de 1561-1562 à 1566-1567. Les sources épigraphiques n'apportent aucun détail sur l'aspect technique de la construction (elles ne le font pas davantage pour les centaines d'autres édifices religieux évoqués dans les inscriptions du Lān Nā et du Lān Xāng), mais elles témoignent de l'importance des forces engagées - et par là même de la puissance du monarque commanditaire - lorsqu'elles évoquent les centaines de travailleurs mis à contribution. Par la suite, le monument a dû donner lieu à des additions importantes que la mémoire écrite n'a pas préservées. Il faut rappeler qu'un nombre très important de stèles ont été détruites au cours du sac de Vientiane en 1829, et que rares sont en fait les temples de la capitale pour lesquels nous avons quelques données épigraphiques. Quant aux chroniques, elles sont extrêmement lacunaires pour tout le $\mathrm{XVII}^{\mathrm{c}}$ siècle (elles ignorent pratiquement le règne de Suriya Vongsa, dont nous savons pourtant qu'il fut propice aux arts, à commencer par la statuaire bouddhique) et elles se concentrent ensuite sur Luang Prabang. Le Hollandais G. van Wuysthoff nous apprend que l'important cloître du That Luang, dont la mention est absente dans le texte des Phongsāvadān, existait déjà en 1641. Après Setthāthirāt, plusieurs souverains du Lān Xāng en quête de gloire, de légitimité ou de mérites durent ainsi contribuer au développement, à l'accroissement et à l'enrichissement du monument. 
En ressuscitant la mémoire des noms anciens du monument - «Phra Mahā Thāt Chao Chiang Mai » et "Lokacūlämani-thüpa»-, l'étude des inscriptions du That Luang nous fait passer brutalement du cadre réduit de l'histoire locale à celui bien plus vaste des relations anciennes entre les royaumes du Lān Xāng et du Lān Nā. Il semble en effet que les deux noms lao et pâli du stūpa, peu en rapport avec celui de la relique, aient été associés dans la conscience collective des contemporains de Setthāthirāt à des événements historiques très précis, mais que le temps contribua rapidement à faire oublier. Si la dimension symbolique du monument élevé par le jeune roi lao ne peut être niée - la référence explicite aux trente pāramī en est la meilleure preuve -, il est possible également que des considérations beaucoup plus humaines et personnelles aient eu leur importance. Nous avons remarqué que le That Luang n'était peut-être pas uniquement un reliquaire - comme l'indique un peu conventionnellement le rédacteur du texte pâli, qui révèle peut-être son embarras en qualifiant la relique de guyhadhātu - mais qu'il pouvait avoir la fonction beaucoup plus courante (les reliques "authentiques » étant rares) de monument funéraire ou commémoratif. Il est probable en effet qu'il a été lié à un personnage dont l'identité devait être révélée à la fois par la référence populaire au roi ou au prince de Chiang Mai, à travers le nom lao de "Phra Mahā Thāt Chao Chiang Mai », et par la référence plus érudite à un lieu nommé Lokacūlămani, dans le texte pâli. Concluant de l'étude de certaines sources manuscrites que Setthăthirāt avait succédé à son grand-père maternel sur le trône du Lān Nā, nous avons proposé de voir dans les deux noms originels du That Luang un hommage direct à cet aïeul, puisqu'il avait été roi de Chiang Mai et que ses cendres reposaient dans un des stüpa de la capitale t'ai du Nord - le Wat Lokamoli dont le nom est sémantiquement équivalent à Lokacūlāmani. Il semblerait d'ailleurs que les données de l'archéologie tendent à confirmer cette identification.

Le That Luang paraît avoir été à l'origine un monument royal davantage qu'un monument religieux. En cela, il constitue un exemple tout à fait particulier dans l'histoire des monuments des peuples t'ai des régions septentrionales. Son identité semble d'ailleurs avoir été profondement liée à la personne de Setthāthirāt, ainsi qu'aux membres les plus proches de sa famille : sa fille, d'abord, offerte comme esclave au reliquaire ; son fils, étroitement associé au monument, y compris lorsqu'il régnera lui-même sur le Lān Xāng ; une de ses épouses, dont nous ne connaissons pratiquement rien; et son grand-père maternel, probablement, qui lui aurait d'ailleurs transmis son nom. L'épigraphie t'ai ne nous offre pas d'exemple semblable, sauf peut-être quelques inscriptions de Sukhothai qui mettent en scène des personnages royaux.

Les références épigraphiques aux nombreuses et vastes terres attribuées au monument suscitent également la surprise et l'intérêt de l'historien. L'analyse d'un certain nombre de données permet en effet de poser les premiers jalons d'une histoire du développement de la ville de Vientiane, mais également d'une histoire agraire de toute la plaine qui l'entoure. D'une façon générale, on peut d'ailleurs dire que l'étude des inscriptions du That Luang ouvre pour la recherche historique sur le Laos des domaines d'investigation jusqu'ici insoupçonnés ou mal perçus. Elle met surtout en évidence la nécessité de multiplier les angles d'approche. Elle révèle également l'importance qu'il convient d'accorder à certaines disciplines jusqu'ici quasiment ignorées au Laos, à commencer par l'archéologie.

\section{Ouvrages consultés}

ANONYME

1930

1931

1934
«Chronique. Laos - L. Fombertaux : travaux de restauration du Vat Sisaket et du That Luong de Vieng Chan », BEFEO 30/3-4, p. 583-585.

"Chronique. Laos : restauration du That Luong de Vieng Chan », BEFEO 31/3-4, p. 623-625. «Chronique. Laos : restauration du That Luong de Vieng Chan », BEFEO 34/2, p. 771-772. 
ARCHAIMBAULT, $\mathrm{Ch}$

1973 "La fête du T'at à Luong P'răbang », in La fête du T'at, Vientiane.

Buddhadatta, A. P. (éd.)

1962 Jinakālamālì, Londres, Pali Text Society.

Claeys, J. Y.

1931 «L'archéologie du Siam », BEFEO 31, p. 361-448.

COLLECTIF

1986

1991

1995

Careuk Nai Prathet Thai, Lem 5, Bangkok, Krom Silapakorn (en thaï)

1999

Cāreuk Lān Nā, Phāk 1, Bangkok, Amarin (en thaï).

Prachum Cāreuk Muang Phayao, Bangkok, Silapa-Watthanatham (en thaï).

issane - 15 vol., en thaï).

2000 Prachum Cāreuk Lān Nā, Lem 4 : Cāreuk Nai Phiphithaphan Chiang Mai, Chiang Mai, Social Research Institute (en thaii).

CEDĖs, G.

1924 Recueil des inscriptions du Siam, Bangkok.

1925 «Documents sur l'histoire politique et religieuse du Laos occidental », BEFEO 25/1, p. 1-202.

CUSHMan, R. D.

2000 The Royal Chronicles of Ayuthaya, Bangkok, The Siam Society.

DEJVONGYA, C.

1996 Phra Chedi Muang Chiang Saen, Bangkok (en thaii).

1998 Phra Chedi Muang Chiang Mai, Bangkok (en thaii).

2001 «Kān Seuksā Priep Thiep Chedī Nai Muang Chiang Mai Lae Luang Phra Bāng », Khuam Samphan Rawang Lān Nā Lān Chāng: Koranī Seuksā Silapakam Nai Muang Chiang Mai Lae Luang Phra Bāng, Chiang Mai, p. 34-50 (en thaï).

EADE, J. C.

1996 The Thai Historical Record-A Computer Analysis, Tokyo, The Toyo Bunko.

FINOT, L.

1903 «Ex-voto du That Luong de Vieng-Chan (Laos) », BEFEO 3, p. 660-663.

1915 «Les inscriptions du Musée de Hanoi », BEFEO 15/2, p. 1-38.

1917 «Recherches sur la littérature laotienne », $B E F E O$ 17/5, p. 1-218.

GAGNEUX, P.-M.

1975 Contribution à la connaissance de la civilisation laotienne d'après l'épigraphie du Royaume de Vientiane (XV'-XIX siècles), thèse de $3^{\mathrm{c}}$ cycle, Paris, EHESS.

1977 Les sites anciens de la plaine de Vientiane (VIT-XI' siècles) - Rapport préliminaire, document ronéotypé, Vientiane.

$1980 \quad$ Notes de mise à jour de L'art du Laos, n. p.

GARNIER, F.

$1885 \quad$ Voyage d'exploration en Indo-Chine, Paris, Hachette.

Giteau, $M$.

2001 Art et archéologie du Laos, Paris, Éd. Picard.

HeIn, D. ; BarbetTi, M. ; SayavongKhamdy, T.

1989 An Excavation at the Sisattanak Kiln Site, Vientiane.

IIJIMA, A.

2002 «Rāy Ngān Beuang Ton Kio Kap 'The short chronicle of Vientiane' ", Kān Seuksā Prawatisāt Lè Wannakam Khong Klum Chāti Phan Thai, Chiang Mai, p. 208-219 (en thaï).

JAYAWICKRAMA, N. A. (trad.)

1978 The Sheaf of Garlands of the Epochs of the Conqueror, Londres, Pali Text Society.

LEJOSNE, J. C. (trad.)

1993 Le journal de voyage de Gerrit van Wuysthoff et de ses assistants au Laos (1641-1642), Metz, CDIL.

LORRILLARD, $\mathrm{M}$

1999 «Quelques données relatives à l'historiographie lao », BEFEO 86, p. 219-232.

1999 «La succession de Setthāthirāt: réappréciation d'une période de l'histoire du Lān Xāng », Aséanie 4, p. 45-64.

2001 « D’Angkor au Lān Xāng : une révision des jugements », Aséanie 7, p. 19-34. 
2003 «The Earliest Lao Buddhist Monasteries According to Philological and Epigraphic Sources ", The Buddhist Monastery - A Cross-cultural Survey, P. Pichard \& F. Lagirarde éd., EFEO (Études thématiques 12), p. 187-198.

LUNET DE LAJONQUIÈRF, Cap. L.

1901 «Vieng-Chan », BEFEO 1/2, p. 99-118.

Malalasekera, G. P.

1997 Dictionary of Pāli Proper Names, vol. II, PTS, [rééd.].

MARChAL, H.

$1964 \quad L$ 'art décoratif au Laos, n spécial Arts Asiatiques 10/2.

Nagara, P. N. \& Griswold, A. B.

1992 "An Inscription of 1563 A.D. Recording a Treaty Between Laos and Ayodhyā in 1560 », in Epigraphic and Historical Studies (rééd. des articles parus dans le Journal of Siam Society), p. 788-803.

- «The inscription of King Rama Gamhèng of Sukhodaya (1292 A.D.) », in Epigraphic and Historical Studies, op. cit., p. 241-290.

NotTon, C. (trad.)

1932 Annales du Siam, vol. III : Chronique de Xieng Mai, Paris, P. Geuthner.

PARMENTIFR, $\mathrm{H}$.

1948 L'art architectural hindou dans l'Inde et en Extrême-Orient, Paris, Van Oest.

1954 L'art du Laos, 2 vol. (texte et iconographie), Paris, EFEO (PEFEO 35), [rééd. révisée par M. Giteau en 1988].

Pavie, A. (Mission Indo-Chine, 1879-1895)

1898 Études diverses II, Recherches sur l'histoire du Cambodge, du Laos et du Siam, Paris, Ernest Leroux.

PUNNOIHOK, Th.

s. d. Sülā Careuk Ásān Samay Thai Lāo, Bangkok (en thaï).

REINHORN, M.

1970 Dictionnaire laotien-français, 2 vol., Paris, CNRS.

RHYS-DAvids, T.W. \& STEDE, W.

1999 Pali-English Dictionary, Pali Text Society, [rééd.].

SouvanNavong, B. (Phagna)

1970 "Le That-Louang de Vientiane », Bulletin des Amis du Royaume Lao 3, p. 7-20.

TAILlARD, Ch.

1974 «Les berges de la Nam Ngum et du Mekong - Systèmes économiques villageois et organisation de l'espace dans la plaine de Vientiane (Laos) », Études rurales 53-56, p. 119-168.

Velder, Ch.

1965 «La poterie du Wat Si Satthanak, Vientiane (Laos) », Felicitation Volumes of SoutheastAsian Studies presented to H.H. Prince Dhaninivat, Bangkok, vol. 2, p. 199-201.

VIRAVONG, Maha Sila

s. d. Paval Phra Cedi Lokaculāmani Lü Phra Thāt Luang Vieng Chan, Vientiane.

WyAtT, D. K. \& WichiEnKeEO, A. (trad.)

1995 The Chiang Mai Chronicle, Chiang Mai, Silkworm Books.

Archives EFEO

Fonds H. Parmentier.

Fonds « Monuments historiques, Laos (1899-1954) », carton $n^{\circ} 7$. 